\title{
The impact of pregnancy and lactation on the nutritional status of women living in rural Kenya
}

Citation for published version (APA):

Keverenge-Ettyang, G. A. (2005). The impact of pregnancy and lactation on the nutritional status of women living in rural Kenya. [Doctoral Thesis, Maastricht University]. Universitaire Pers Maastricht. https://doi.org/10.26481/dis.20050908gk

Document status and date:

Published: 01/01/2005

DOI:

10.26481/dis.20050908gk

Document Version:

Publisher's PDF, also known as Version of record

\section{Please check the document version of this publication:}

- A submitted manuscript is the version of the article upon submission and before peer-review. There can be important differences between the submitted version and the official published version of record. People interested in the research are advised to contact the author for the final version of the publication, or visit the DOI to the publisher's website.

- The final author version and the galley proof are versions of the publication after peer review.

- The final published version features the final layout of the paper including the volume, issue and page numbers.

Link to publication

\footnotetext{
General rights rights.

- You may freely distribute the URL identifying the publication in the public portal. please follow below link for the End User Agreement:

www.umlib.nl/taverne-license

Take down policy

If you believe that this document breaches copyright please contact us at:

repository@maastrichtuniversity.nl

providing details and we will investigate your claim.
}

Copyright and moral rights for the publications made accessible in the public portal are retained by the authors and/or other copyright owners and it is a condition of accessing publications that users recognise and abide by the legal requirements associated with these

- Users may download and print one copy of any publication from the public portal for the purpose of private study or research.

- You may not further distribute the material or use it for any profit-making activity or commercial gain

If the publication is distributed under the terms of Article $25 \mathrm{fa}$ of the Dutch Copyright Act, indicated by the "Taverne" license above, 
The impact of pregnancy and lactation on the nutritional status of women living in rural Kenya 


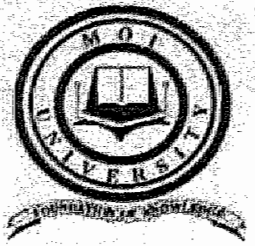

MOI UNIVERSTTY

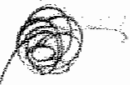

M U N D O

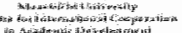

\section{nutrim \\ intiili}

The studies presented in this thesis were performed at the Nutrition and Toxicology Research Institute Maastricht (NUTRIM), which participates in the graduate school VLAG (Food Technology Agrobiotechnology, Nutrition and Health Sciences) accredited by the royal Netherlands Academy of Arts and Science.

Cover design: a wall hanging designed in the earth colors of rural Africa Printed by Dakwyse, Universitaire Pers. Marastricht

(C) Grace Adisa Keverenge - Ettyang, Maastriclut 2005

ISBN $905278471 \mathrm{X}$ 


\section{The impact of pregnancy and lactation on the nutritional status of women living in rural Kenya}

\section{PROEFSCHRIFT}

ter verkrijging van de graad van doctor aan de Universiteit Maastricht op gezag van de Rector Magnificus Prof.mr. G.P.M.F. Mols volgens het besluit van het College van Decanen in het openbaar te verdedigen op donderdag 8 september 2005 om 14.00 uur door

Grace Adisa Keverenge - Ettyang geboren te Vihiga District, Kenia

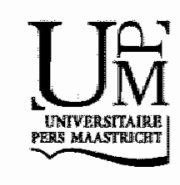




\section{Promotor}

Prof.dr.ir. W.H.M. Saris

\section{Co-promotores}

Dr. W. wan Marken Lichtenbelt

Prof dr F Esamai (Moi University, Kenya)

\section{Beoordelingscommissie}

Prof.drir. R.P.Mensink (voorzitter)

Dr.ir. P.C. Dagnelie

Prof.dr. J.G.A.J Hautvast (Wageningen Universiteit)

Prof.dr. G. Hornstra

Dr. G.P. Majoor

The research in this thesis was funded through the Moi University, Maastricht University, MHO/NUFFIC, Collaborative Project and a loan from the Moi University MUSCO Funds.

The printing of this thesis was founded by Mundo. 
Nutrition is a key element in any strategy to reduce the global burden of disease.

Hunger, malnutrition, obesity and unsafe food all cause disease, and better nutrition will translate into large improvements in health among all of us, irrespective of our wealth and home country.

Dr Gro Harlem Brundtland As Director-General, WHO At the World Economic Forum 2000.

Dedication:

To all that work today for a better tomorrow. 
a $\quad 4 \quad$ 


\section{CONTENTS}

Chapter 1 Introduction 9

Chapter 2 Serum retinol, iron status and body composition of lactating women in Nandi, Kenya 25

Chapter 3 Assessment of body composition in lactating mothers in a rural African community using deuterium oxide 39

Chapter 4 Vitamin A consumption of breast feeding children in rural Kenya 53

Chapter 5 Assessment of body composition and breast milk volume in lactating mothers in pastoral communities in Pokot, Kenya, using deuterium oxide 69

Chapter 6 Differences in body composition, iron stores and vitamin A status between pastoral and farming women in West Pokot, Kenya, during late pregnancy and lactation 81

Chapter 7 Factors underlying the prevalence of low infant weight at birth and up to 4 months of age in pastoral and farming communities of West Pokot, Kenya 99

Chapter 8 General discussion 117

Summary 131

Acknowledgement 135

About the author 139

Research papers 140 


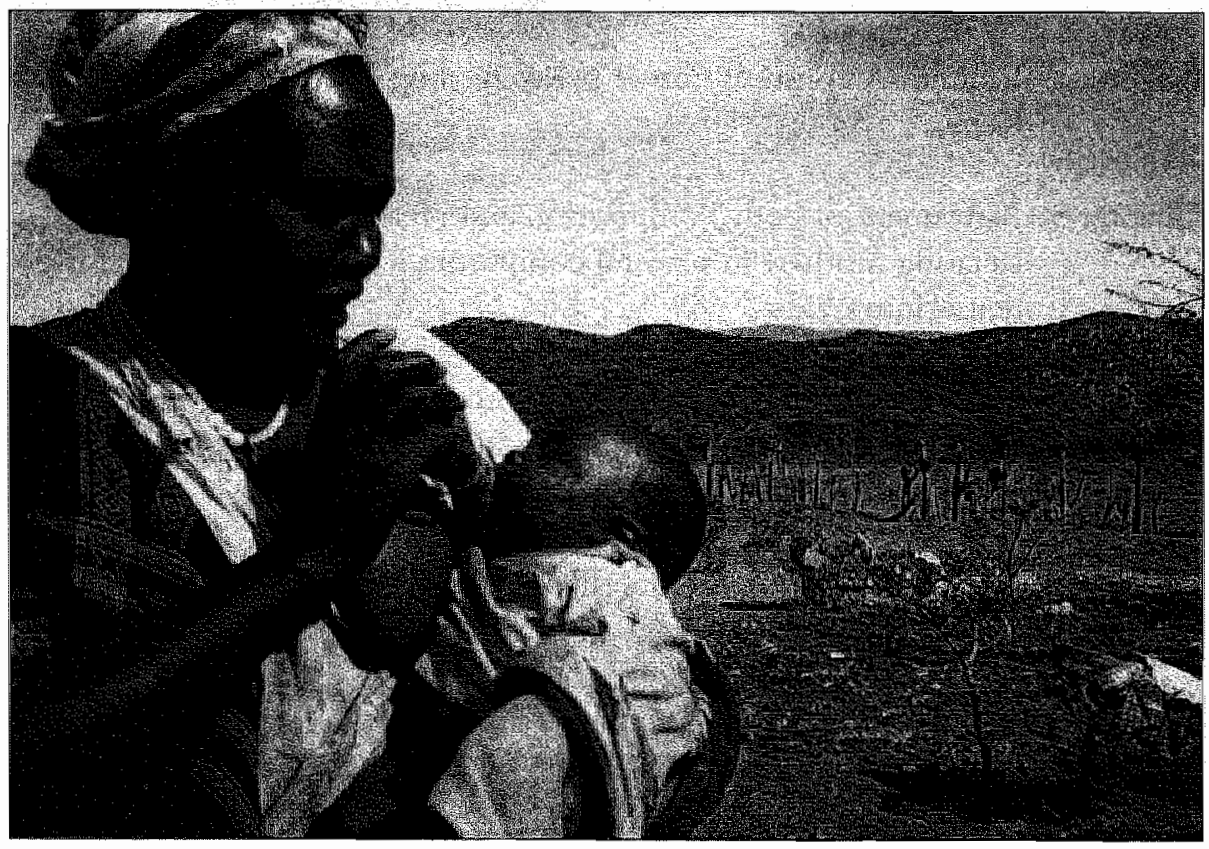


1

\section{General Introduction}

Healthy nutrition means that the food we eat everyday provide us with all the required essential nutrients. In adults, inadequate intake of nutrients results in underweight and a low body fat percentage; in infants, it results in a low weight for age. In both adults and infants this is commonly identified with protein energy malnutrition (PEM). Widespread PEM is associated with micronutrient malnutrition, higher risks of infection and mortality [1-3]. The resulting maternal deficiencies in micronutrients such as iron and vitamin $\mathrm{A}$, especially during the periods of pregnancy and lactation [Figure 1], may reinforce the malnutrition infection cycle [4-5], and in infants it may contribute to overall] poor health [6] and sub-optimal growth [7]. There is limited research that specifically addresses the issue of how the socio-economic/environmental conditions of countries in sub-saharan Africa impact on whether a specific group in a given community becomes more vulnerable to inadequate nutrient intake. This chapter examines the underlying factors and outcomes of under-nutrition during periods of pregnancy and lactation in women living in the rural communities of sub-saharan Africa; particularly, in Kenya. For this purpose, the following topics will be reviewed: distribution of poverty and inequality in rural communities; food patterns in farming and pastoral communities; maternal work demands and body composition; micronutrient deficiencies and pregnancy outcome; vitamin A status, breast milk vitamin A concentration and infant growth. Finally, the opportunity is taken to point out a number of lessons from past experience which may be relevant to future intervention strategies.

\section{Distribution of poverty and inequality in rural communities}

In sub-saharan Africa and Kenya, 76.6\% (315.8 million) and 58.8\% (18.2 million) of the population live on less than 2 dollars per day [8]. In order to provide community based data about the distribution of poverty and inequality within and between Kenyan urban and rural communities, the 1997 Welfare Monitoring Surveys (WMSs) data on expenditure/consumption was combined with the complete geographic coverage provided by the 1999 Population and Housing Census (PHC). The WMSs data related household expenditures to a 


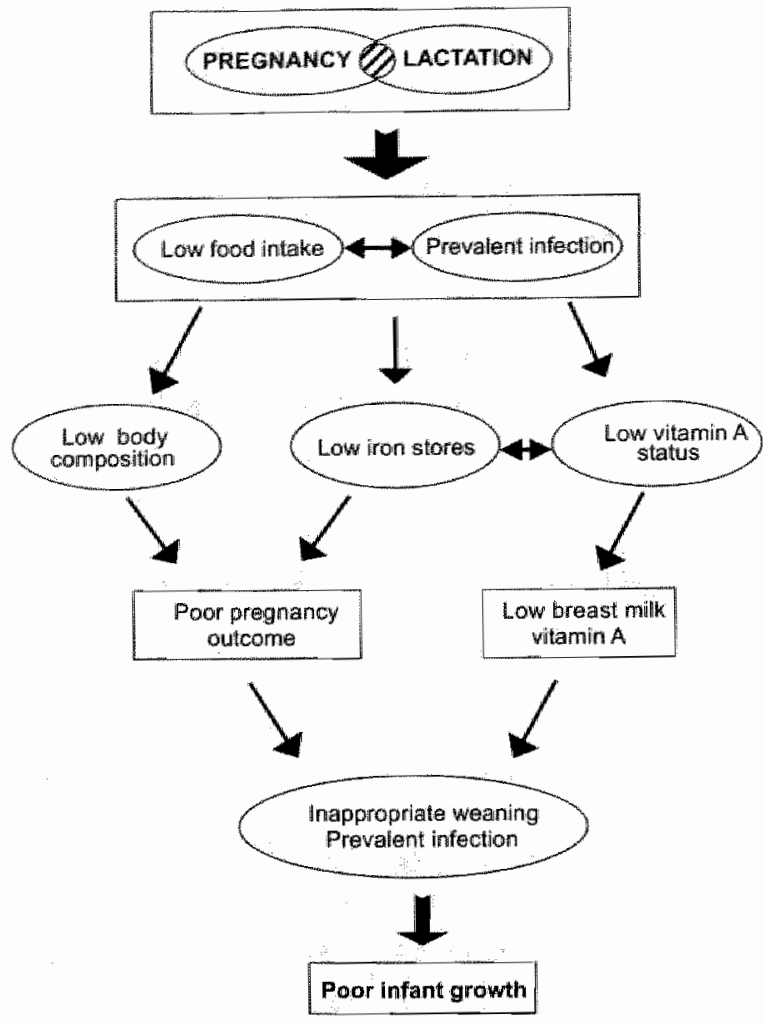

Fígure 1. Periods of pregnancy and lactation, low food intake and infection as associated causes of poor pregnancy outcome low breast milk vitamin $A$ and infant growth faltering.

number of socio-economic variables including household size, education levels, housing characteristics and access to basic services [8].

To determine how many people are poor, a monetary poverty line was derived based on the expenditure required to purchase a food basket that met the minimum nutrition requirement of 2,250 kcalories per adult equivalent (AE) per day. In Kenya, this poverty line was estimated to be about Ksh. 1,239 (\$15) for rural and Ksh. 2,648 (\$33)for urban households, respectively. The total population in a given area whose consumption is below the poverty line indicates the incidence of poverty in the community. In 1997, based on this measure it was estimated that about $53 \%$ of the rural and some $50 \%$ of the urban population in Kenya could be deemed poor. They showed a consumption and an expenditure pattern valued at less than Ksh. 1,239 (\$15) per AE per month [8]. From the same data, the poverty gap(which is a very crude measure of the 
Table 1. Rural poverty rates for Rift Valley Province, Turkana, Nandi, and West Pokot Districts.

\begin{tabular}{lllr}
\hline Administrative locality & $\begin{array}{l}\text { \% Below } \\
\text { poverty line }\end{array}$ & Poverty gap $p^{2}$ & $\begin{array}{c}\text { Number of } \\
\text { individuals }\end{array}$ \\
\hline Rift Valley Province & $44(4.1)$ & $17(2.1)$ & $5,751,114$ \\
Turkana District & $62(6.8)$ & $26(4.8)$ & 331,568 \\
Nandi District & $50(4.4)$ & $18(2.2)$ & 537,270 \\
$\quad$ Kowet Location & $44(14.1)$ & $14(6.5)$ & 2,908 \\
West Pokot District & $53(4.8)$ & $19(2.5)$ & 288,965 \\
Chepkopegh Location & $53(10.2)$ & $19(5.3)$ & 9,709 \\
Ywalateka Location & $63(11.4)$ & $26(7.2)$ & 6,723 \\
\hline
\end{tabular}

* Modified from Ref 8 ; ${ }^{2}$ Percent (SE) of individuals with consumption and expenditure < Ksh. 1,239 ; ( 15 ) per AE per month; ${ }^{2}$ Poverty gap as percent (SE) of poverty line (crude measure of the minimum; amount of resources necessary to eradicate poverty); ${ }^{3}$ Based on the 1999 population census

minimum amount of resources necessary to eradicate poverty) can be determined. The 1997 poverty gap for the rural population in Kenya was about $19.3 \%$. This implies that every poor person in a rural area would require, on average, an additional Ksh 240 (\$3) per month to reach the poverty line (i.e. $19.3 \%$ of the Ksh. 1,239 rural poverty line). This national average, however, conceals important variations and the monthly expenditure of many rural people are substantially less. For example, as shown in Table 1, inequality at province level (i.e. the Rift Valley which has an estimated population of 5.8 million), is markedly lower than at district and location levels. This is consistent with historical and anecdotal accounts of very a divergent evolution of society and economic structures in the pastoral and farming communities within the three districts. This calls for further exploration into outcomes and factors underlying the differences in the estimated incidence of high poverty. Differences in pastoral and farming life styles could be a factor associated with the incidence of high poverty. In both communities, frequent droughts may lead to the inadequate level of maternal nutrient intake that leads to poor pregnancy outcome and infant growth.

National data on the living location of the poor is available [8]. For the first time this provides a unique opportunity of combining community specific nutritional status data with estimates on the incidence of community based poverty. This is a critical first step towards reducing the existing information gap on the little addressed issue of how the socio-economic/environmental conditions in a country impact on whether a specific group in a given community becomes more vulnerable to inadequate nutrient intake [Figure 2]. Such data is critical in the design and implementation of more specific, targeted policies. Moreover, it 


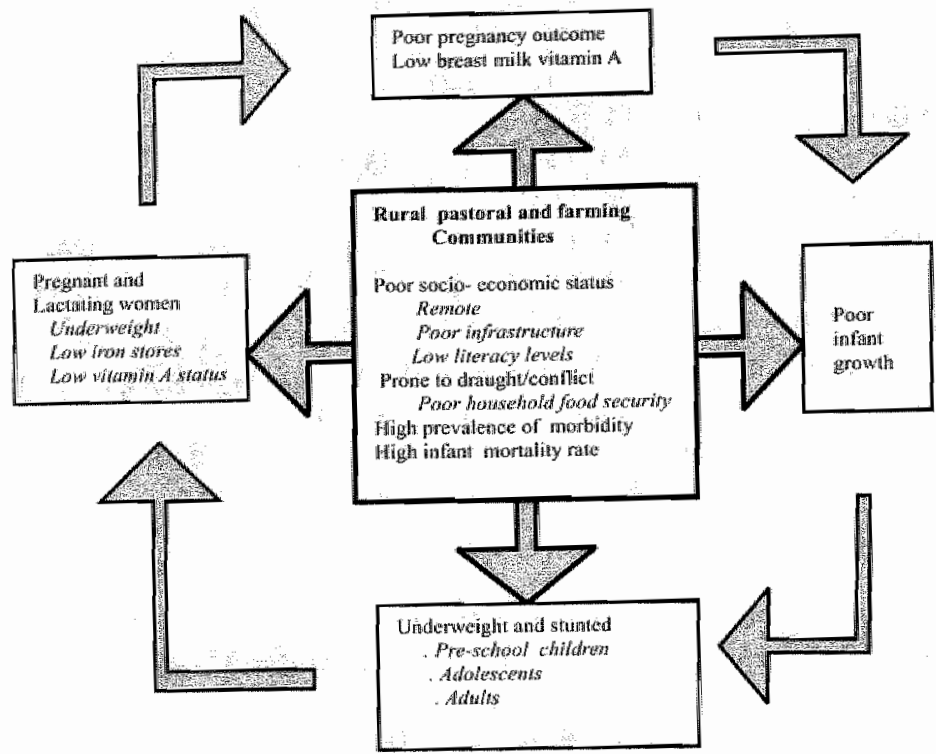

Figure 2. Underlying factors and outcones of under ruturition during periods of pregrancy and lactation in women living in rutal communities of sub-saharan Africa (modifed from refi 1)

possibly generates further insights into potential community level approaches for tackling the root causes of such rampant high levels of poverty that lead to poor maternal and infant nutritional status [2].

\section{Food pattems in farming and pastoral communities}

The marked differences that occur in ecological factors in rural communities has an influence on nutritional deficiency disorders more than on most other disease. Under-nutrition among the worst affected pastoral and farming households is a function of declining food availability that is exacerbated by chronic food insecurity. In view of poor rains, conflict and other hazards, the food security of farming and pastoralist grouss is becoming increasingly fragile. One poor season appears to be sufficient to precipitate a crisis. In farming communities, this results in poor harvests. For pastoral communities, current pasture and water are unjikely to support livestock until the beginning of the long rains. As expected, the conditions of cattle and goats deteriorates significantly as trekking 
distances between watering points increases to over $20 \mathrm{~km}$. This drastically reduces the market value of livestock.

The association of mutritional status with ecological factors or incidence of poverty may be paradoxical. For example, in a community with a predominantly farming lifestyle, white maize as the staple food with very little intake of animal sources of vitamin A is likely to make households more prone to vitamin A deficiency [9]. Furthermore, the seasonal benefits of dark green vegetables may be limited by inefficient bioconversion of provitamin $A$ carotenoids to vitamin $A$ in the body [10]. In the pastoral community, prevalent malaria may undermine the benefits of the limited consumption of animal sources of vitamin $A$ in terms of milk-fat and of iron from blood. For both communities, recent work with stable isotopes shows that healthy individuals may be high or low responders to vitamin $A$ [11].

\section{Maternal work demands and body composition}

In the most rural areas of sub-Saharan Africa, family nutrition is commonly the responsibility of women [12]. Due to limited resources, women in these rural communities have to meet the demands of a heavy daily workload [13-14]. In farming communities, the peak period for heavy physical activity is from January to June; a time for land preparation and weeding. In pastoral communities, draughts are frequent and women spend a considerable amount of time looking for firewood and water. In both communities, this degree of physical activity performed by women in various phases of the reproductive cycle, is not offset by increases in energy intake [15-16]. Poor nutrient utilisation due to high rates of morbidity [17] is a frequent occurrence. The resulting imbalances in energy supply are reflected in low weight gain, poor fat stores [18-20], and a decreased ability to sustain milk production [15]. The majority of the women are often left vulnerable to pregnancy and childbirth complications. The low weight of infants born to such women, are themselves vulnerable to life threatening disease [21] and nutritional problems in later life [1,22]. A recent review by Baker suggests that under-nutrition is one of the influences that program the human body and can have lifelong consequences [23].

\section{Micronutrient deficiency and pregnancy outcome}

Where protein energy malnutrition exists, it is inevitable that other nutrient deficiencies will also be present [24]. Most notable will be micronutrient defi- 
ciencies such as iron and vitamin $A$. Vitamin $A$ deficiency involved in the etiology of nutritional anemia 125,26 , ] is likely to increase vulnerability to other illnesses in both women and children. Its' deficiency contributes to poor maternal performance during pregnancy and lactation, and to growth deficits in children $[24,27]$. Where adequate matennal and infant intake of vitamin $A$ cannot be sustained $[24,28-30]$, the ability of the lactating mother to confer the protective properties of vitamin $A$ to her infant $[27,31]$, as is her iron status $[32]$, are compromised. In turn low iron stores negatively impact on the maternal ability to effectively engage in the daily demands of a heavy workload [33].

In developing countries, an estimated prevalence of $43 \%$ and $48 \%$ for nutritional anemia has been reported in non-pregnant and pregnant women respectively. $[1,34-35]$. Among pregnant women in Kenya, 57\% are reported to be anemic [36]. Their iron intake is not only low but the bio-availability of this nutrient is poor because of the high phytate, fiber and tea content of the diet [37]. A good postpartum iron status is important because the mother will enter a subsequent pregnancy with better iron stores [38]. The non-malnourished pregnant woman can cope with the extra demands of pregnancy without becoming anemic [39] only if there is adequate iron in her diet. Iron deficiency, especially in the first trimester of pregnancy, significantly reduces fetal growth. Deficiency in the second and third trimester seems to have little effect $[40,41]$. As such, if fetal growth and development are the dependent variables of interest, it is possible that the real window of opportunity for a positive intervention against iron deficiency will have passed if the prenatal period is not targeted. Relying on intervention late in the first trimester or early in the third trimester of pregnancy may be too late [42].

The role of vitamin $A$ (retinol) in the etiology of anemia [25], the metabolic interaction between vitamin $A$ and iron, and the reported risks associated with vitamin $A$ and iron deficiency in lactating mothers [31] is well documented $[26,32,43]$ but tends not to address the contribution of under-nutrition [24]. Low vitamin $A$ intake by typically undernourished mothers during the first six months of an infant's life, has been estimated to fall short of meeting the recommended infont reguirements for vitamin $\mathrm{A}[30]$.

\section{Matenal vitamin A status, breast milk vitamin $A$ concentration and infant growth}

Vitamin $A$ is an essential micronutrient for the normal functioning of the visual system, growth and development. Vitamin A deficiency disorder (VADD) is a 
more comprehensive term that includes all aspects of abnormalities due to lack of vitamin A [44]. Sub clinical deficiency canses imparment in function of the rod photoreceptor cells of the retina leading to the loss of dark adaptation and is subjectively expressed as night blindness. There has long been evidence that vitamin $A$ has many other functions besides visual aspects: Late in gestation, adequate maternal vitamin $A$ status is important for newborn reserves and for sustaining adequate breast millk concentrations [27]. In undernourished lactating women with an average breast milk vitamin $A$ concentration of about 1.05 fumol/ 1 , their solely breastfed infants will remain vitamin $A$ deficient at 6 months of age $[45,46]$. Maternal vitamin $A$ status plays a critical role in the health and growth of infants [27]. Its deficiency during pregnancy has been reported to have a negative impact on maternal iron status [25]. Iron deficiency, in turn, is associated with risk of pre-term delivery and low infant birth weight $[47,48]$. Field studies have demonstrated the importance of vitamin A in infant growth, development, and survival $[9,49]$. Deficiency in infants results in increased severity of some infections and increased infant mortality [50]. At the community level, the high prevalence of having an infant with a birth weight below $2500 \mathrm{~g}$ and an infant growth rate below $-2.00 \mathrm{z}$ scores, are considered triggers for public health action requiring population wide interventions aimed at reducing the prevalence of under-weight in new born infants [51].

\section{Intervention strategies}

Balanced macro- and micronutrient intake with protection against serious and prolonged infections remains the foundation of an optimal maternal and infant nutritional status. Accordingly, information on the changes that occur in maternal micronutrient status during the reproductive cycle will provide a better focus in the selection of intervention strategies deployed to improve the growth and development of infants. During the 1980 's and 90 's emphasis was on the implementation of various measures to control severe micronutrient deficiency within individuals. The bigger problem of sub-clinical deficiency has remained relatively untouched. Documented evidence from Nepal shows that pregnancy is a period in life when there is increased risk of vitamin A deficiency, and it has been shown in children that there is an increased mortality risk $[52,46,49]$. To date, it appears that lactation has not been extensively investigated even though studies in Nandi lactating mothers conducted by our group [53] as well as by Stoltzfus et al [54] have suggested the vulnerability of infant and mothers during this period. 
Intervention strategies aimed at improving maternal iron status need to take into account the effects of vitamin $A$ deficiency $[25,26]$. A good vitamin $A$ status has beneficial effects on maternal iron status and reduces mortality by an average of $24 \%$ during the second 6 months of infant life [46]: Determination of vitamin A status should therefore be considered when measures to improve maternal and child iron status are considered [28]. The reported impact of maternal vitamin A supplementation seems to indicate different response rates in the infant [55]. Future implementation of intervention strategies needs to take into account this biological variability. It is suggested that this may be a reflection of the effects of differences in maternal vitamin $A$ status, morbidity experience, body' size, and lifestyle [30]. Investigations into the effect of lifestyle on the nutritional status of pregnant and lactating women will contribute to the development of programs for the control of macro- and micronutrient deficiency in the farming and pastoral communities of sub-Saharan Africa.

Now more than before, improving women's own nutritional status, more often an under-recognized problem, needs greater focus [14]. Ensuring proper nutrition throughout the life of the woman enables her to have a much healthier life to pursue her multiple responsibilities. This will safeguard the nutrition of infants, children, and indeed future generations [1]. Though interventions aimed at improving child health must take into account maternal nutritional necds, approaching each micronutrient deficiency in isolation is no longer a viable option. In communities at risk of under-nutrition, any meaningful improvement must deal first with those ways in which the health and nutrition of the women are adversely affected by the existing social, cultural and economic systems. It must go beyond the provision of health and nutrition services and recognize that nutritional problems have their origin in social and economic systems. Further exploration into outcomes and factors underlying the differences in the incidence of poverty between the various communities will be a contribution towards empowering individual communities and stimulating more efficient allocation of limited resources. Analysts and policy makers will be assisted in the designing and monitoring of possible poverty alleviation measures.

\section{The study sites in Kenya}

Kenya's 40 different ethnic groups are divided by separate languages or dialects and in many areas, by differing lifestyles [16,56,57]. Difficult terrain and long distances has resulted in marked differences in the rural economic and social development. The only national data on the nutritional status of pregnant 
women is a night-blindness prevalence of $11.6 \%$ which is indicative that vitamin A deficiency may be a serious public health problem. Data on pregnancy outcome is based on hospital deliveries with $9.2 \%$ newborn infants reported to have had a birth weight $<2.500 \mathrm{~kg}$. Infant mortality rate is 78 deaths per 100 live births. Under the age of five years, the mortality rate is 114 deaths per 1,000 live births. This implies that 1 in every 9 children borne in Kenya die before celebrating their fifth birthday and $21.2 \%$ are reported to be undenweight $(<-2$ SD). The 2003 national demographic and health survey [57] reported that $64.4 \%$ of hospital treatment was related to malaria while households using bed-nets was still low at only $17.2 \%$. The national prevalence rate of HIV for both sexes is reported to be $6.7 \%$. Between 1989 and 2003, the infant and under five mortality rate increased by $30 \%$ which is indicative of deterioration in quality of life over the last 20 years.

The studies described in this thesis were carried out in two study sites located in the Rift Valley province districts of Nandi and West Pokot [Figure 3]. These study sites were selected because it was our purpose to conduct our investigations in communities that were similar in ethnicity but who had markedly different lifestyles. In both study sites the prevalence of malaria and HIV/Aids are increasingly becoming health problems of great public health significance.

The Nandi District study site is inhabited by people of Kalenjin ethnicity. The study area was based in Kosirai Division with an estimated population (1999) of 33,324 [58]. All community members are subsistence farmers mainly growing white maize and keeping grade cattle for milk. Very few fruits are grown in the area, but there is seasonal availability of white cabbage and traditional vegetables. Milk, the main source of income, has to be transported and sold in Eldoret, a medium sized town $30 \mathrm{~km}$ away. With market liberalization and the closure of the only milk processing plant in the town, income from the sale of milk las become less certain. A baseline survey carried out prior to the implementation of a water and sanitation program revealed a high prevalence of malnutrition and environmental related diseases. Malaria, diarrhea, upper respiratory tract infections, and tuberculosis had a common occurrence. The estimate for individuals who were living below the poverty line was $43 \%$; there was a poverty gap of $15 \%[8]$.

The West Pokot district study site is inhabited by Pokot people who are a Nilo-hamatic group of Kalenjin ethnicity. The study area was based in Chepereria division with an estimated population of 65,991 people. Data from the Nandi age sets suggests that the Pokot were already living in their present 


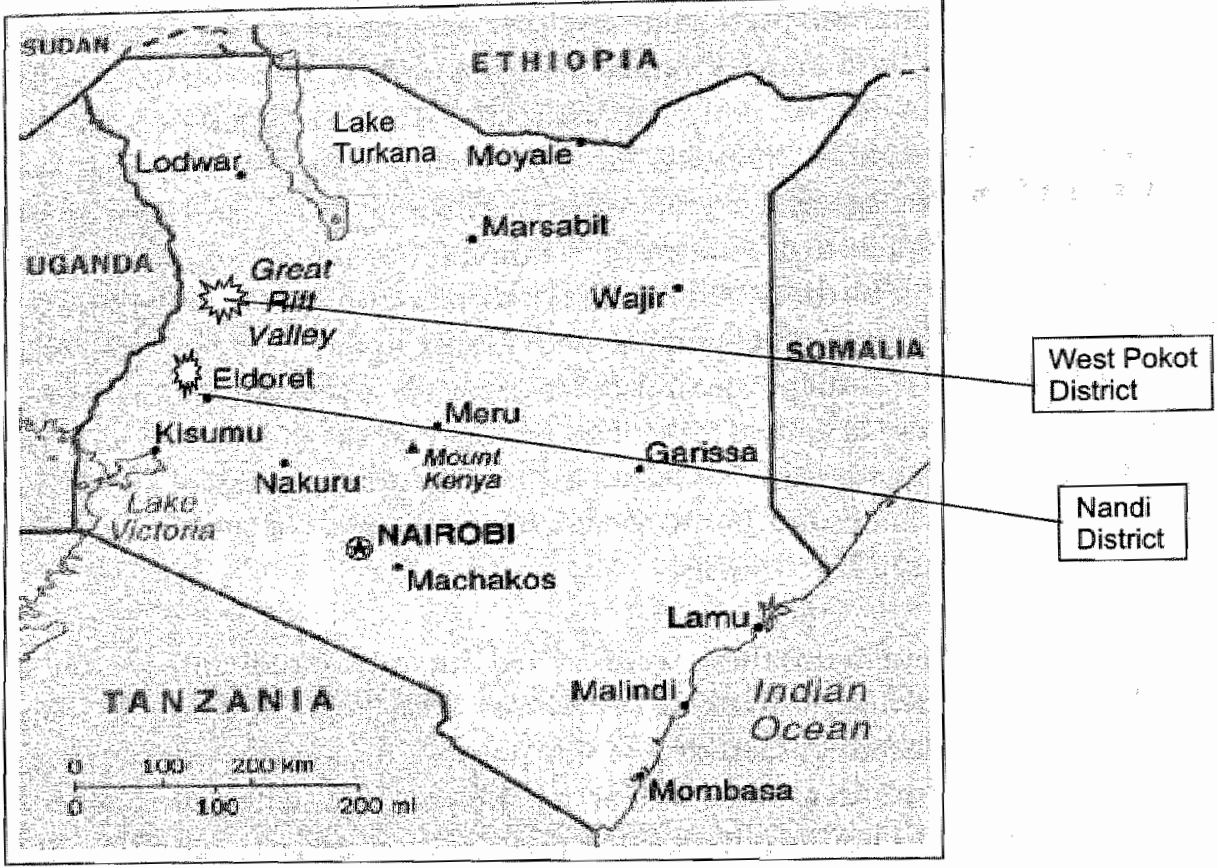

Figure 3. Location of the Nandi District, Kosirai Division and the West Pokot District, Chepereria Division study sires.

homelands by $1500-1600$ [60]. The land is very hilly in the south where some peaks in the Cherangani range exceed 10,000 feet. Plains with elevation of $3000-5000$ feet comprise the rest of the district. The pastoral Pokot live in plains and cattle occupy a central part in their economic and social life. The agricultural Pokot community inhabit the escarpments between the Turkwell gorge and the river Marich, and the escarpment south of River Marich to River Chesegon [59]. They live in sprawling villages made up of 50 or more permanent households. The main crops grown are white maize, sorghum, millet, beans and tobacco. Some areas have irrigation systems which are communally controlled and maintained. The Ortum mission hospital serves the study area and covers an estimated total population of about 46,000 people. Malaria and anemia remain the most common cause of hospital admissions. Malaria has a high prevalence in the months of May, June and July and frequently results in death. Other common diseases include gastroenteritis, kaalazar, upper respiratory tract infections, and tuberculosis. Prolonged severe drought during the last two years has left families in the two communities at very high risk of starvation. The estimate for individuals living below the poverty line was $54 \%$ with a poverty gap of $20 \%$ [8]. 


\section{Aims and motivation}

Prevention of multiple nutrient deficiencies necessitates a lifelong adequate provision of nutrients and for a long time, a lot of emphasis has been put on the implementation of various measures to control severe micronutrient deficiency disorders. The bigger problem of sub-clinical deficiency still remains relatively untouched. One reason for this is the lack of data that addresses the causes or the reasons why nutrient deficiency occurs in the first place. In theory, there are many possible ways in which a nutrient deficiency might arise. There is scanty research that specifically addresses the issue of how the socio-economic/environmental conditions of countries in sub-sahara Africa, impact on whether a specific group in a given community has an under-nutrition problem. The lack of a deep understanding of cultural beliefs and practices is obviously still hampering the detection and eradication of under-nutrition in poor mothers and children. Most interventions that address this issue have concentrated on children under five, mainly because the impact of micronutrient deficiencies on their nutritional status is viewed as more urgent and to some extent more dramatic and manifest early. Women on the other hand, despite continued exposure to chronic under mutrition, continue to fulfill stressful physiological obligations such as pregnancy and lactation. Among other things, optimal nutrition during these critical periods of a woman's life are generally adversely affected by the existing cultural and socio-economic systems that determine their lifestyle. Their low intake of iron and vitamin $A$ has a profound negative impact not only on their own nutritional status but also on the health, growth, and development of their infants. Where attempts have been made, the interventions selected have a tendency to approach each micronutrient deficiency in isolation with disregard for sub-clinical deficiency, environmental and life style factors. With a view to contribute to the development of programs for control of macro- and micronutrient deficiency in poor rural pregnant and lactating women in sub-Saharan Africa, the immediate objectives of this thesis were to: 1) investigate the factors underlying the prevalence of low body composition, iron stores, serum and breast milk vitamin $A$ in rural women;2) assess the application of methods for assessing body composition and infant breast milk intake in rural African field conditions and to contribute to the improvement of these methods; 3) investigate the role of lifestyle on maternal nutritional status during periods of pregnancy and lactation, and to determine how this affects infant growth during the first four months of life. 


\section{Outline of the thesis}

In the following chapters of this thesis, results are presented from studies in lactating and pregriant womer conducted in the Nandi and West Pokot districts of the Rift valley province, Kenya. Chapter 2 reports the results of a cross-sectional study describing the prevalence and the relationship of vitamin $A$ and iron status to the body composition of lactating Nandi women. Chapter 3 describes the validation of the deuterium oxide method against the widely used skinfold measurement based equation of Durnin and Womersley, in assessing the body composition of rural lactating Nandi women. Chapter 4 investigates the prevalence of breast milk vitamin A deficiency and assesses the adequacy of the nutritional intake of the lactating women and their breast-fed infants. Chapter 5 uses the dose-to-mother deuterium technique to assess maternal body composition and volume of infant milk intake, in exclusively breast-fed pastoral infants. Chapter 6 investigates the effect of the differences in diet and lifestyle on the body composition, iron and vitamin A status of pregnant and lactating Pokot women living in two communities in West Pokot district. Chapter 7 examines the factors underlying the prevalence of low infant weight at birth and up to the age of four months, in infants born in farming and pastoral communities of West Pokot district. In Chapter 8 , the findings of the various studies and their practical implications are discussed.

\section{References}

1. ACC/SCN. Fourth report on the world nutrition situation. Nutrition throughout the life cycle. Geneva: 2000. ACC/SCN in collaboration with IFPRI.

2. Schuftan C Ramalingaswanni V Levinson FJ. Micronutrient deficiencies and protein energy malnutrition Lancet $1998 ; 351: 1812$

3. Schuftan $C$. The different challenges in combating micronutrient deficiencies and protein energy malnutrition. Ecol Food Nutr 2000;38:505-513.

4. Dallman PR. Iron deficiency and the immune response. Am J Clin Nutr 1987;46:329-34

5. Has JD Brownlie T. Tron deficiency and reduced work capacity: a critical review of the research to determine a causal relationship. J Nutr 2001;131:676S-90S

6. Tomkins A Watson F. Malmutrition and infection: a review, United Nations Admunnstrative Committee on Co-ordination/Sub-committee on Nutrition 1989 Geneva Switzerland

7. Haurvast JL Tolboom JJ Kafwembe EM et al. Severe linear growth retardation in mal Zambian children: the influence of biological variables. Am J Clin Nutr 2000;1:550-59

8. Incidence of poverty in Kenya www. wonldbank,org/research/poverty maps/Kenya

9. Mac Laten DS. The control of xerophtalmia: a century of contributions and lessons. Sight and life news letter 2004

10. de Pee $S$ West CE Muhilal et al. Lack of improvement in vitanin A status with increased consumption of dark green leafy vegetables. Lancet 1995;346:75-81.

11. Burri JB The formation of vitamin A from b-carotene: good, bad and wariable. Sight and Life Newsletter $2001 ;(1 / 2): 3-5$ 
12. Browm LR, Feldstein $\mathbb{H}_{3}$ Haddad L, Pena $C$, Quisumbing $\mathrm{A}$. Women and food secunty The unfinished agenda - perspectives on overcoming hungex, poverty and emwironmentat degradation IFPRI 2001 .

13. ACC/SCN. Women's rolle in food chain activities and the implications for nutrition Nutrition policy discussion paper 1989. No. 4 (ACC/SCN).

14. ACC/SCN. Women and nutrition - Nutrition policy discussion paper No.6 (ACC/SCN) 1990.

15. King JC Physiology of pregnancy and nutrient metabolism. Am J Clin Nutr 2000;71:12185 $-25 \mathrm{~S}$.

16. Kigutha HN Assessment of dietary intakes among rual communities in Africa: experiences from Kenya. American J. Cl. Nut 1997,65:S1168- \$1172

17. Nurture. Healthy mothers: Children's first line of defence. 1996 Washington, DC Nurture.

18. Shetty PS Adaptation to low energy intakes: the responses and limits to low intakes in infants, children, and adults Eur J Clin Nutr 1999:53: S14-33

19. Winkvist $A_{n}$ Rasmussen KM, Habicht JP. A new definition of maternal depletion syndrome. Anu J Public Health 1992;82:691-4

20. Poppitt SD, Prentice AM, et al. Evidence of energy sparing in Gambian women during pregmancy: a longitudinal study using whole-body calorimetry. Am J Clin Nutr 1993;57:353 -64

21. Baker DJP, Gluckman PD, Godfrey KM, Harding JE, Owens JA, Robinson JS. Fetal nutrition and cardiovascular disease in adult life. Lancet 1993;341:938-941

22. Rotimi C, Okosun I, Johnson L, Owoaje E, Lawoyin T, Asuzu M, Kaufman J, Adeyemo A, Cooper $\mathrm{R}$. The distribution and mortality impact of chronic energy deficiency anong adult Nigerian men and women. Eur J Clin Nutr 1999:53:734-739.

23. Baker DJP. In utero programming of chronic disease. Clinical Science 1998;95:115-128

24. Underwood BA Arthur $R$. The contribution of vitamin A to public health. FASEB Jourual 1996;10:1040-8 1996.

25. Suharno D, West CE, Muhilal Karyadi D, Hautwast JGAJ. Supplementation with vitamin A and iron for nutritional anaemia in pregnant women in West Java, Indonesia. Lancet $1993 ; 342 ; 1325-1328$.

26. Bloem M. M Wedel, R. Egger et al Iron metabolism and vitamin A deficiency in children in North East Thailand. Am. J. Clin. Nut. 1989;50: 332-338.

27. Underwood BA. Maternal vitamin A status and its importance in infancy and early childhood. Am J Clin Nutr 1994;59:517S - 522S.

28. WHO Safe vitamin $A$ dosage during pregnancy and lactation, The micro nutrient initiative 1998 WHO/NUT. 98.4

29. Rice AL Stoltzfus RJ de Francisco A Chakraborty J, Kjolhede CL Wahed MA. Matermal vitamin $A$ or $(1-$ carotene supplementation in lactating Bangladeshi women benefits mothers and infants but does not prevent sub-clinical deficiency. J Nutr 1999; 129:356-65

30. Humprey JHE Amy LR: Vitamin A supplementation of young children. The Lancet: $2000 ; 356: 422-424$

31. Allen LH Maternal micronutrient malnutrition effects on breast milk and infant nutrition and priorities for interventions 1994. SCN Nesws. No 11

32. Hodges RE, Sauberlich HE Canham JE et al. Haenaropoietic studies in witamin A deficiency. Am. J. Clin. Nutr. 1979;31:1439-44

33. Haas JD Brownlie T. iron deficiency and reduced work capacity: a critical review of the research to determine a causal relationship. J Nutr 2001;131:6765-90S

34. WHO. The prevalence of andenua in woment a tabulation of available information. $19922^{\text {nd }}$ ed. Geneva WHO 
35. Yp AR Iron deficiency: Contemporary scientific issue and international programmatic approaches. J Nutr 1994;124:14795-1490s.

36. Fishman C, Hansch S. Beyond, Child Survival Programme option to benefit infant nutrition in sub-sahara Africa. 1995 Washington DC: Academy for Educational development.

37. Cook JD, Monsen ER Food iron absorption in human subjects III Comparison of the effect of animal proteins on non heme iron absorption Am J Chn Nutr 1976;29:859-867.

38. Preziosi P Prual A Galan P Daouda H Boureima Hhercberg $\mathrm{S}$. (1997) effects of iron stipplementation on the iron status of pregrant women: consequences for newborns. A f Clin Nutr $1997 ; 66: 1178-82$

39. Bartet JF Whitsker PG Willams JG Lind T. Absorption of non-haem iron from food during normal pregnancy. BMJ; 1994:309:79-82

40. Murphy ]F, ORtordan J. Newcombe RJ et $a_{1}$, Relation of hemoglobin levels in the first and second trimester to outcomes of pregnancy. Lancet 1986:992-5.

41. Scholl TO, Hediger ML Fischer RL, Shearer JW Anemia vs. iron deficiency: increased risk of pre-term delivery in a prospective study. Am J Clin Nutr:1992;55:210-22

42. Beard JL Effectiveness and strategies of iron supplementation during pregnancy. J Clin Nutr 2000: $71: 12885-945$.

43. Bloem MW, Wedel vans Agtmaal $M$ et al. Vitamin $A$ interwention. Short-term effects of a single, oral massive dose on iron metabolism. A J Clin Nutr 1990;51;76-79.

44. Sommer A Davidson FlR. Assessment and control of vitamin A deficiency: the Annecy accords. I Nutr 2002 132;2845S-2850S

45. WHO/CHD. Inmunization -Linked Vitamin A supplementation study group Randomised trial to assess benefits and safety of vitamin $A$ supplementation linked to immunzation in early infancy. Lancet 1998; 352:1257-63

46. West KP Jt, Katz J Shresha SR ET al. Mortality of infants $<6$ months of age supplemented with vitamin A: a randomised double-masked trial in Nepal. An J Clin Nutr 1995; 62: $143-48$

47. Scholl TO Reilly "T. Anemia iron and pregnancy outcome J Nurn 2000;30:443S-447S

48. Allen LH Pregnancy and iron deficiency: unresolved issues Nutr Review 1997:55:91-101

49. Sommer A West KP Jr. Vitamin A deficiency: Health, Survival, and vision. 1996. Oxford University Press, New York

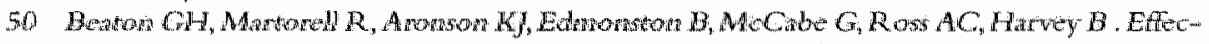
tiveness of vitamin A supplementation in the control of young child morbidity and mortality in developing countries. ACC/SCN. State of art series, Nutrition Policy Discussion Paper No. 131993 Geneva ACC/SCN

5. Brada JA, Tsang RC. Biological mechanisms of environmentally induced causes of IUGR. Eur J Clin Nutr 1998;52:S21-\$28

52 Christian $\mathrm{P}$, West KP, Kharty $\mathrm{S}$ et al. Night blindness during pregnancy and subseguent mortality among women in Nepal: Effects of vitamin $A$ and B-carotene supplementation. An J Epidemiology 2000,152:542-547.

53 Ettyang GA, van Marken Lichtenbelt WD, Oloo A. Saris W H M. Serum retinol, iron status and body composition of lactating women in Nandi Kenya Annals of Nutration and metabolism $2003 ; 47: 276-283$

54 Stolzzus R. Underwood B. Breast milk vitanin A as an indicator of the vitamin A status fro womern and infants. WHO Bullecin 1995;73:703-711

55 Stoltzfus R, Hakima M, Miller $\mathrm{KW}$ et al. High dose vitamin A supplementation of breast feeding Indonesian nothers: effects on the vitamin A status of mother and infant. J Nutr $1993 ; 123: 666-675$

56 Robert WA. A history of the African people. 1992 Waveland Printers. 
57 Central Bureau of Statistics: The Kenya Demographic and Health Survey. 2003. http:/www.kenya/cbs.go.ke. (Accessed May 2004)

58 Central Bureau of Statistics: The Kenya Population Survey 1999

59 Pkosing D, Krop S, Lopetakou W, Sikamov P. The Pokot land clams in Trans Nzoi District (1896 - 2002). Presented to the Constitution of Kenya Review Conmission (CKRC). http:/ www.kenyaconstitution.org April 2002. (Accessed May 2004) 


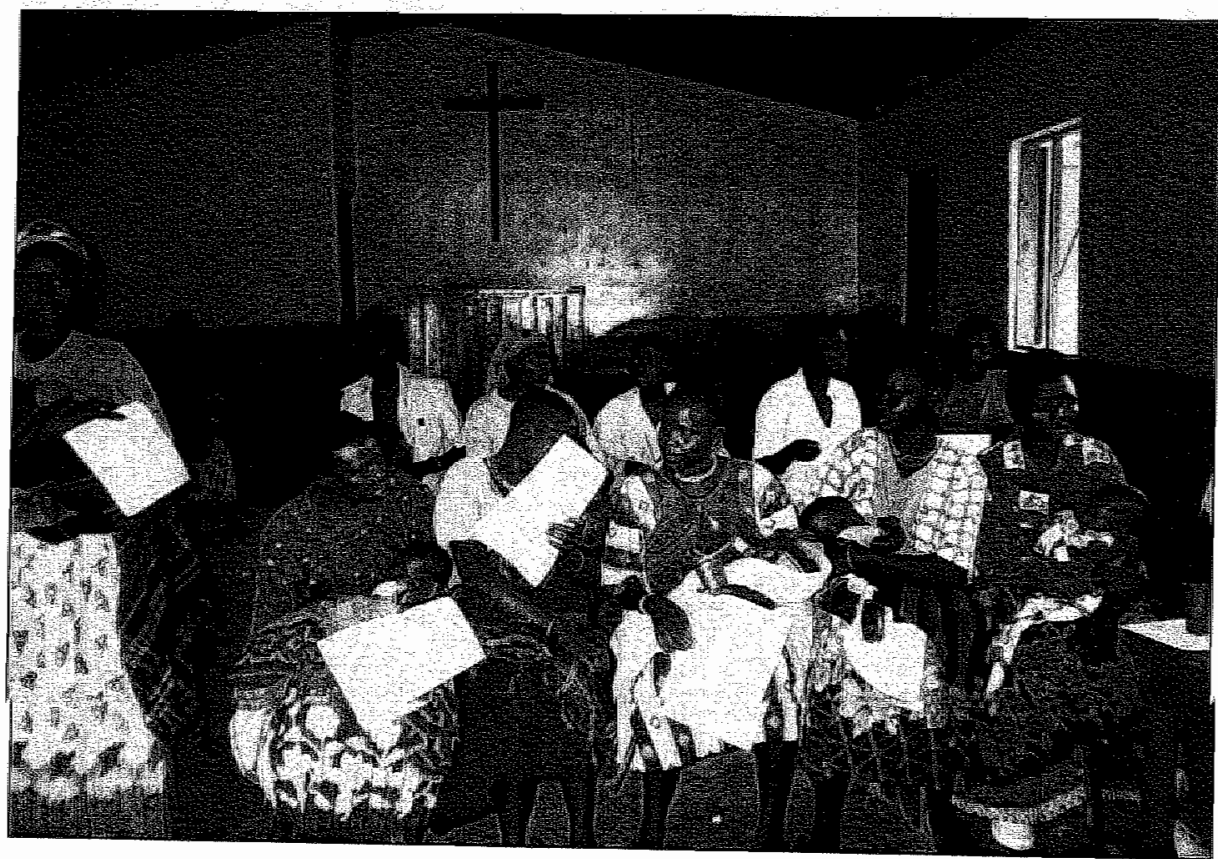


is

Serum retinol, iron status and body composition of lactating women in Nandi, Kenya

G.A. Ettyang, W.D. van Marken Lichtenbelt. A. Oloo, W.H.M. Saris 


\section{Abstract}

Background: Maternal vitamin A and iron status was investigated among lactating mothers in a rural community in Kenya. The aim of the study was to establish the prevalence and the relationship of these key nutrients to maternal body composition.

Methods: Eighty eight mothers provided samples of breast milk and blood for

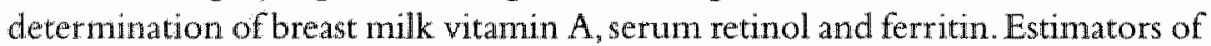
body composition were based on the mother's weight, height and skinfold measurements.

Results: A total of $78.1 \%$ women had breast milk retinol $<1.05 \mu \mathrm{mol} / 1$ with $38 \%$ and $62 \%$ having lactated for a period of $<$ and $>4$ months respectively. Prevalence of severely deficient serum retinol $<0.35 \mu \mathrm{mol} / 1$ and ferritin $<12$ $\mu \mathrm{g} / 1$ wats $10 \%$ and $37 \%$ respectively. Women with serum ferritin $<12 \mu \mathrm{g} / 1 \mathrm{had}$ significantly lower average hemoglobin $(p<0.01)$, hematocrit $(p<0.01)$ and serum retinol $(p<0.05)$. Serum retinol for mothers who had lactated for $<4$ months was significant but negatively correlated with total body fat $(\mathrm{r}=$ $-0.40 ; p<0.05$ ). With a lactation period of $>4$ months a close relationship was found between serum retinol and hemoglobin $(r=0.26 ; \mathrm{p}=<0.01)$, serum retinol and serum ferritin $(r=0.20 ; p<0.05)$ and fat free mass significant but negatively correlated with breast milk fat $(r=-0.27 ; p<0.05)$. Serum retinol in combination with haematocrit significantly affected both maternal hemoglobin $(p<0.01)$ and serum ferritin $(p<0.01)$.

Conclusion: A high prevalence of vitamin $A$ and iron deficiency was observed in this group of lactating women. Low levels of fat mass were directly related to these indicators of malnutrition.

\section{Introduction}

Vitamin A and iron deficiency anaemia are considered to be among the major nutritional deficiencies in developing countries $[1-2]$. Low weight in combination with small iron stores and low serum retinol levels leads to a risk of depletion and hence malmutrition. Furthermore the additional low concentrations of both serum and breast milk vitamin A puts the solely breast-fed child at high risk of low intake of vitamin A [3]. In the national survey of pre-school age children $35 \%$ of this vulnerable group were reported to be vitamin A deficient [4]. The only small survey done in Machakos indicated that vitamin A deficiency during pregnancy is community specific [5]. National figures for iron deficiency are not yet available. A survey done on pregnant women has reported $57 \%$ to be anaemic [6]. The lactating mother in Kenya has been found to be underweight 
while living under the constraints of a limited food supply and the demands of hard physical work [7-8]

Successive pregnancies and lactation have cumulative effects on specific nutrients [9] and depending on maternal body stores lead to the well documented Maternal Depletion Syndrome (MDS) [10]. Among the key nutrients affected may include Vitamin $A$ and iron whose requirements are increased during pregnancy and lactation. Vitamin A deficiency may exacerbate iron deficiency anaemia [11] and its supplementation to pregnant mother's [12] and children [13] has improved iron status as well as child health [14]

The national survey on household food security reports that $23 \%$ of Kenyans come from households where members of the family are unlikely to meet their minimum energy requirements even if the household concentrated all its spending on food [15]. In these households women frequently enter pregnancy with little or no maternal fat stores [16]. Vitamin A and iron may be a problem of public health significance among all the members of the family including the lactating mothers. Maternal nutrition is of paramount importance if the nutrition and health condition of the child is to be improved [17]. Supplementation with iron or vitamin A tends to target the pregnancy phase of the reproductive cycle. Relying on intervention in the late first trimester or early second trimester of pregnancy may be too late [18]. Information on how and when to intervene is critical and needs to be tailored to meet the unique needs of each target group [19-20]. This necessitates the identification of communities where both pregnant and lactating mothers may not only be undernourished but are also at risk of vitamin $A$ and iron deficiency.

The present study was therefore undertaken to investigate the prevalence of vitamin $\mathrm{A}$ and iron deficiency anaemia among lactating mothers living in a rural community in Kenya. We present the results of a cross-sectional study in which we determined the prevalence of vitamin $A$ and iron deficiency in lactating women in the Kokwet location of Nandi district, Kenya. We also examined whether there is an association between serum retinol ferritin, breast milk retinol concentrations and body composition.

\section{Materials and methods}

The study was carried out in December 1998 and January 1999. It involved the examination of 88 normal lactating women aged $15-45$ years with their breast feeding children aged between 2 weeks and 15 months from 7 villages in Kokwet location of Nandi district, an area $30 \mathrm{~km}$ south west of Eldoret Town. The women in this study came from a rural farming community and are considered at risk in relation to low energy and nutrient intake. All the lactating 
mothers in the 7 villages were identified and visited in their homes and interviewed. In addition to food intake, child health and nutritional status, other variables of interest were maternal body composition, iron and vitamin A status. The study was carried out following the ethical standards of Mor University, Eldoret and with clearance and permission from the Kenya government.

\section{Anthropometry, blood and breast milk collection}

Information on age, parity, length of lactation, interval since last pregnancy was recorded by using a questionnaire. Anthropometric measurements comprising height, weight, mid-upper arm circumference (MAC) and skinfold thickness were performed and used to determine maternal fat mass (FM) and fat free mass (FFM) [21], Venous blood sample of about $5 \mathrm{ml}$ were taken and stored on ice for transportation to the laboratory. Serum was separated from blood by centrifugation at $200-\mathrm{x} \mathrm{g}$ for $15 \mathrm{~min}$ at room temperature on arrival and samples stored separately at $-20^{\circ} \mathrm{C}$ in the dark. Breast milk was collected from one breast that had not been used to feed the infant for at least I hour [22] and covered and stored in a cool box for transportation to the laboratory. Milk samples were re-homogenized at room temperature and the samples stored separately at $-20^{\circ} \mathrm{C}$ in the dark.

\section{Biochemical analysis}

Leshmann stain was used to make blood smears and erythrocyte, and leukocytes status of the lactating mothers determined and cell morphology classified into three categories of normal, mild and moderate. The blood slides were examined for the distribution of macrocytic cells due to Vitamin $B_{12}$ or Folic acid deficiency, microcytic hypochromic anemia due to iron deficiency and the presence of hypochromic cells. A Coulter counter, model 560 was used to determine hemoglobin $(\mathrm{Hb})$, haematocrit ratio ( $\mathrm{Hct}$ ) mean cell volume $(\mathrm{MCV})$ and red blood cell (RBC) count.

The creamatocrit method as described by Lucas [23] was used to determine the breast milk fat (BMF) and energy concentration: The vitamin $A$ concentration was expressed as a ratio to the fat concentration in percent i.e. $1.5 \mu \mathrm{mol} / \mathrm{l}$ vitamin A , $5 \%$ fat $=0.3 \mu \mathrm{mol} / \%$ fat $[20,22]$. Retinol levels in serum and breast milk were assayed using high-performance liquid chromatography (HPLC). Measurement of serum ferritin (SF) was performed using the enzyme linked inmunosorbent assay (ELISA) (Boehringer Mannheim Immundiagnostic Mannheim, Germany).

Nutritional anaemia was assessed by using both $\mathrm{Hb}$ and $\mathrm{Hct}$ [24]. The lactating mothers were categorized as having iron deficiency anaemia when found with a 
$\mathrm{Hb}$ of $<12 \mathrm{~g} / \mathrm{dl}$ or a Hct ratio of $<37$. Depletion of iron stores was based on the levels of SF concentration: severe $<12 \mu \mathrm{g} / 1$; marginal $12-29 \mu \mathrm{g} / 1$ and normal ${ }^{3} 30$ $\mu \mathrm{g} / \mathrm{l}$. Vitamin A status was based on serum retinol concentration: deficient, $<0.35 \mu \mathrm{mol} / \mathrm{l}(10 \mu \mathrm{g} / \mathrm{dl})$ and marginal, $<0.70 \mu \mathrm{mol} / 1(20 \mu \mathrm{g} / \mathrm{dl})$. The same cutoff points was used for deficiency in breast milk retinol levels.

\section{Statistical analyses}

Data were analyzed with the SPSS/PC statistical package (Version 9.2 1998). Mean, standard deviations and median were calculated. Independent samples Student's t-test was used to determine the significance of the differences between lactating mothers with normal and depleted iron stores. The Chi-square was used to compare the difference between proportions of mothers with normal and low serum retinol and ferritin. Pearson's correlation tests were performed to examine the relationships between body composition, serum retinol and measures of iron status. In order to identify individual and the combination of factors likely to affect fat stores, iron deficiency anaemia and the vitamin A status of the rural lactating mothers both backward and step mulltiple regressions were done. $\mathrm{Hb}$ status, $\mathrm{SF}$ and $\%$ body fat were treated as dependent variables. Due to a skewed distribution natural $\log$ transformed values were used for SF concentration. The following predictor variables were used in the multiple regression analyses. Maternal: age and parity. Child: age and reported birth weight. Vitamin A: breast milk fat; breast milk retinol and serum retinol. Anaemia: RBC count; MCV; SF; haematocrit and haemoglobin. Body composition: mid arm circumference; body mass index; \%body fats and fat free mass. Using $\mathrm{p}>0.10$ for exclusion the significant $(\mathrm{p}<0.01)$ combination of variables related to $\mathrm{Hb}$, iron and fat stores were identified.

\section{Results}

All the mothers lactating infants $<15$ months were recruited from 7 villages making a total of 88 mother child pairs. From all mothers body composition measurements were taken. Eight mothers had infants of less than one month and 12 were unable to provide breast milk. Fifteen declined to provide blood. Table 1 shows maternal and child characteristics and indices of iron and serum retinol status. The average ( $\pm \mathrm{SD}$ ) age of the breast-feeding child was 7.6(4.9) months. On average \% body fat of the mothers was 26.1(5.4) while FFM was $41.3(5.1)$. Average breast milk retinol, serum retinol and SF were $0.90(0.7)(\mu \mathrm{mol} / 1), 0.69$ (0.26) $(\mu \mathrm{mol} / \mathrm{l})$ and $21.5(16.3)(\mu \mathrm{g} / \mathrm{l})$ respectively. 
Table 1. Characteristics and biochemical indexes of the lactating women.

\begin{tabular}{|c|c|c|c|c|}
\hline & \multicolumn{4}{|l|}{ Percentules } \\
\hline & Mean $\pm S \mathrm{SD}^{\circ}$ & $5^{\mathrm{rh}}$ & $50^{\text {th }}$ & $95^{\mathrm{fh}}$ \\
\hline & & & 280 & 383 \\
\hline Age of mother $(y)$ & $27.2 \pm(6.1)$ & 18.8 & 28.0 & \\
\hline Age of the child (m) & $7.6 \pm(4.9)$ & 1.3 & 6.2 & 15.0 \\
\hline Child birth weight & $3.4 \pm(.54)$ & 2.5 & 3.4 & 4.2 \\
\hline No, of children & $3.9 \pm(2.4)$ & 100 & 3.5 & 8.5 \\
\hline Lactation length (m) & $7.8 \pm(4.9)$ & 1.3 & 8.2 & 15.0 \\
\hline Height (cm) & $161.1 \pm(5.9)$ & 150.9 & 161.9 & 171.6 \\
\hline Weight (kg) & $56.5 \pm(9.7)$ & 42.5 & 55.0 & 76.9 \\
\hline Mid Arm Circ. & $24.8 \pm(2.7)$ & 21.0 & 24.7 & 29.8 \\
\hline Body Mass Index & $21.7 \pm(3.2)$ & 17.2 & 21.4 & 28.0 \\
\hline Body fat (BF $\%$ ) & $26.1 \pm(5.4)$ & 7.4 & 26.1 & 35.9 \\
\hline Fat free mass $(\mathrm{kg})$ & $41.3 \pm(5.1)$ & 33.3 & 41.3 & 506 \\
\hline Hemoglobin $(g / d)(n=73)$ & $11.9 \pm(1.8)$ & 8.9 & 12.3 & 14.8 \\
\hline Hematocrit ratio $(n=73)$ & $34.9 \pm(3.2)$ & 28.7 & 36.0 & 38.8 \\
\hline $\mathrm{MCV} / 1(\mathrm{n}=69)$ & $81 \pm(7.5)$ & 67.0 & 83.0 & 95.0 \\
\hline $\operatorname{RBC}\left(10^{12} / 1\right),(n=56)$ & $44.6 \pm(3.7)$ & 39.1 & 44.3 & 52.5 \\
\hline Serum ferritin $(\mathrm{og} / 1)(\mathrm{n}=67)$ & $21.5 \pm(16.3)$ & 4.5 & 15.4 & 50.1 \\
\hline Serun retinol $(\mu \mathrm{mol} / \mathrm{l})(\mathrm{n}=69)$ & $0.69 \pm(0.26)$ & 0.34 & 0.69 & 1.2 \\
\hline Breast milk fat $(\%)(\mathrm{n}=68)$ & $4.3 \pm(2.3)$ & 1.0 & 4.0 & 9.6 \\
\hline Breast mik retinol $(\mu \mathrm{mol} / \mathrm{l})(\mathrm{n}=73)$ & $0.90 \pm(0.7)$ & 0.23 & 0.70 & 2.84 \\
\hline
\end{tabular}

* $\mathrm{n}=88$ except where otherwise noted.

Vitamin A status of the lactating mothers based on serum retinol concentrations was $10 \%, 40.7 \%$ and $49.3 \%$ respectively for severely deficient $(<0.35 \mu \mathrm{mol} / \mathrm{l})$, marginal $(<0.70 \mu \mathrm{mol} / 1)$ and adequate $(>0.70 \mu \mathrm{mol} / \mathrm{l})$. Low breast milk retinol concentration $(<1.05 \mu \mathrm{mol} / 1)$ was found in $78.1 \%$ of these lactating women. Mothers who had both low serum and breast milk retinol concentration were $55.7 \%$.

Mild to moderate microcytosis and macrocytosis occurred in $29 \%$ and $16 \%$ of the mothers while $35 \%$ of the mothers had mild to moderate hypochromia. $\mathrm{Hb}$ status $<12 \mathrm{~g} / \mathrm{dl}$ and $\mathrm{Hct}$ ratio $<37$ were found in $43.8 \%$ and $69.9 \%$ of the women respectively. SF concentration was severely deficient $(<12 \mu \mathrm{g} / 1)$ in $37 \%$, marginal $(<30 \mu g / l)$ in $39 \%$ and adequate $(>30 \mu \mathrm{g} / \mathrm{l})$ in $24 \%$ of the lactating mothers.

Mothers with severely depleted irons stores (SF $<12 \mu \mathrm{g} / \mathrm{l}$ ) had significantly lower average $\mathrm{Hb}(p<0.01)$, Hct $(p<0.01)$ and serum retinol levels $(p<0.05)$ 


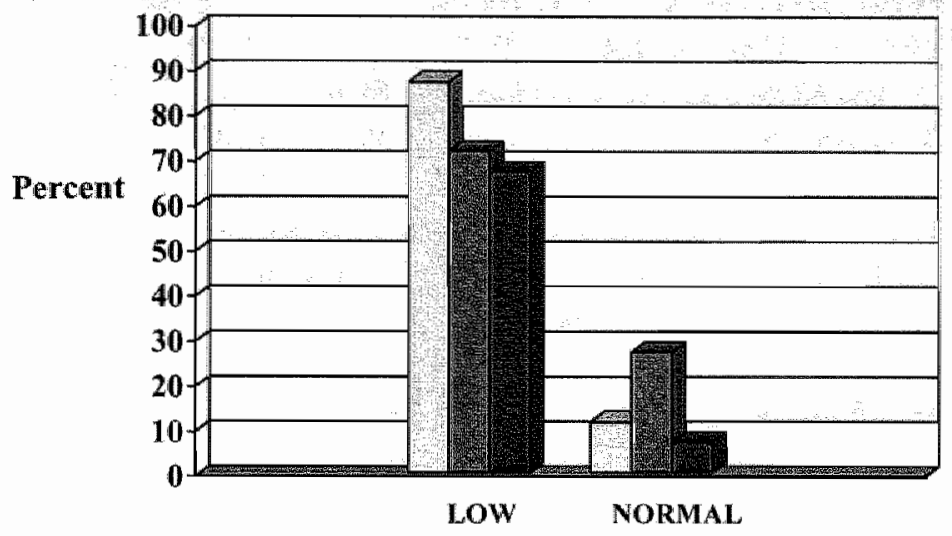

\begin{tabular}{|c|c|c|}
\hline & $\square$ Retinol & 盷 Ferritin \\
\hline Low & $\begin{array}{l}\text { Serum ferritin } \\
\text { Serum retino] }\end{array}$ & $\begin{array}{l}30 \mu \mathrm{g} / 1 \\
1.05 \mu \mathrm{mol} / 1\end{array}$ \\
\hline Normal & $\begin{array}{l}\text { Serum ferritin } \\
\text { Serum retinol } \\
\text { Pearson Chi-s }\end{array}$ & $\begin{array}{l}30 \mu \mathrm{g} / \mathrm{l} \\
1.05 \mu \mathrm{mol} / 1 \\
\text { lare } \mathrm{P}<0.05\end{array}$ \\
\hline
\end{tabular}

Figure 1. Maternal iron stores and vitamin A status.

(Table 2). There was a significant difference $(p<0.05)$ between mothers $(67 \%)$ with low serum retinol $(<1.05 \mu \mathrm{mol} / 1)$ and SF $(<30 \mu \mathrm{g} / \mathrm{l})$ and mothers $(7.7 \%)$ with both normal serum retinol $(>1.05 \mu \mathrm{mol} / \mathrm{l})$ and SF $(>30 \mu \mathrm{g} / \mathrm{l})$ (Figure 1)

Mothers with a lactation period of $<$ or $>4$ months were $37.7 \%$ and $62.3 \%$ respectively. In the early months of lactation $(<4$ months) serum retinol was significant but negatively correlated with total body fat $(r=-0.40 ; p<0.05)$. Mothers with a longer lactation period had fat free mass that was significant but negatively correlated with breast milk fat $(r=-0.27 ; p<0.05)$. The correlation matrix relating maternal $\mathrm{Hb}$ status as well as SF concentration with $\mathrm{Hct}$, and serum retinol is shown in Table 3. Mothers with a lactation period of $<4$ months had a $\mathrm{Hb}$ status that was highly significant and positively correlated with $\mathrm{SF}(\mathrm{r}=0.46 ; \mathrm{p}<0.01)$ and $\mathrm{H}$ ct $(\mathrm{r}=0.65 ; \mathrm{p}<0.01)$. For both $\mathrm{Hb}$ status and $\mathrm{SF}$ concentration the correlation coefficients were high and statistically significant for lactation duration of $>4$ months. Serum retinol was highly significant and positively correlated to $\mathrm{Hb}$ status $(\mathrm{r}=0.26 ; \mathrm{p}=<0.01$ and significant and positively correlated to $\mathrm{SF}(r=0.20 ; \mathrm{p}<0.05)$. 
Table 2. Significance of mean values of microntrients and body composition in lactating mothers with normal and depleted jron stores based on serum ferritin lewels.

\begin{tabular}{|c|c|c|c|c|}
\hline Variable & Iron Stores & N & Mean $^{2}$ & P Value \\
\hline Hernoglobin & Severe depletion & 25 & $10.7 \pm 1.8$ & $<0.01$ \\
\hline$(g / d)$ & Marginal to normal & 42 & $12.6 \pm 1.4$ & \% \\
\hline \multirow[t]{2}{*}{ Hematocrit ratio } & Severe depletion & 25 & $32.6 \pm 3.6$ & $<0.01$ \\
\hline & Marginal to nomal & 42 & $36.3 \pm 2.1$ & \\
\hline \multirow{2}{*}{$\begin{array}{l}\text { Serume retinol } \\
(\text { amol/d) }\end{array}$} & Severe depletion & 24 & $0.63 \pm 0.15$ & $<0.05$ \\
\hline & Marginal to nomnal & 41 & $0.74 \pm 0.30$ & \\
\hline \multirow{2}{*}{$\begin{array}{l}\text { Breast milk retinoll } \\
\text { (uwol/s) }\end{array}$} & Severe depletion & 25 & $0.98 \pm 0.90$ & $>0.05$ \\
\hline & Marginal to normal & 42 & $0.86 \pm 0.60$ & \\
\hline \multirow[t]{2}{*}{ Body mass index } & Severe depletion & 25 & $22.3 \pm 2.6$ & $>0.05$ \\
\hline & Marginal to normal & 42 & $21.4 \pm 3.7$ & \\
\hline \multirow{2}{*}{$\begin{array}{l}\text { Body fat } \\
(\% l)\end{array}$} & Severe depletion & 25 & $27.5 \pm 5.3$ & $>0.05$ \\
\hline & Marginal to normal & 42 & $25.3 \pm 5.8$ & \\
\hline \multirow{2}{*}{$\begin{array}{l}\text { Fat free mass } \\
(\mathrm{kg})\end{array}$} & Severe depletion & 25 & $42.0 \pm 4.1$ & $>0.05$ \\
\hline & Marginal to normal & 42 & $40.8 \pm 6.1$ & \\
\hline
\end{tabular}

"Serum ferritin $<12 \mu \mathrm{g} / \mathrm{l}$ severe depletion; Serum ferritin $>12 \mu \mathrm{g} / 1$ marginal to normal., " Mean $\pm \mathrm{SD} ;{ }^{3} \mathrm{P}$ - value based on $\mathrm{t}-$ test for independent samples.

Table 3. Correlation and level of statistical significance of maternal indexes of iron and serum retinol for lactation duration of $<4$ or $>4$ months.

\begin{tabular}{|c|c|c|c|c|c|c|c|c|}
\hline & \multicolumn{4}{|c|}{$\begin{array}{l}\text { luctation }<4 \text { months } \\
n=30\end{array}$} & \multicolumn{4}{|c|}{$\begin{array}{l}\text { lactution }>4 \text { months } \\
n=50\end{array}$} \\
\hline & \multicolumn{2}{|l|}{$\mathrm{Hb}$} & \multicolumn{2}{|c|}{ Werritin } & \multicolumn{2}{|c|}{$\mathrm{Fb}$} & \multicolumn{2}{|c|}{ Ferritin } \\
\hline & $r$ & $p$ & $r$ & $\mathrm{p}$ & $r$ & p & $\mathrm{r}$ & $p$ \\
\hline $\mathrm{Hb}$ & & & .46 & $<0.05$ & & & .53 & $<0.01$ \\
\hline Perritin & .46 & $<0,01$ & & & .54 & $<0.01$ & & \\
\hline Hematocrit & .65 & $<0.01$ & .43 & $<0.05$ & .77 & $<0.01$ & .67 & $<0.01$ \\
\hline Rotinol & -.06 & $>0.05$ & .10 & $>0.05$ & .26 & $<0.01$ & .20 & $<0.05$ \\
\hline
\end{tabular}


Table 4. Coefficients ( $\beta)$ and significance levels (p) from multiple regression analyes of $\mathrm{Hb}$ for all mothers and iron store status for mothers with ferritin concentration in serum $<30 \mathrm{mg} / 1$ as the dependent variables.

\begin{tabular}{|c|c|c|c|c|c|c|c|c|c|c|}
\hline \multirow[b]{2}{*}{ Predictor Variables } & \multicolumn{5}{|c|}{$\begin{array}{l}\text { Hb status } \\
n=67\end{array}$} & \multicolumn{5}{|c|}{$\begin{array}{l}\text { Ferritin concentration }(<30 \mu \mathrm{g} / \mathrm{l}) \\
\mathrm{n}=51\end{array}$} \\
\hline & $\beta$ & $r$ & $n^{2}$ & $\mathrm{~F}$ & $\mathrm{p}$ & $\beta$ & $r$ & $r^{2}$ & $\mathrm{~F}$ & $p$ \\
\hline Constant & -2.89 & & & & & -22.10 & & & & \\
\hline Haematocrit & 0.43 & .74 & .54 & 40.0 & $<0.01$ & 1.03 & .56 & .32 & 17.4 & $<0.01$ \\
\hline Constant & -4.00 & & & & & -27.04 & & & & \\
\hline Haematocrit & 0.42 & .77 & .60 & 24.7 & $<0.01$ & 1.00 & .64 & 41 & 12.8 & $<0.01$ \\
\hline Serum Retinol & 1.80 & & & & & 8.78 & & & & \\
\hline
\end{tabular}

An analysis of variance based on forward step multiple regression is shown in Table 4 . Using $\mathrm{Hb}$ and $\mathrm{SF}<30 \mu \mathrm{g} / 1$ as dependent variables, and based on all the predictor variables haematocrit and serum retinol were highly significant $(\mathrm{p}<0.01$ ) factors that explained $77 \%$ and $64 \%$ of the total variation in $\mathrm{Hb}$ status and SF concentrations respectively. The correlation coefficients of haematocrit $(0.42 ; 1.00)$ and serum retinol $(1.81 ; 8.78)$ respectively for $\mathrm{Hb}$ status and $\mathrm{SF}$ concentrations show a positive direct linear relationship.

Backward multiple regression identified haematocrit $(p<0.01)$, breast milk fat $(p>0.05)$, serum retinol $(p<0.05)$, body mass index $(p<0.05)$, fat free mass $(p>0.05)$ and $\%$ body fat $(p>0.05)$ as predictor variables able to explain $68 \%$ of the variation in the $\mathrm{Hb}$ status of the lactating women. Haematocrit and Serum retinol have a significant effect and need to be taken into account when making predictions and estimates that determine the $\mathrm{Hb}$ status and SF concentrations of lactating mothers.

With regard to maternal body composition, there may be a significant linear relationship between percent body fat, serum ferritin and retinol when you take into account maternal age and the child's reported birth weight (Table 5). Though these four factors explain $64 \%$ of the variation in percent body fat, except for maternal age, the other three coefficients show a negative direct linear relationship. 
Table 5. Coefficients $(\beta)$ and significance levels $(p)$ from multiple regression analyses of $\%$ body fot as the dependent variable for 88 lactating women.

\begin{tabular}{|c|c|c|c|c|c|}
\hline Predictor Variables & $\beta$ & + & $\mathrm{R}^{2}$ & $\mathrm{~F}$ & $\mathrm{p}$ \\
\hline Constant & 38.67 & & & & \\
\hline Child birts weight & -3.52 & 34 & .12 & 5.48 & $<0.05$ \\
\hline Constant & 49.87 & & & & \\
\hline Child birth weight & -5.18 & .47 & .22 & 5.64 & $<0.01$ \\
\hline Serum retinol & -7.54 & & & & \\
\hline Constant & 51.54 & & & & \\
\hline Child birth weight & -5.19 & .55 & .30 & 5.50 & $<0.01$ \\
\hline Serum tetinol & -6.91 & & & & \\
\hline Serum ferritin & -0.09 & & & & \\
\hline Constant & 41.55 & & & & \\
\hline Child birth weight & -4.61 & .64 & .41 & 6.69 & $<0.01$ \\
\hline Serum retinol & -6.56 & & & & \\
\hline htSerun ferritin & -0.12 & & & & \\
\hline Age of the mother & 0.30 & & & & \\
\hline
\end{tabular}

\section{Discussion}

The present study explores the relationship between 'serum retinol' and biochemical measures of iron nutriture and breast milk retinol, body composition in a population of lactating mothers in rural Kenya. A large percentage (73\%) of the Kenyan population still lives in the rural area [15]. Nutritional studies in the country have tended to concentrate on the preschool age child and to a very small degree on the pregnant mother. Lactating mothers were chosen as the subjects of this study because they are equally vulnerable to the documented vitamin $A$ and iron metabolic interactions. During the reproductive cycle continuous depletion of these nutrients has negative effects on both the health and nutritional status of the mother and the infant. To this we now add the interactions likely to occur in relation to maternal body composition.

The WHO identifies an $\mathrm{Hb}$ level below $12 \mathrm{~g} / \mathrm{dl}$ as being anaemic. We found $43.8 \%$ of the lactating mothers anaemic by this criterion. This compares with the prevalence of $43 \%$ in non-pregnant women in the developing countries [25]. In a rural area in northern Natal a prevalence of anemia in females aged 6-74 years was found to be $52 \%$ [26]. In Bangladesh Ahmed et al [27] found a 
prevalence of $44 \%$ among adolescent female garment factory workers with rural roots. When simple correlation tests were used we observed a highly significant correlation between $\mathrm{Hb}$ and $\mathrm{Hct}$, SF concentration and MCV. This suggests that iron status was likely to be an important determinant of $\mathrm{Hb}$ and hence anaemia. On the basis of combined cut-off points for $\mathrm{Hb}$ and SF $(\mathrm{Hb}<12 \mathrm{~g} / \mathrm{dl}$ and SF $<$ $12 \mu \mathrm{g} / \mathrm{l}) 27 \%$ of the lactating mothers with a mean $\mathrm{Hb}$ of $9.89 \mathrm{~g} / \mathrm{dl}$ were iron deficient. Similar relationships have been found in adolescent girls in peri-urban Bangladesh [28]. It was also found that those lactating mothers with depleted iron stores had significantly lower $\mathrm{Hb}$ and $\mathrm{Hct}$ compared with the lactating mothers who had SF levels ${ }^{3} 12 \mu \mathrm{g} / \mathrm{l}$ reinforcing the impression that anaemia in this group of lactating mothers was causally related to iron status. These mothers were also found to have lower serum retinol levels indicating a possible relationship between vitamin $\mathrm{A}$ status and the use of iron for $\mathrm{Hb}$ formation.

A number of population studies have found positive correlation between serum retinol and biochemical indicators of iron status [11-12] and supplementation intervention have tended to target pregnant women and children. The results of our study show that even lactating mothers are equally at risk. The $\mathrm{Hb}$ and serum retinol relationship found in this study is similar to the one reported by Surhano et al [12] for pregnant women in West Java Indonesia. Bloem et al [29] found that in children aged 1-8 years there was no association with $\mathrm{Hb}$, but an association for serum retinol with transferrin and serum iron. In the lactating mothers studied high levels of serum retinol were associated with higher levels of $\mathrm{Hb}(\mathrm{r}=0.26)$. Studies done in Bangladesh by Ahmed et al [30] also showed that adolescent girls with higher $\mathrm{Hb}$ had better serum retinol levels.

Based on the WHO criteria for serum retinol and breast milk vitamin $A$ concentration the low levels of breast millk retinol and serum retinol identifies this group of lactating mothers as being vitamin A deficient [20]. A high percentage of (88.4\%) lactating mothers were at risk of vitamin A deficiency with serum retinol values of less than $1.05 \mu \mathrm{mol} / 1$. The average breast milk fat concentration of $1.29 \pm(0.69) \mu \mathrm{mol} / 1$ is below the recommended cut off value of $1.4 \mu \mathrm{mol} / 1$. In our study $78 \%$ of the infants were breast feeding on breast milk with an estimated vitamin $A$ concentration of $<1.05 \mu \mathrm{mol} / 1$ [ [20]. A recent analysis by Humphrey and Amy [3] based on data from studies conducted in Thailand by Stoltzfus and Underwood [22] suggests that this low intake put the breast fed infant at risk of vitamin A deficiency.

As shown in table 5, maternal fat stores during lactation need to take into account not only the negative effects on birth weight and maternal age but also 
on serum retinol and ferritin. The hactation phase of the reproductive cycle is energy demanding. Maternal body composition stores are a proxy for adequacy of energy and protein intake. This in turn may also have an effect on the mother's iron and vitamin $A$ status. There are no previous Kenyan studies, that have looked at the relationship between body composition, vitamin $A$ and iron status in lactating mothers. In this study, the occurrence of a negative significant correlation between serum retinol and fat mass $(r=0.040)$ in mothers with a lactation period of $<4$ months indicates a possible initial significant depletion in maternal energy stores.

With a prolonged lactation period of $>4$ months the increase in breast milk fat is at the expense of a decrease in maternal protein reserves $(r=-0.27)$. This may affect not only the concentration of breast milk vitamin $A$ but also the long-term preservation of maternal energy and protein reserves [16]. The data show that in this rural Kenyan community, mothers with a low level of fat mass also had a high prevalence of vitamin $\mathbf{A}$ and iron deficiency. Among rural Pakistan women maternal nutritional status was evaluated across a full reproductive cycle and it was found that marginally nourished women lost weight during the reproductive cycle concurrent with a positive trend in infant birth weight [31]. A study done on rural Bangladesh women concludes that women failed to gain sufficient weight during the last half of pregnancy to maintain body weight during lactation when energy demand is high [32]. Most studies on body composition during lactation have tended to concentrate on changes in body weight without taking into account the micronutrient deficiencies that are likely to occur. Ability to produce breast milk that is adequate to support the normal growth, nutrient store and development of infants may be compromised when mothers consume poor-quality diets that are low in animal products and in most vitamins. Decades of exclusive support fro children's programs have meant neglect of the welfare of the lactating mother. More work is needed to determine the optimal quantity of nutrients needed to replenish maternal stores and restore breast milk concentrations. In this study body composition indices were computed based on skinfold measurements. Use of more accurate methods may reveal a more clearer picture of the extent of depletion in maternal energy and protein reserves.

The data show a high prevalence of nutritional anaemia and sub-clinical vitamin A deficiency among these rural lactating mothers. There is also an interaction between serum retinol, ferritin and percent body fat. In the present study we have shown that even in a group of lactating mothers who may appear otherwise well, marginal vitamin A status is likely to compromise iron stores. This 
makes it imperative to prevent maternal iron and vitamin $A$ deficiency so that the true long-term benefits of these two nutrients are realized for both the mother and the infant. Mothers should be helped to enter their next pregnancy with better iron reserves [33, 34]. In summary we found in this group of lactating women lower vitamin $\mathrm{A}$ and iron stores and that these indicators of malnutrition were related to each other. Changes in dietary intake may be the preferred long-term solution to the problem of maternal vitamin $A$ and iron deficiency. There is a need to include lactating mothers in intervention strategies aimed at improvement of vitamin $A$ and iron status.

\section{Acknowledgements}

This study was supported by the MUNDO Moi University and Maasricht University project. We are grateful for the facilitation role played by the dean Prof. B.O. Khwa-Otsyula and the former dean of the Faculty of Health Sciences, Prof. H.N.K. arap Mengech. We thank the chief and the mothers of Kokwet community and Mr. L.C. Kimile for providing excellent field and laboratory support and Dr. A.M. Ngindı for fruitful discussions.

\section{References}

1. WHO/OMS: Highlights of recent activities in the context of the world declaration and plan of action for nutrition. WHO/OMS/95.2. Geneva: World Health Organization, 1995.

2. UN'ICEF: The state of the world's children. New York: Oxford Uniwersity Press. 1995.

3. Humprey JH, Amy LR: Vitamin A supplementation of young children. Lancet $2000 ; 356: 422-424$.

4. Ngare DK: Vitamin A deficiency in Kenya. Rep $17^{\text {th }}$ Int Vitamin A Consultative Group Meet, Guatemala, March 18-22 1996.

5. Kusin J A: Vitamin A status of pregnant and Jactating women as assessed by serum levels in Machakos area Kenya, East Afr Med J 1985;62:476-479.

6. Fishman $\mathrm{C}$, Hansch S: Beyond Child Surviwal: Programme option to benefit infant nutrition in sub-sahara Africa. Washington. Academy for Educational development 1995

7. Mwadime RK: Dietary considerations in designing nutrition intervention programmes in rural areas of Kenya. East Afr Med J 1995;7:442-8

8. Kigutha HN: Assessment of dietary intakes among tural communities in Africa: Experiences from Kenya. An J Clin Nutr. 1997; 65: \$1 168- $\$ 1172$

9. Jelife DB, Maddocks I: Ecological malnutrition in the New Guinea Highlands. Clin Paediar $1964 ; 3: 432-428$

10. Winkvist A, Rasmussen KM, and Habicht JP: A new definition of matermal depletion syndrome. Am J Public Health 1992:82:691-4

11. Bloem MW, Wedel M ran Agtmaal M: Vitamin A intervention. Short-term effects of a single, oral massive dose of iron on metabolism. Am J Clin Nutr 1990; 51:76-79. 
12. Surhano $D_{y}$ West CE, Muhila, Karyyad D, Hautwast JG: Supplementation with vitamin $A$ and iron for nutritional anaema in pregnant women in West Java, Indonesia Lancet 1993; $342: 1325-1328$.

13. Meja $L A$, Chew $\mathrm{F}$. Haematological effect of supplementing anaemic children with vitamin A alone and in combuation with iron. Am J Cin Nutr 1988;48.595-600.

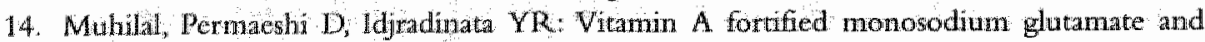
health, growth, and surwival of children: a controlled feld trial. An J Clin Nutr 1988; $48: 1271-1276$

15. CBS: The first report on poverty in Kenya Incidence and depth of powerty wol. 1. Ministry of Planing and National Development 1998.

16. Shetty PS: Adaptation to low energy intakes: The responses and limits to low intakes in infants, children and adults. Eur I Clin Nutu 1999;53 (suppl 1) S14-\$33.

17. Underwood BA: Maternal vitamin A status and irs importance in infancy and early childhood. An J Clin Nutr 1994;59 (suppil): 517\$-524S.

18. Beard JL. Effectiveness and strategies of iron supplementation during pregnancy. Am J Clin Nutr 2000: 71 (suppl 5): $12885-12945$.

19. Djoko Suharno, Muhilal: Vitamin A and nutritional anaemia. Food Nutr Bull. 1996, 17:7-10.

20. WHO: Indicators for assessing vitamin A deficiency and their application in monitoring and evaluating intervention programmes. World Health Organisation 1996: WHO/NUT/96.10

21. Gibson R: Principles of Nutritionall assessment. Oxford University Press. 1990

22. Stoltzfus RJ Underwood B: Breast milk vitamin $A$ as an indicator of the vitamin $A$ status for women and infants. Bulli World Health Org 1995;73(5):703-711

23. Lucas A, Gibbs JAH, Lyster RLJ, Baum JD: Creamatocrit: Simple clinical technique for estimating fat concentration and energy value of human milk. BMJ 1978; 1018-1020.

24. Cook JD, Finch CA: Assessing iron status of a population. Am I Clin Nutr 1979 $32: 2115-2119$

25. WHO: The prevalence of anaemia in women: A tabulation of available information. Ed 2 Geneva, World Health Organisation 1992.

26. Mayer FGH, Schutte CHJ, Reinach SG. Anaemia among the inllabitants of a rural area in Northern Natal. S Afr Med J 1985;67:458 462.

27. Ahamed $\mathbb{F}$, Hasan $N$, Kabir $Y$ : Vitamin $A$ deficiency among adolescent female garment factory workers in Bangladesh. Eur 1 Clin Nutr 1997:51:698-702

28. Ahaned F Khan MR, Iflam M. Kabir I. Fuchs GJ: Anaemia and iron defaciency among schoolginls in peri-urban Bangladesh. Eur J Clin Nutr 2000,54:678-683

29. Bloem $M$, Wedel $M$, Egger RJ: Iron metabolism and vitamin A deficiewcy in children in northeast Thailand. Anu. J. Clin. Nut. 1989;50:332-338.

30. Ahamed F, Khan MR, Karim R, Taj $\mathrm{S}$, Hyderi T, Faruque MO, Margetts BM Jackson AA: Serum retinol and biochemical measures of iron status in adolescent schoolgirls in urban Bangladesh. Eur J Clin Nutr 1996;50:346-351.

31. Winkvist A, Habicht JP Ramussen KM: Linking maternal and infant benefits of a nutritional supplement during pregnancy and lactation Am J Clin Nutr 1998;68;656m661.

32. Alam DS, van Raaij $M_{2}$ Hautwast $J G$, Yunus $M$, Fuchs GJ Energy stress during pregnancy and lactation: Consequences for maternal nutrition in rural Bangladesh. Eur f Clin Nutr $2003 ; 57: 151-156$.

33. Allen LH: Anemia and iron deficiency: effects on pregnancy outcome. Am I Clin Nutr $2000: 71$ (suppl): $12805-12845$.

34. Beand JL. Effectiveness and strategies of iron supplementation during pregnancy. Am J Clin Nutr. 2000: 71 (suppl):1288S-1294S 
I

Assessment of body composition in lactating mothers in a rural African community using deuterium oxide

G. A. Ettyang, W.D. wan Marken Lichtenbelt, W. H. M. Saris. K.R. Westerterp 


\section{Abstract}

Background and objective. The deuterim oxide $\left(\mathrm{D}_{2} \mathrm{O}\right)$ dilution method for measuring body composition was validated against the widely used skinfold (SF) measurement-based equation of Durnin and Womersly. The study involved 10 lactating women living in a rural community in Nandi, Kenya and participating in a cross-sectional study aimed at determining their iron and vitamin A status.

Methods. The selection criteria were exclusive breast-feeding, infants between 2 and 4 months of age, maternal parity $<4$, birth weight more than $2500 \mathrm{~g}$ and no congenital abnormalities. Maternal and infant anthropometrical measurements were taken.

$\mathrm{D}_{2} \mathrm{O}$ (approximately $0.1 \mathrm{~g}^{2} \mathrm{H}_{2} \mathrm{O} /$ body water) was given orally to each mother accordingly to the Maastricht protocol $\mathrm{D}_{2} \mathrm{O}$ for total body water (TBW) determination. The enrichment of the urine was measured using gas -isotope-ratio mass spectrometry. Blood samples were collected. Serum retinol and ferritin were determined using high performance liquid chromatography (HPLC) and enzyme-linked immunosorbent assay (ELISA) respectively. Body mass index (BMI) was determined as weight/height $\left(\mathrm{m}^{2}\right)$. The Bland-Altman pair-wise comparison was used to compare maternal fat-free mass (FFM), body fat (BF) and percentage body fat $(\% \mathrm{BF})$ that were determined based on $\mathrm{D}_{2} \mathrm{O}$ and $\mathrm{SF}$ techniques.

Results. Maternal mean \pm standard deviation (SD) for parity, age, BMI, haemoglobin $(\mathrm{Hb})$, serum ferritin and serum retinol were 3(2), 26(4), 23.4 (4), 12.1 $(1.8) \mathrm{g} / \mathrm{dl}, 10.3(4.0) \mu \mathrm{g} / \mathrm{l}$ and $0.696(0.300) \mu \mathrm{mol} / 1$ respectively. The FFM, BF and $\% \mathrm{BF}$ accordingly to the $\mathrm{D}_{2} \mathrm{O}$ and $\mathrm{SF}$ methods respectively were $44.0(4.7)$ $\mathrm{kg}$ v. $42.9(5.9) \mathrm{kg}, 16.7(8.8) \mathrm{kg}$ v. $1.7 .8(7.5) \mathrm{kg}$ and $26.2(8.1) \%$ v. $28.4(6.4) \%$. Limits of agreement for underestimation of FFM and \% BF were $4.4 \mathrm{~kg}$ (SEE 3.4) and 11.6\% (SEE 5.8) respectively. Bias in the measurement of FFM and $\%$ BF was $1.1 \mathrm{~kg}$ (SEE 1.9 ) and $-2.2 \%$ (SEE 3.3) respectively.

Conclusion. The variability $(5.8-17.5 \%)$ observed in the SF technique may result in lower prediction of $\%$ BF. This may be an important factor for community based nutritional interventions that aim at improving the body composition of vulnerable groups such as pregnant and lactating women or subjects with severe under nutrition.

\section{Introduction}

The first report on poverty in Kenya indicates that the majority of the population $(73 \%)$ live in rural areas and $23 \%$ are likely to have inadequate food intake 
and hence a compromised body composition. [1]. Responses of the body to reduced food intake include low body weight and body mass index (BMI). There is marked reduction in body fat (BF) and fat-free mass (FFM) $[2,3]$. Very few studies bave been done on changes likely to occur in the body composition of individuals in developing countries living on long-term marginal food intake [4]. Assessment of nutritional status based on determination of variations in $\mathrm{BF}$, FFM and percentage body fat (\%BF) will help to bring the magnitude and implications of low food intake into focus. This factor is critical in determining the impact of community-based nutritional interventions that am at improving the body composition of vulnerable groups such as lactating mothers or those with severe wasting due to acute and frequent infections.

Techniques need to be accurate and practical in field conditions. This factor, plus the cheapness and ready availability of deuterium oxide $\left(\mathrm{D}_{2} \mathrm{O}\right)$, has led to its extensive use in body composition research [5-8]. Use of the Maastricht protocol [7] under field conditions provides the same accuracy as obtained in carefully controlled laboratory settings. A limiting factor in $\mathrm{D}_{2} \mathrm{O}$ research has been the complexity of the laboratory measurements, which require use of a mass spectrometer and trained personnel. Because of this most $\mathrm{D}_{2} \mathrm{O}$ validation studies tend to be small in sample size $[9,10]$. In our study transportation and analysis costs determined our sample size of 10 lactating women from a rural community in Nandi, Kenya. In future this may change. A welcome recent development has been a faster and easy measurement of deuterium oxide $\left(D_{2} O\right)$ sample enrichment using Fourier transformed infrared spectrophotometer (FTIR) [11,12].

Anthropometric measurements are widely used in the estimation of body composition indices. Compared with laboratory based method they are relatively fast, non-invasive, require the minimum of equipment and most important of all the measurement can be done anywhere [13]. The skinfold (SF) thickness equations developed for predicting body composition indices use measurements usually obtained from well nourished subjects living in developed countries $[14,15]$. To date the validity of using the SF thickness equations in predicting body composition of lactating mothers in a rural community in Africa has not been established. Therefore the objective of this study were: (i) to use the $\mathrm{D}_{2} \mathrm{O}$-based method under field conditions in a rural Kenyan community to determine the body composition of lactating women; and (ii) to determine the degree of agreement between a widely used SF thickness method and the $\mathrm{D}_{2} \mathrm{O}$ based Maastricht protocol for the assessment of body composition. 


\section{Subjects and methods}

\section{Stwdy area}

The study was conducted in 7 villages based in a rural community in Nand, about $30 \mathrm{~km}$ south-west of Eldoret in Kenya. The subjects were lactating women and their infants. These women were participants in a cross-sectional study aimed at determining iron and vitamin $A$ status during lactation [16]. In the sampling strategy we used a cluster of seven Nandi villages. The selection criteria for inclusion in this study were exclusive breast-feeding, infants between 2 and 3 months of age, maternal parity $<4$, birth weight more than $2,500 \mathrm{~g}$ and no congenital abnormalities. Maternal body composition was assessed and recorded for 10 women randomly selected from each village by quota. Maternal body composition indices were determined based on the isotope dilution technique and anthropometric measurements. Clearance to conduct the study was obtained from Moi University, Eldoret and the Kenyan government, and informed consent obtained was obtained from all 10 subjects.

\section{Anthroponetry and blood collection}

Maternal body weight was measured to the nearest $0.1 \mathrm{~kg}$ using an electronic scale (SECA) and height was measured to the nearest $0.1 \mathrm{~cm}$ using a height meter. BMl was computed as weight/height $\left(\mathrm{m}^{2}\right)$. The mid upper arm circumference (MUAC) was measured using standard techniques. A Holtain thickness caliper (UK) was used to measure quadruple biceps, triceps, supra-iliac and sub-scapular SF thickness [17]. One investigator did all the measurements. The infant's body weight was measured to the nearest $0.1 \mathrm{~kg}$ using a baby weighing scale and height was measured to the nearest $0.1 \mathrm{~cm}$ using a height stadiometer. Five milliliter venous blood samples were taken and stored on ice for transportation to the laboratory. Serum was separated from blood by centrifugation at 3000 revolutions for 10 minutes at room temperature on arrival and samples were stored at $-70^{\circ} \mathrm{C}$ until analyzed for serum retinol and ferritin.

\section{Urine sample collection and processing}

A background urine sample was collected in the evening 5-10 minutes before the deuterium oxide intake. The next morning 1-3 hours before the final urine sampling the mothers were asked to make sure that they empty their bladders. This part of urine was not collected. A sample was collected from a second urine voiding 1 hour later. As far as possible the time between drinking of $\mathrm{D}_{2} \mathrm{O}$ and the last urine sampling was 10 hours ( \pm 10 minutes). The urine samples were frozen and stored at $-20 \mathrm{C}$ until transported to the analytical laboratory in Maastricht. 


\section{Determination of body composition}

$\mathrm{D}_{2} \mathrm{O}$ : The stock mixture of $\mathrm{D}_{2} \mathrm{O}\left(\mathrm{CH}_{2} \mathrm{O}\right)$ was prepared from separate (un) labelled water. The subjects were given a standard dose of $70 \mathrm{ml}$ water with 5 $A P E D_{2} \mathrm{O}[8]$ after preparation using the $\mathrm{Pt}$ equilibration technique [18] the samples were analysed using an isotope ratio mass spectrometry (Aqua Sira VG, UK).

$\mathrm{D}_{2} \mathrm{O}$ was measured in hydrogen gas. Hydrogen gas was produced from the sample on-line using the hot uranium technique [19]. The FFM was calculated as total body water (TBW) $/ 0.724$ as suggested by van Raaij [20]. Maternal BF and $\% \mathrm{BF}$ were calculated form body weight $(\mathrm{BW})$ by difference. Thus $\mathrm{BF}=$ $\mathrm{BW}-\mathrm{FFM}$ and $\% \mathrm{BF}=(\mathrm{BF} \times 100) / \mathrm{BW}$.

SF measurement: Bicep, tricep, subscapular and supra-iliac SF measurements were used to estimate body density [14]. The Siri equation [21] was used to determine $\mathrm{BF}$ and $\% \mathrm{BF}$. Based on maternal body weight $(\mathrm{BW})$ the estimates for FFM were determined as BW - BF [13,15]. A body weight $<52 \mathrm{~kg}$ and FFM $<42.8 \mathrm{~kg}$ was considered indicative of mild to chronic under nutrition [4].

\section{Biochemical analysis}

A coulter counter, model 560 was used to determine haemoglobin (Hb). Retinol levels in serum were assayed using high-performance liquid chromatography. Measurement of serum ferritin was performed using the enzyme-linked immunosorbent assay (ELISA) (Boehringer Mannheim Immundiagnostic Mannheim, Germany). Anaemia was considered present if $\mathrm{Hb}$ was less than $12 \mathrm{~g} / \mathrm{dll}$ [22]. Depletion of iron stores was based on the levels of serum ferritin concentration as follows: severe $<12 \mu \mathrm{g} / \mathrm{l}$, marginal $12-29 \mu \mathrm{g} / \mathrm{l}$ and normal $\geq 30 \mu \mathrm{g} / 1$ [23]. Vitamin $A$ status was based on serum retinol concentrations as follows: deficient $<0.35 \mu \mathrm{mol} / 1(10 \mu \mathrm{g} / \mathrm{dl})$, and marginal $<0.70$ $\mu \mathrm{mol} / \mathrm{l}(20 \mu \mathrm{g} / \mathrm{d}])[24]$.

\section{Statistical analyses}

Means, standard deviations (SDs), median and ranges were computed. The Bland-Altman pair-wise comparison [25] was used to compare BF, FFM and \% $\mathrm{BF}$ estimated by using the $\mathrm{SF}$ and $\mathrm{D}_{2} \mathrm{O}$ techniques respectively. The degree of bias and the limits of agreement between the two methods were determined. Data were analysed using the SPSS/PC statistical package version 11.1. 


\section{Results}

Mean values for nutritional and biochemical characteristics of the 10 lactating mothers are given in Table 1. Infant growth is comparable to NCHS/ World Health Organistion reference standards. For this group of 10 lactating Nandi women, $H b$ status was within the normal range, vitamin $A$ status was marginal and iron stores were severely deficient. Based on BMI $(<20) 20 \%$ of the mothers would be considered underweight. The mean values for body composition are shown in Table 2 Using a FFM cut off point of $42.8 \mathrm{~kg}, 60 \%$ of the mothers would be considered undernourished based on $5 \mathrm{~F}$ calculations compared with $40 \%$ based on the $\mathrm{D}_{2} \mathrm{O}$ method. Although not significantly different, the $\% \mathrm{BF}$ estimates derived from SF measurements were higher while those for FFM were lower companed with the $\mathrm{D}_{2} \mathrm{O}$ method.

The body composition indices derived from the $\mathrm{D}_{2} \mathrm{O}$ and $\mathrm{SF}$ measurements were all significantly $(\mathrm{p}<0.01)$ and positively correlated for $\mathrm{BF}(\mathrm{r}=0.95)$, FFM $(\mathrm{r}=0.88)$ and $\% \mathrm{BF}(\mathrm{r}=0.82)$. For the $\mathrm{D}_{2} \mathrm{O}$ derived body composition indices (mean \pm SD) maternal TBW, FFM, and BF were 53.3(5.9)\% 73.8(8.08) and $26.15(8.1) \%$ expressed as a percentage of body weight respectively. The estimates for $\mathrm{BF}, \mathrm{FFM}$ and $\% \mathrm{BF}$ derived from the $\mathrm{D}_{2} \mathrm{O}$ method account respectively for $91 \%, 78 \%$ and $66 \%$ of the total variability observed in the values derived from the SF measurement.

The relation between differences in body composition indices obtained from the $\mathrm{D}_{2} \mathrm{O}$ and $\mathrm{SF}$ methods and the average of the values from these two methods

Table 1. Nutritional and biochemical characteristics of 10 lactating Nandi women.

\begin{tabular}{|c|c|}
\hline & Mean $\pm S D$ \\
\hline Age & $25.8 \pm 4.7$ \\
\hline No. of children & $3.4 \pm 2.4$ \\
\hline Infant weight/age z-scone' & $0.067 \pm 0.860$ \\
\hline Lactation duration (nionths) & $4.0 \pm 3.3$ \\
\hline Weight (kg) & $60.7 \pm 12.4$ \\
\hline Height (m) & $1.6 \pm 0.1$ \\
\hline$B \mathrm{MI}^{2}$ & $23.4 \pm 4.0$ \\
\hline $\operatorname{MUAC}(\mathrm{cm})^{3}$ & $25.3 \pm 3.1$ \\
\hline $\mathrm{Hb}(\mathrm{g} / \mathrm{dl})$ & $12.1 \pm 1.8$ \\
\hline Serum ferritin (ug/ 1 ) & $10.3 \pm 4.0$ \\
\hline Serum retinol (unol/1) & $0.695 \pm 0.300$ \\
\hline
\end{tabular}

'Based on NCHS World health Organization reference standards; ${ }^{2}$ Body Mass Index (Wt/Ht ${ }^{2}$ $\left(\mathrm{kg} / \mathrm{m}^{2}\right) ;{ }^{3}$ Mid upper arm circumference. 
(a) Maternal fat free mass (FFM)

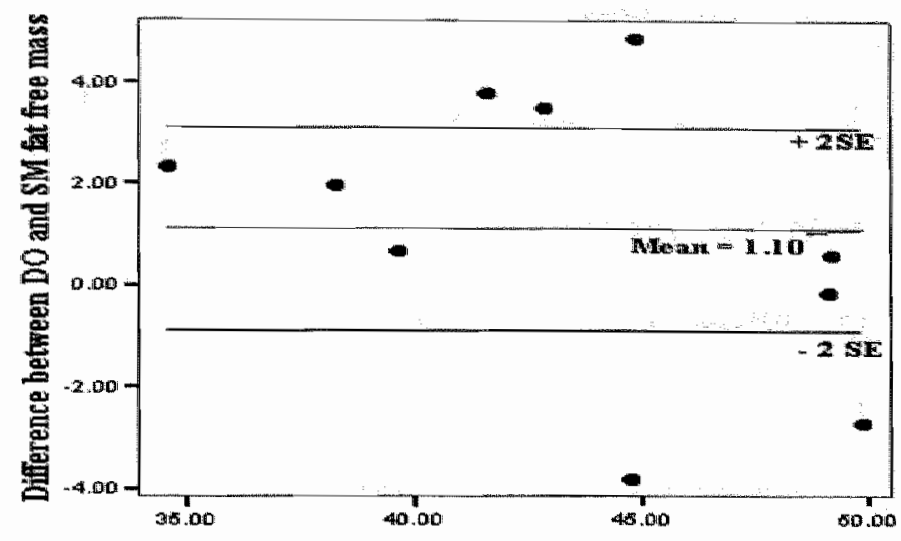

Average of DO and SF fat free mass

(b) Maternal $\%$ body fat ( $\%$ BF)

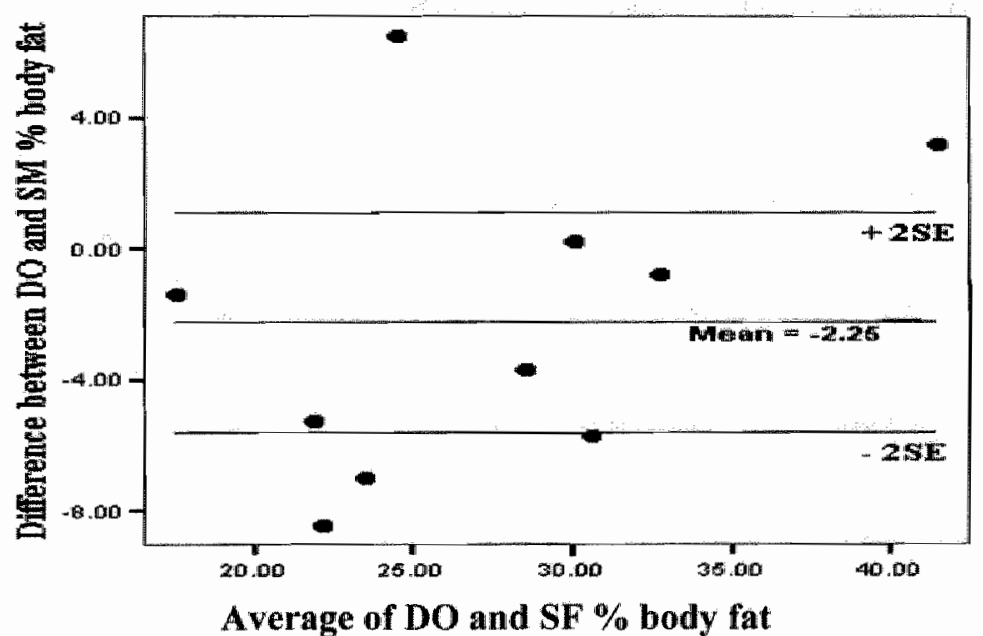

Figure 1. Mear diference and $95 \%$ CI for body composition indices deriwed from deaterinm oxide $\left(D_{2} \mathrm{O}\right.$ ) and from skinfold-thickness measurements (SF) plotted aganst the racan walue for both the methods. 
Table 2. Body composition indices of 10 latating Nandi women.

Mean \pm SD Minimurn Maximum

Skinfold thickness

\begin{tabular}{|c|c|c|c|}
\hline Bucepsi (min) & $9.9 \pm 6.7$ & 5.0 & 24.6 \\
\hline Triceps (mm) & $16.7 \pm 6.7$ & 8.0 & 29.5 \\
\hline Suprailac (num) & $13.4 \pm 7.7$ & 5.2 & 29.6 \\
\hline Subscapular (mm) & $20.6 \pm 10.5$ & 8.3 & 38.5 \\
\hline Fotal body water (TBW) & $31.8 \pm 3.4$ & 25.9 & 35.8 \\
\hline \multicolumn{4}{|l|}{ Body composition (SFlb) } \\
\hline $\mathrm{BF}^{\mathrm{F}}(\mathrm{kg})^{b}$ & $17.8 \pm 7.5$ & 8.7 & 34.0 \\
\hline FFM $(\mathrm{kg})$ & $42.9 \pm 5.9$ & 33.4 & 51.2 \\
\hline$\% \mathrm{BF}^{\mathrm{b}}$ & $28.4 \pm 6.4$ & 18.2 & 39.9 \\
\hline
\end{tabular}

Body composition $\left(\mathrm{D}_{2} \mathrm{O}^{\circ}\right)$

\begin{tabular}{llll}
$\mathrm{BF}(\mathrm{kg})$ & $16.7 \pm 8.8$ & 8.1 & 36.7 \\
$\mathrm{FFM}(\mathrm{kgg})$ & $44.0 \pm 4.7$ & 35.7 & 49.5 \\
$\% \mathrm{BF}$ & $26.2 \pm 8.1$ & 16.8 & 43.1 \\
\hline
\end{tabular}

"Estimates based on skinfold thickness measurement (SF); Estimates based on Deuterimm Oxide dilution; BF Body fat; FFM. Fat free mass; \% Body Percentage body fat

Table 3. Mean differences and variation in the limits of precision and agreement between maternal body composition indices estimated from the deuterim dilution technique and anthroponetric measurements of skinfold thickness for the 10 rural lactating mothers.

\begin{tabular}{|c|c|c|c|c|c|}
\hline \multirow[b]{2}{*}{ Body } & \multirow[b]{3}{*}{ Meann } & \multirow{2}{*}{\multicolumn{2}{|c|}{$95 \%$ Cl for }} & \multicolumn{2}{|l|}{$95^{\circ} \mathrm{Cl}$ for } \\
\hline & & & & Limits of agre & nent \\
\hline Composition & & Precision b & Agwerrent & $\leftarrow 10,0$ value & $>\mathrm{D}_{2} \mathrm{O}$ value \\
\hline$\triangle \mathrm{BF}(\mathrm{kg})$ & $-1.11 \pm 2.80$ & $-1.11 \pm 1.99$ & $-1.11 \pm 5.6$ & $6.71 \pm 3.46$ & $4.49 \pm 3.46$ \\
\hline$\triangle A F M(k g)$ & $1.11 \pm 2.80$ & $1.11 \pm 1.99$ & $1.11 \pm 5.6$ & $4.49 \pm 3.46$ & $6.71 \pm 3.46$ \\
\hline$\triangle \% \mathrm{BF}$ & $-2.25 \pm 4.70$ & $-2.25 \pm 3.34$ & $-2.25 \pm 9.4$ & $11.65 \pm 5.81$ & $7.15 \pm 5.81$ \\
\hline
\end{tabular}

"Mean difference $\pm S D$; Mean difference \pm ( $x$ SE) $[25)^{\circ}$ "Mean difference $t 2 S D(t \times 35 E)$ [25]; Body fat (BF), Fat free mass (FFM) percentage body fat (\%BF)

are shown in Figure 1. The estimates for $\%$ BF had the biggest bias, with a mean ( $\pm \mathrm{SD}$ ) difference of $-2.2 \%(4.7)$. Across the range of body composition indices represented by this population of lactating mothers, the Bland-Altman relation of inter-method differences and means indicate considerable lack of agreement 
between the two methods and some bias in the body composition indices derived from the SF method.

The limits of agreement and differences in accuracy levels for the two methods are shown in Table 3 . The range of agreement between the two methods is large for all the body composition indices. The limits of agreement estimates ( $\pm 95 \%$ confidence interval (CD) for \% BF were $-2.2 \pm 9.4$ resulting in a SF \% BF estmation that is $11.6 \%$ (SEE 5.8) below the $\mathrm{D}_{2} \mathrm{O}$ value for $\%$ BF. For FFM the limits of agreement ( $\pm 95 \% \mathrm{CI}$ ) between the two methods was $1.1 \pm 5.6$ indicating that the SF and FFM estimates were likely to be $6.7 \mathrm{~kg}$ (SEE 3.5) above the estimates made from the $\mathrm{D}_{2} \mathrm{O}$ method. For $\% \mathrm{BF}$ and FFM limits of precision $( \pm 95 \% \mathrm{CI})$ were $-2.2 \pm 3.4$ and $1.1 \pm 1.9$ respectively. The accuracy of the SF estimates for $\% \mathrm{BF}$ may be up to $5.6 \%$ below the values derived from $\mathrm{D}_{2} \mathrm{O}$. The accuracy for FFM above the $\mathrm{D}_{2} \mathrm{O}$ - derived values could be as high as 3.1 $\mathrm{kg}$. The variability $(5.8-17.5 \%)$ observed in the SF technique may result in lower prediction of \% BF. The Maastricht protocol for assessment of body composition was applied with relative ease under the field conditions in a rural community in Kenya. "The combination of this method with other nutritional status indicators can provide valuable information for monitoring community-based nutritional interventions.

\section{Discussion}

Studies of body composition in developing countries require accurate and practical techniques that interfere minimally with the busy physical life of rural communities. All the subjects in this study were lactating mothers living in a rural community in Kenya. Their TBW was estimated based on the Maastricht protocol for determination of body composition [7-8]. Since it is administered in the evening, the method does not interfere with the lactating mother's busy day time routine. The very minimal field laboratory requirements and ease of sample collection will make researchers in developing countries appreciate the tremendous strides that the Maastricht protocol entails. Its application in a field situation in a rural community provides an opportunity to make a fairly accurate assessment of nutritional status. In this study the body composition indices derived on the basis of $S F$ thickness from the deuterium dilution tecinnique were only compared with body composition indices derived from the age-and sex specific logarithmic equation of Durnin and Wormersly [14]. The purpose of the study was to provide further validation for the use of the isotope dilution technique in the estimation of body composition indices. 
Fat free mass is assumed to contain all the total body water (TBW) that comprises $730 \mathrm{~g} / \mathrm{kg}$ FFM. Isotope dilution provides an indirect measure for TBW. Hence by measuring TBW the FFM can be estimated as TBW/0.730 [20]. An 8-10 hour equilibration time for determination of $\mathrm{D}_{2} \mathrm{O}$ enrichment gives more accurate estimates of TBW. The Maastricht protocol recommends 10 hours as the optimal time for isotopic equilibritum for $\mathrm{D}_{2} \mathrm{O}[6,8]$. Its application under field conditions seems quite feasible.

The various levels of accuracy and limits of agreement examined in this study show considerable variability in estimates for FFM and \% BF In this study using $\mathrm{D}_{2} \mathrm{O}$ as the more accurate method, evaluation of the relative accuracy of the SF methods shows that the limits of agreement for FFM were $1.1 \pm 5.5 \mathrm{~kg}$. This gives a SF overestimation of $6.7 \mathrm{~kg}$ (SEE 3.5) compared with the limits of agreement for \% BF which were $-2.2 \pm 9.4 \%$ leading to an $11.7 \%$ (SEE 5.8) SF underestimation of $\% \mathrm{BF}$. The advantages of the $\mathrm{D}_{2} \mathrm{O}$ dilution technique are the relative ease with which it can be applied in developing country field conditions and the possibility of combining this type of evaluation with other nutritional indices providing valuable information for nutritional interventions. The main disadvantage may be the complexity of the laboratory measurements, which requires use of a mass spectrometer and trained personnel. This limitation may now be reduced by suing the Fourier transformed infrared spectrophotometer (FTIS) to measure $\mathrm{D}_{2} \mathrm{O}$ sample enrichment $[11,12]$ This new development will facilitate wider use for the $\mathrm{D}_{2} \mathrm{O}$ method.

As shown in this study the $\mathrm{D}_{2} \mathrm{O}$ method can be combined with other nutritional indicators, thus providing a better assessment of the subjects nutritional status. The method offers an opportunity to determine maternal body composition and breast-milk output simultaneously [26] as a factor critical in studying breast-feeding practices. A good example of this is the study done on 30 Otomi Indians from Mexico [27] where it was observed that lactation performance correlated significantly with maternal size and body composition. In a number of investigations of energy requirements and expenditure FFM has been used as a primary predictor of basal metabolic rate (BMR). A general prediction equation of $B M R=370+21.6$ (FFM) has been suggested by Cunningham [28]. This equation explains $65-90 \%$ of the variation in BMR. It predicts $1235 \mathrm{kcal}(5.17$ $\mathrm{MJ} /$ day for a standard individual of $40 \mathrm{~kg}$ FFM living in a developing country. In our study the $\mathrm{D}_{2} \mathrm{O}$ estimation for maternal FFM was $44.0 \mathrm{~kg}$. When the Cunningham prediction equation is applied it yields a maternal BMR of 1320 $\mathrm{kcal} /$ day $(5.52 \mathrm{~mJ} / \mathrm{day})$. The validity of generalised regression equation is debatable and the use of predictive equations applicable to the subjects under study is 
generally recommended $[29,30]$. The $\mathrm{D}_{2} \mathrm{O}$ FFM combined with local estimation of BMR can be used to generate local predictions for BMR. Average energy expenditure may then be estimated from BMR multiplied by an appropriate activity factor that varies from 1.2 to 1.4 [30]. This may be useful in studies of energy requirements and expenditure in developing countries where pregnant and lactating women tend to be undernourished, are overworked due to too many demands on their time, and often have limited access to resources that could help them cope with their circumstances.

Accurate assessment of body composition indices continues to be necessary because determining changes in body size and composition provides important information on the consequences of lowered energy intakes, especially if sustained at low levels as is often the case in rural communities in the developing world. The most pronounced outcome of this study is that the observed limits of agreement for FFM and \% BF can be attributed to the variation in $\mathrm{SF}$-derived body composition indices. Compared with the $\mathrm{D}_{2} \mathrm{O}$ - derived body composition indices, when the Durnin and Womersly SF thickness equation is used individual \% BF can be underestimated by as much as $11.6 \%$ (SEE 5.81) or overestimated by up to $7.1 \%$ (SEE 5.8 ). The variability $(5.8-17.5 \%$ ) in the SF measurements lower prediction of $\% \mathrm{BF}$ must be taken into account in the evaluation of undernutrition in a rural African community

\section{Acknowledgement}

This study was supported by the MUNDO Moi University and Maasricht University project. We are grateful for the facilitation role played by the dean Prof. B.O. Khwa-Otsyula and the former dean of the Faculty of Health Sciences, Prof. H.N.K. arap Mengech. We thank the chief and the mothers of Kokwet community and Mr. L.C. Kimile for facilitating sample collection and analysis.

\section{References}

1. Central Bureau of Statistics: The first report of poverty in Kenya incidence and depth of poverty. Ministry of Planning and National Development (CBS) June 1998; Vo.

2. Shetry PS: Adaptive changes in basal metabolic rate and lean body mass in chronic undernutrition. Hum Nutr.:Clin Nutr $1984 ; 38,573-581$

3. Barac-Nieto $M$, Spurr GB, Lotero $H$, Maksud MG: Body composition in chronic undernutrition. Am J Clin Nutr 1978; 31:23-40.

4. Shett PS. Adaptation to low energy intakes: the responses and linits to low intakes in infants, children and adults. Eur J Clin Nutr 1999;53 Suppl 1:S14-33 
5. Lukaski HC Johnson PE: A simple inexpensive method of determining total body water wising a tracter dose of $\mathrm{D}_{2} \mathrm{O}$ and infrared absorption of biological fluds. Am J Clin $\mathrm{Nurr} 1985$. $41: 363-370$.

6. wan Marken Lichterbelt WD Westerterp KR Wouters $L$ : Deuterium dilution as a method for determing total body water effect of test protocol and sampling time. Brit J of Nutr 1994 $72: 491-497$.

7. Westerterp KR Wouters I wan Marken Lichtenbelt WD: The Maastricht protocol for the measturenent of body composition and energy expenditure with labeled water. Obes Res 1995 [suppl] 3: 49-57.

8. Westerterp KR. Body composition, water turnover and energy turnover assessment with labelled water. Proce of the Nutr Soc 1999;58:945-951.

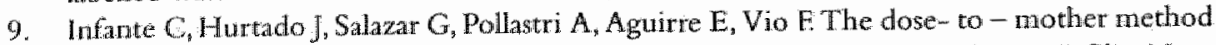
to measure milk intake in infants by deuterium dilution: validation study: Eur J Clin Nutr. $1991 ; 45$ (3): $121-9$.

10. Fjeld CR, Brown KH, Schoeller DA. Validation of the deuterium oxide nethod for neastring average daily millk intake in infants Am J Clin Nutr 1988; 48:671-679.

11. Caire $G$, Calderon de ia Barca AM, Bolanos AV et al. Measurement of deuterium oxide by infrared spectroscopy and isotope ratio mass spectrometry for quantifying daily milk intake in breast fed infants and maternal body fat. Food Nut Bull 2002;23: Suppl 3, 38-41

12. Cisse AS, Bluck L Dialnam B, Dossou N, Guir AT, Wade S. Use of Fourier transformed infrared spectrophotometer (FTIR) for determination of breast millk output by the deuterium dilution method among Senegalese women. Food Nutr Bull 2002;23:Suppl3; $138-141$

13. Roche AF Siervogel RM Chumlea WC Webb P: Grading body fatness from limited anthroponetric data. Am J Clin Nutr 1981; $34: 2831-2838$

14. Durnin JVG Womersley J: Body fat assessed from total body density and its estimation from skinfold thickness measurements in 4.81 men and women aged from 16 to 72 years. B J Nutr $1974 ; 32: 77-97$

15. Brodie DA: Techniques of measuring body composition. Part I. Sports Med 1988; 5:11-40.

16. Ettyang GA van Marken Lichtenbelt WD, Oloo A, Saris WHM. Serum retinol, iron status and body composition of lactating women in Nandi, Kenya. Ann Nutr Metab $2003 ; 47: 276-283$.

17. Gibson RS. Anthropometric measurement of body composition; in Gibson $\mathbb{R} S$ : Principles of Nutricional Assesminent New York; Oxford Uniwersity Press 1990 pp $187-208$

18. Sorimgeour CM Rollo MM Muidambo SMKT Handey LL Prosser SJ: A simplified method for deuteritum/hydrogen isotope natio measurements on water samples of biological origin. Biological Mass Spectronetry 1993;22;383-387

19. Wong WW Lee LS Klein PD: Deuterium and ${ }^{13}$ oxygen measurements on microlitre samples of urine, plasma, saliva and human milk. Am J Clin Nutr 1987:45:905-913

20. Raaij JMA wan Peek MEM Vermart-Miedema SH Schonk CM Hautvast JGAJ: New equations for estimating body fat mass in pregrancy from body density or total body water . Am J Clin Nutr 1988; 48:24-29.

21. Siri WE: Body composition from fluid spaces and density: analysis of methods. In Techniques for measuring body composition. Washington DC.National Academy of Sciences, National Reseanch Council, 1961 pp $223-224$

22. ACC/SCN . Fourth report on the world nutrition situation. Nutrition throughout the life cycle. Geneva: ACC/SCN in collaboration with IFPRI 2000

23. Yip. R. Iron deficiency: Contemporary scientific issue and international programunatic approaches I Nutr 1994:124:1479S - 1490S 
24. WHO: Indicators for assessing vitamin A deficiency and their application in monitoring and evaluating interwention programmes. WHO/NUT/96.10 Genewa: WHO 1996

25. Bland JM Altman DG: Statistical methods for assessing agreenent between two methods of clinical measurement. The Lancet 1986;1:307 10

26. Coward WA, Colle TJ Sawyer MB, Prentice AM. Breast-milk intake meatsurement in mixed-fed infants by administration of deuterium oxide to their mothers. Hum Nutr Clin Nutr. 1982;36(2): $141-148$

27. Villalpando SF Butte NF Wong WW Flores-Huerta S Hernandez-Beltran MJ Smith EO Garza C: Lactation performance of rural Mesoamerindians Eur J Clin Nutr 1992; 46: 337348.

28. Cunningham J: Body composition as a determinant of energy expenditure: a synthetic review and a proposed general prediction equation. Am J Clin Nutr 1991; 54:963-9.

29. Norgan NG Ferro-luzzi A: The estimation of body density in man: are general equations general? Ann Hom Biol $1985 ; 12: 1-15$

30. Durnin JVGA. Energy requirements: general principles. Eur J Clin Nutr 1996; 50: Suppl, $52-9$ discussion $9-10$ 


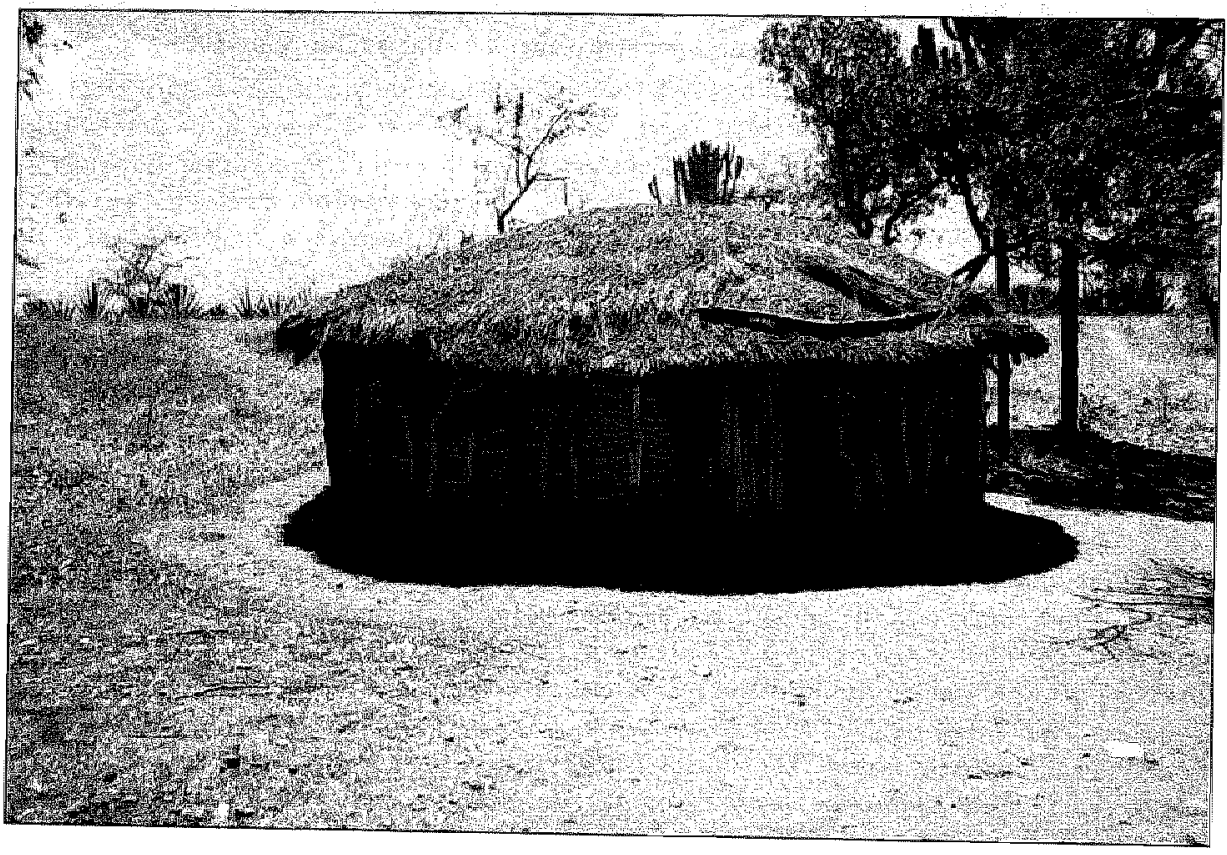


to

Vitamin A consumption of breast feeding children in rural Kenya

G.A. Etyang, A. Oloo. W.D. Wan Marken Lichtenbel, W.H. Sars.

Food and Nutrition Bulletin 2604:25(3): $256-263$ 


\section{Abstract}

Background and objective. Vitamin A deficiency remains a significant health risk in developing countries, affecting infants and children in particular. To counter child malnutrition, mothers are encouraged to breastfeed to ensure that their children receive adequate macro- and micronutrients, including vitamin $A$. However, this assumes that the mother has sufficient vitarnin $A$ intake to provide enough vitamin A to her child. This study investigates maternal and infant intakes of locally available foods of high vitamin A content in a rural agricultural community in Kenya. The study aims to establish the community risk for vitamin $\mathrm{A}$ deficiency and to assess whether breastmilk is adequate to maintain and build retinol reserves of the breastfed infant.

Methods. The study assesses 62 mother-child pairs and employs several methods to support its objectives, including the Helen Keller International food-frequency survey, maternal and infant anthropometric measurements, and maternal breastrnilk and blood samples to determine breastmilk and serum retinol levels.

Results. We found that mothers with marginal $(<0.700 \mu \mathrm{mol} / 1)$ serum retinol and breastmilk deficient $(<1.05 \mu \mathrm{mol} / \mathrm{l})$ in retinol accounted for $45.2 \%$ and $77.4 \%$, of our sample, respectively. A significant ( $p<.05$ ) proportion $(40.3 \%)$ of mothers had breastmilk deficient in retinol and marginal levels of serum retinal. The risk of vitamin A deficiency in breastfed infants older than six months was high, because $89.5 \%$ of them did not consume foods high in vitamin A content three times weekly. The primary source of vitamin A for infants younger than six months was breastmilk deficient in retinol vitamin $A$.

Conclusions. This study suggests that in this rural community, breastfed infants may not receive appropriate foods with high vitamin A content and that although exclusive breastfeeding is advocated, most breastmilk is deficient in retinol, further heightening the risk of vitamin A deficiency.

\section{Introduction}

Vitamin A deficiency remains a significant public health problem, with an estimated 250 million children at risk worldwide [1]. Lack of data from developing countries limits government and policy makers' ability to quantify the magnitude of the problem in women and preschool-age children [2,3]. In healthy populations, less than $5 \%$ have subclinical deficiency, defined as serum retinol $<$ $0.70 \mu \mathrm{mol} / 1[4]$. There are concerns that a high prevalence of marginal vitamin A status may contribute to the etiology of anemia in women $[5,6]$. Hemoglobin response to iron supplementation is suppressed in those found to be deficient in 
vitamin A [7]. Vitamin A-deficient lactating women have been reported to produce inadequate vitamin $A$ in breast milk to maintain and buld body reserves in their rapidly growing infants $[4,8]$. The consequences of vitamin $A$ deficiency in preschool-age children include increased severity of some infections [9] and an increased risk of death [10]. In populations with vitamin A deficiency, improvement in vitamin A status has reduced infant mortality rates by about $23 \%[11]$.

All infants are born with low stores of vitamin $A$ and depend on vitamin A-rich breast milk to initially accumulate and maintain adequate stores until complementary foods provide significant additional amounts of vitamin $\mathrm{A}$, in keeping with the growing child's increasing requirements. Breast-milk vitamin $A$ concentration is therefore considered a unique indicator of maternal and infant vitamin A status [12]. Most retinol in breast milk is in the form of retinyl esters and is related to the fat content of breast milk [4, 7]. Breast-milk proximate composition is relatively stable during the period from one to eight months postpartum, and its vitamin A concentration depends on maternal food intake. When diets are adequate in vitamin $\mathrm{A}$, average breast-milk concentrations for vitamin A range from 1.75 to $2.45 \mu \mathrm{mol} / 1$ [13], and few mothers have breast-milk values under $1.05 \mu \mathrm{mol} / 1[4,13]$. In this ideal situation, breast milk is likely to be the major source of dietary vitamin A for the infant, with complementary foods contributing little if any additional amount [4].

Breast milk is not a sensitive indicator for predicting the risk of clinical vitamin A deficiency [4]. In surveys to assess whether vitamin A deficiency is a public health problem, breast-milk data need to be supported by nutritional status and diet-related indicators [4]. In situations in which precise weighing of food intake is not feasible, general eating habits are easier to remember and are therefore more reliably reported than specific quantities of foods [4]. The Helen Keller International food-frequency questionnaire is simple and often used to identify communities at risk for low intake of vitamin $A[4,14]$. The method has been validated against serum retinol in Tanzania [15]. The questionnaire allows for incorporation of locally available key plant and animal foods that contain at least 100 retinol equivalents (RE) per $100 \mathrm{~g}$. In wiew of the new knowledge on the relative efficiency of carotenoids in meeting recommended vitamin $A$ intakes, these REs may be updated in future [16] The seven-day food-frequency method captures eating patterns during the course of an entire week.

In vitamin A-deficient women, the immediate benefits of vitamin A supplementation are not in dispute and include improvements in the vitamin A 
statiss of the breastfed infant $[7,17]$ and in maternal iron status [18]. However, supplementation alone does not improve overall community consumption patrems for foods of high vitamin A content. Developing countries with a high prevalence of vitamin A deficiency are faced with the challenge of finding community-based alternatives to single-nutrient supplementation [18]. The documented evidence on links between nutritional status at different stages of the life cycle [2] demands sustained, long-term solutions. A starting point is collection of data critical for identifying rural communities and vulnerable groups at risk for vitamin $A$ deficiency [4]. Kenya has a scarcity of data on the vitamin $A$ status of rural communities. The objectives of this investigation were therefore to determine whether, in a rural Kenyan agricultural community, infants and lactating women were at risk for low intake of vitamin $A$ and whether maternal breast-milk vitamin $A$ concentration was adequate to maintain and build body reserves of the breastfed infants.

\section{Materials and methods}

\section{Study area}

This cross-sectional, population-based survey was carried out in Kokwet, a rural community located in Nandi District, between December 1998 and January 1999. This is the end of the short rains and the beginning of the dry season that ends around March, when the long rains begin. Approval for the research was obtained from both the Moi Ethical and Research Committee and the Government of Kenya. The nearest health center to Kokwet is $7 \mathrm{~km}$ away, and it provides health services to a catchment area with an estimated 5,000 households. Kokwet, with its seven villages, falls within this catchment area. The community engages in extensive large-scale maize farming. Due to the climate and zone, the maize crop planted in March and April is not harvested until October and November. The majority of farmers also keep dairy cattle. For many years, both maize and milk were important sources of income for families. This income has become more volatile because of fluctuations in maize prices and liberalization of the milk market. Traditional clark-green leafy vegetables are grown in every homestead and are abundant during the rainy season. Fruits, though not commonly grown, are seasonal and available at reasonable prices from the weekly local market.

\section{Design and subjects}

A register of lactating women in the seven Kokwet villages was compiled with the help of the assistant chief and the village elders. With a relative precision of $50 \%$, we required a minimum sample size of 47 mothers for an anticipated prev- 
alence range of $15 \%$ to $45 \%$ breast milk $f 1.05 \mu \mathrm{mol} / \mathrm{L}$ ( $f 8 \mu \mathrm{g} / \mathrm{g}$ milkfat) [4]. In the sampling strategy we used the seven villages of Kokwet as clusters. The number of lactating women in each cluster was recorded, and a maxinum of 12 lactating women were selected from each cluster. A total of 88 lactating women between the ages of 15 and 45 years, with their breastfeeding infants aged between 2 weeks and 15 months, were identified to participate in the survey. The women received a detailed explanation of the objectives and procedures of the study and gave consent to participate in the study.

Anthropometric measurements, breastfeeding patterns, and intake of key plant and animal sources of vitamin $A$ were recorded for all of the women; however, 15 declined to provide blood and breast milk out of fear that the researchers would use the samples to test for HIV. At the time of data collection; the stigna attached to a positive HIV/AIDS status was very high. For this vitamin $A$ intake survey, 11 infants aged $<2$ months were excluded. This avoided collection of high-colostrum breast-milk samples and ensured inclusion of the period when supplementary feeding was introduced to the breastfed infant. Sixty-two mother-infant pairs met this criterion and provided complete data. Of this group, 48 had infants aged 6 months and older. None of the women in this study received vitamin A supplementation.

\section{Anthroponetry and collection of blood and breast wilk}

Maternal body weight was measured to the nearest $50 \mathrm{~g}$ with an electronic scale (Seca) and height to the nearest $0.1 \mathrm{~cm}$ with a height meter. The body mass index (BMI) was computed as the weight in kilograms divided by the square of the height in meters. Mid-upper-arm circumference (MUAC) measurements were also taken. The infant's body weight was measured to the nearest $50 \mathrm{~g}$ with a baby-weighing scale, and height was measured with a height meter. A single investigator recorded all of the measurements. Collections of $5-\mathrm{ml}$ samples of serum were drawn and divided into two tubes, with and without anticoagulant. The samples were stored on ice for transportation to the laboratory. Serum was separated from the blood by centrifugation at approximately 2,000 RPM for 15 minutes at room temperature on arrival, and the samples were stored at $-70^{\circ} \mathrm{C}$ until they were analyzed for serum retinol. Milk was collected during the day from a single breast that had not been used to feed the infant for at least one hour [12]. The mothers used manual expression to collect 10 to $15 \mathrm{~mJ}$ of breast milk. The breast milk was stored in foilled glass bottles and transported to the laboratory in a cool box with ice packs. Two aliquots were frozen at $-70^{\circ} \mathrm{C}$, and analysis was carried out within one year of breast-milk collection. 


\section{Matemal and infant intake of key vitanin $A$ foods}

A questionnaire was used to collect data on breastfeeding patterns. Through observation, focus group discussions, and a rapid survey of the foods available at the local markets, locally available key plant and animal sources of vitamin A were then identified. Of the maximum 28 food items recommended for inclusion in the Helen Keller International food-frequency questionnaire, 11 were replaced by locally available substitutes. The selected substitute foods contained at least 100 retinol equivalents (RE) of vitamin A per $100 \mathrm{~g}[14,15]$. The modifications resulted in a food-frequency questionnaire based on locally available key plant and animal sources of vitamin $\mathrm{A} .{ }^{\prime}$

The survey's primary question asked for the number of times a given food item had been consumed during the previous seven days. The survey sought to determine the frequency of consumption of vitamin A-containing food by the Nandi lactating women and their breastfed infants by using qualitative questions. The numbers of days on which dark -green leafy vegetables, yellow fruits and vegetables, and foods of animal origin were consumed were thus determined. A master table adapted to the locally available key plant and animal sources of vitamin A was used to analyze the data. From this table, the frequency of consumption of each category of food was calculated $[4,14,15]$.

The community risk for vitamin A deficiency was based on a group of nutrition- and diet-related indicators suggested by the World Health Organization (WHO) [4]. Based on infant nutritional status $[<-2 \mathrm{SD}$ WHO/National Center for Health Statistics (NCHS) growth references], the risk of vitamin A deficiency was present if the prevalence of $\mathrm{HAZ}<-2 \mathrm{SD}$ (stunting) was $\geq 30 \%$ or WHZ $<-2 S D$ (wasting) was $\geq 10 \%$. With regard to food availability, vitamin $A$ deficiency was likely to be present if dark-green leafy vegetables were unavailable in the weekly food market offerings for six or more months per year and foods of high vitamin A content were eaten less than 3 times a week by at least $75 \%$ of lactating women [4]. For infants under six months of age, the risk of vitamin $A$ deficiency was present if fewer than $50 \%$ were receiving breast milk; for those aged six months or more, the risk was present if fewer than $75 \%$ were

1 As a result of recent research findings, there are currently two wnits quantifying vitamin $A$ activity in foods, Both refer to $1 \mu \mathrm{g}$ of all-trans-retinol (vitamin A). The retinol equivalent (RE) is defined as equivalent to $6 \mu \mathrm{g}$ of dietary all-trans- $\beta$-carotene. The more recently recommended retinol activity equivalent ( $\mathrm{RAE}$ ) is defined as equivalent to $12 \mu \mathrm{g}$ of dietary all-tran- $\beta$-carotene. Current food-composition research may still use the $6: 1$ ratio, because that is what is available in food-composition tables. 
receiving foods of high vitamin $A$ content three tines weekly in addition to breast milk [4].

\section{Biochemical analysis}

Breast-milk and serum retinol levels were assayed by high-performance hiquid chromatography. Maternal vitaman A status was based on serum retinol concentration; vitamin $A$ status was considered deficient if the retinol concentration was $<0.35 \mu \mathrm{mol} / 1(10 \mu \mathrm{g} / \mathrm{d})$ and marginal if it was $<0.70 \mu \mathrm{mol} / 1(20 \mu \mathrm{g} / \mathrm{d})$ [4]. The criterion for vitamin A-deficient breast milk was based on a cutoff of $L$ $1.05 \mu \mathrm{mol} / 1[4,12]$ with a population prevalence of $<10 \%, \geq 10 \%$ to $<25 \%$ and $\geq 25 \%$ used to identify vitamin $A$ deficiency as a mild, moderate, or severe public health problem, respectively [4]. Milkfat was determined by using the field-tested [19] "creamatocrit" micromethod [20]. The percentage of cream or $\%$ creamatic was read from the hematocrit capillary tube.

\section{Data analysis}

Means and standard deviations were calculated for serum and breast-milk retinol, and percentages were calculated of the frequency of intake of key plant and animal sources of vitamin $A$. The significance of differences in proportions was determined by chi-square analysis. Pearson correlation coefficients, stepwise and backward linear regression analyses were used to determine the relationship between supposed factors related to breast-milk and maternal serum retinol. Backward regression is useful in identifying the extent to which a combination of independent variables explains the variation in a given dependent variable of interest. General independent variables were: infant age, maternal BMI, serum retinol, breast-milk retinol, maternal hemoglobin status, and frequency of maternal intake of key plant and animal sources of vitamin $\mathrm{A}$. Two models were developed where dependent variable entry inclusion was set at a $p$ value of 0.05 and exclusion at 0.01. The SPSS software package (Windows version 11.1) was used for all statistical analyses, with a $p$ value $<.05$ considered to indicate statistical significance.

\section{Results}

\section{Infant and maternal mutritional status}

Infant wasting (WHZ $<-2 S D)$ was not evident in this group of infants. The percentage of children stunted $(H A Z<-2 S D)$, underweight (WAZ $<-2$ SD), and wasted (HWZ <-2 SD), according to the WHO/NCHS reference, were $8.1 \%, 12.2 \%$, and $4.1 \%$, respectively (table 1). Mean maternal MUAC and BMI were within normal limits (table 1). The percentage of mothers underweight 
Table 1. Nutritional status and bioclymical characteristics of 62 lactating Nandi women and ther breasted infants

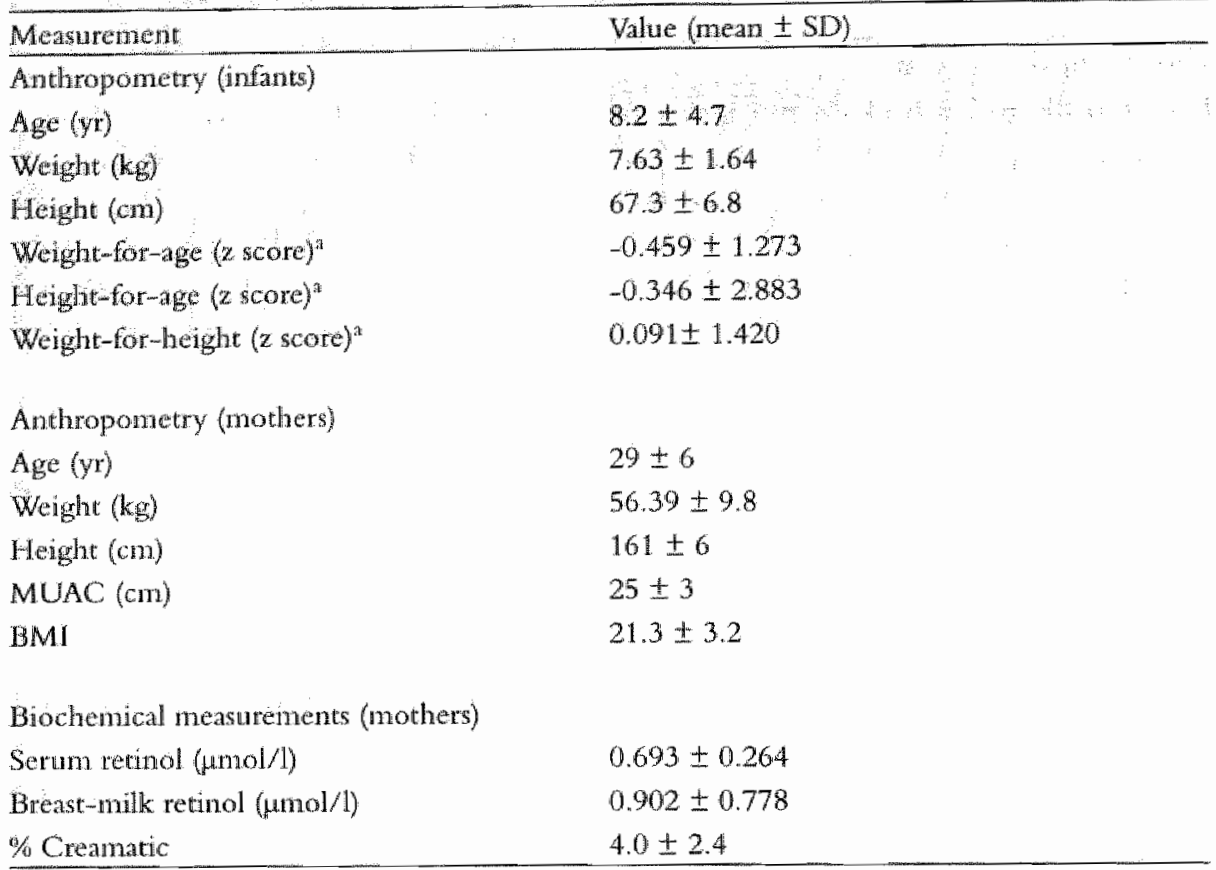

MUAC, Mid-upper-arm circumference; BMI, body-mass index [weight (kg)/height $\left.(\mathrm{m})^{2}\right]$; * Based on WHO/NCHS reference for infant growtly.

(BMI < 18.5) were $13.5 \%$. Both mean breast-milk and mean serum retinol were below $1.05 \mu \mathrm{mol} / 1$ (table 1). The percentages of lactating women with serum retinol $<0.700 \mu \mathrm{mol} / \mathrm{l}$ and breast-milk retinol $<1.05 \mu \mathrm{mol} / 1$ were $45.2 \%$ and $77.4 \%$, respectively. The percentages of children 2 to 5 months and 6 months and older were $14 / 62(22.6 \%)$ and $48 / 62(77.4 \%)$, respectively. None of these children was exclusively breastfed. For children 2 to 5 months old the risk of vitamin $A$ deficiency was based on the percentage with breast-milk intake deficient in retinol. For children 6 months and older, the risk of vitamin A deficiency was based on the percentage with intake of breast milk deficient in retinol and with low-frequency, inappropriate, and inadequate intake of foods high in vitamin $A$ content. The mean ( $\pm \mathrm{SD}$ ) breast-milk retinol of $0.85 \mu \mathrm{mol} / \mathrm{l}$ $(0.73 \mu \mathrm{mol} / 1)$ observed for a lactaton period of 2 to 5 months was not significantly different from that of $0.92 \mu \mathrm{mol} / 1(0.8 \mu \mathrm{mol} / 1)$ observed for a lactation period 6 months or more. 
Table 2. Frequency of consumption of key plant and animal sources of witamisn $A$ by lactuting mothers and breastfed infants aged six months or more

\begin{tabular}{|c|c|c|c|}
\hline \multirow[t]{2}{*}{ Vitamin A source } & \multicolumn{3}{|c|}{ No. (\%) of mothers or infants consuning source } \\
\hline & 0 drys/wk & $1 \mathrm{day} / \mathrm{wk}$ & 2 days $/$ wh \\
\hline \multicolumn{4}{|l|}{ Intake by mothers $\left(\mathrm{n}=73^{\star}\right)$} \\
\hline Dark-green leafy vegetables & $50(67.6)$ & $6(8.1)$ & $9(12.2)$ \\
\hline \multicolumn{4}{|l|}{ Yellow fruits and vegetables } \\
\hline Mango & $66(89.2)$ & $5(6.8)$ & $1(1.4)$ \\
\hline Pumpkin & $53(71.6)$ & $9(12.2)$ & $8(10.8)$ \\
\hline Papaya & $70(94.6)$ & $3(4.1)$ & \\
\hline Yellow sweet potato & $4.5(60.8)$ & $19(25.7)$ & \\
\hline All plants ${ }^{*}$ & $36(49.3)$ & $16(21.9)$ & $11(15.1)$ \\
\hline \multicolumn{4}{|l|}{ Foods of animal origin } \\
\hline Egg & $36(48.6)$ & $22(29.7)$ & $10(13.5)$ \\
\hline Small whole fish & $62(83.8)$ & $6(8.1)$ & $4(5.4)$ \\
\hline Liver & $67(90.5)$ & $5(6.8)$ & \\
\hline All animal sources ${ }^{3}$ & $29(39.2)$ & $26(35.1)$ & $9(12.2)$ \\
\hline \multicolumn{4}{|l|}{ Intake by infants ( $\mathrm{n}=48$ ) } \\
\hline Dark-green leafy vegetables & $37(77.1)$ & $6(12.5)$ & $4(8.3)$ \\
\hline \multicolumn{4}{|l|}{ Yellow fruits and vegetables } \\
\hline Mango & $38(79.2)$ & $8(16.7)$ & \\
\hline Pumpkin & $33(68.8)$ & $9(18.8)$ & $4(8.3)$ \\
\hline Papaya & $47(97.9)$ & $1(2.1)$ & \\
\hline Yellow sweet potato & $34(70.8)$ & $9(18.8)$ & $2(4.2)$ \\
\hline All plants & $36(49.3)$ & $16(21.9)$ & $11(15.1)$ \\
\hline \multicolumn{4}{|l|}{ Foods of animal origin } \\
\hline Egg & $18(37.5)$ & $18(37.5)$ & $11(22.9)$ \\
\hline Small whole fist & $44(91.7)$ & $3(6.3)$ & $1(2.1)$ \\
\hline Liver & $45(93.5)$ & $3(6.5)$ & \\
\hline Cod liver oil & $4.4(91.7)$ & $4(8.3)$ & \\
\hline All animal sources & $16(33.3)$ & $17(35.4)$ & $10(20.8)$ \\
\hline
\end{tabular}

* Sample size is 88 it excludes from the 88 the 15 mothers who did not give blood samples; Combined as suggested when using the HKI food frequency method [14].

\section{Consumption of foods high in vitamin $A$ content}

Although these foods were in season, the percentages of infants six months old or older receiving pumpkin, papaya, and yellow sweet potato once weekly were only $18.8 \%, 2.1 \%$, and $18.8 \%$, respectively (table 2 ). The percentages of mothers and children not receiving dark-green leafy vegetables, and animal sources of vitamin $A$ were $67.6 \%$, and $39.2 \%$, respectively, for mothers, and $77.1 \%$, and 
Table 3. Descriptive statistics of serum retinol in 62 lactating Nandi women with breast-milk retiviol less than and more than $1.05 \mu \mathrm{mol} / \mathrm{L}$.

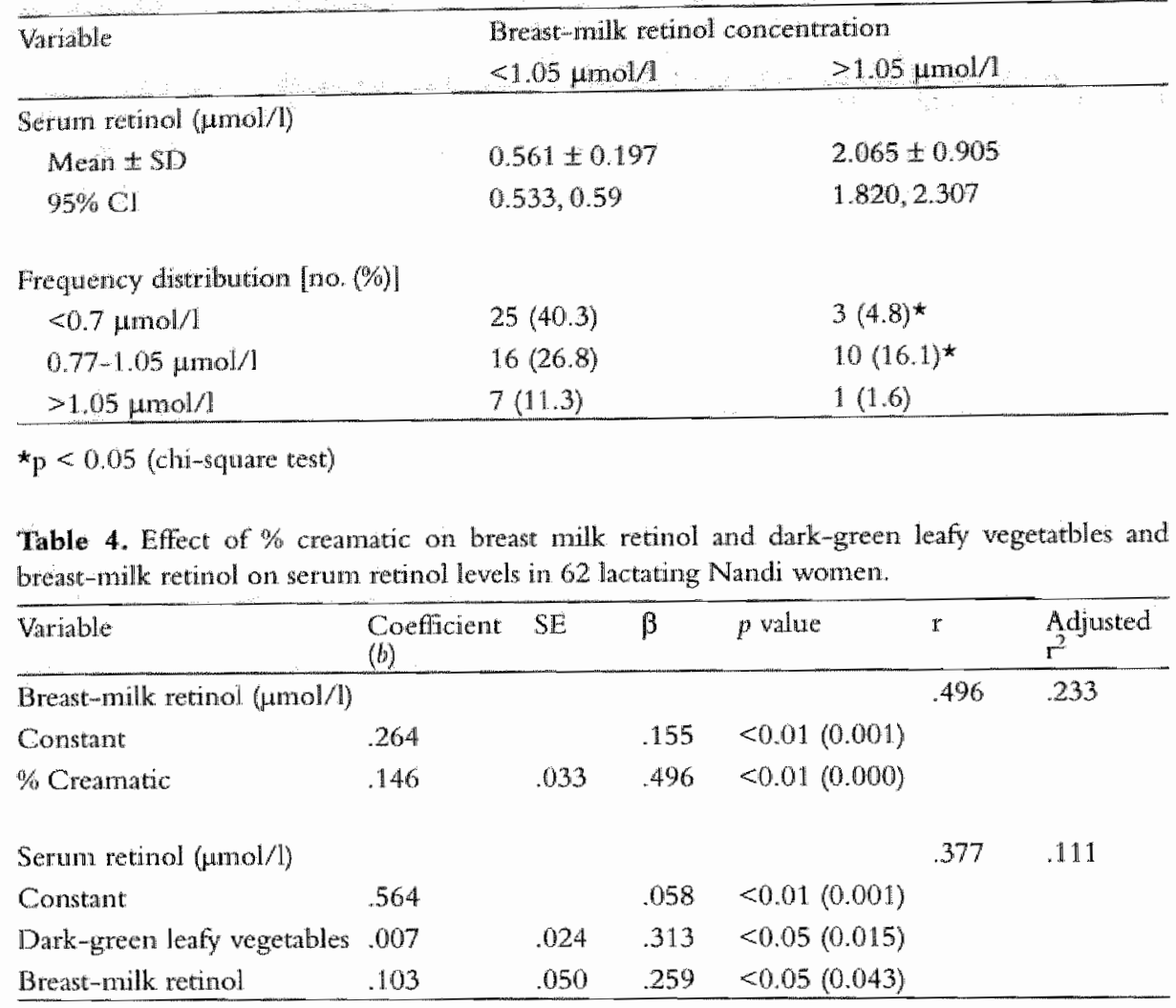

$33.3 \%$, respectively, for infants (table 2 ). The percentages of mothers and children receiving animal sources of vitamin $\mathrm{A}$ fewer than three times weekly were $86.5 \%$ and $89.5 \%$, respectively.

\section{Breast-milk and matemal serum refinol concentration}

The mean ( 4 SD) serum retinol levels were, respectively, $0.561(0.197) \mu \mathrm{mol} / \mathrm{l}$; $95 \% \mathrm{Cl} 0.533,0.59$ for breast-milk retinol $<1.05 \mu \mathrm{mol} / 1$ and $2.065(0.905)$ $\mu \mathrm{mol} / \mathrm{l}$; $95 \%$ Cl $1.820,2.307 \mu \mathrm{mol} / 1$ for breast-milk retinol $>1.05 \mu \mathrm{mol} / \mathrm{l}$ (table 3). A significant $(p<0.05)$ proportion (40.3\%) of mothers with breast milk deficient $(<1.05 \mu \mathrm{mol} / 1)$ in retinol had marginal $(<0.700 \mu \mathrm{mol} / \mathrm{l})$ serum retinol (table 3 ).

\section{Determinants of retinol in breast-milk and maternal serum}

Results of an ANOVA (analysis of variance) based on stepwise regression is shown in table 4 . Breast-milk retinol as the dependent variable was related to $\%$ 
creamatic, explaining $23.3 \%$ of the total variation in breast-milk retinol. Controlling for breast milk \% creamatic left frequency of intake of sweet potatoes as the main predictor but explained only $7 \%$ of the variation in breast-milk retinol. When backward regression was applied to our data breast-milk retinol was significantly correlated with $\%$ creamatic $(r=0.5 ; p<0.01)$ and frequency of intake of sweet potatoes $(r=.298 ; p<0.05)$. Serum retinol as the dependent variable was related to dark-green leafy vegetables and breast-milk retinol, explaining $11 \%$ of the total variation in maternal serum retinol. Controlling for breast milk \% creamatic left dark-green leafy vegetables as the only predictor, explaining $6 \%$ of the variation in serum retinol. Serum retinol was significantly correlated with the frequency of intake of dark-green leafy vegetables $(r=.287$; $p<0.05)$.

\section{Discussion}

The prevalence $(45.2 \%)$ of marginal $(<0.700 \mu \mathrm{mol} / \mathrm{D})$ serum retinol observed in the Nandi lactating women is higher than the less than $5 \%$ recommended for healthy populations [4] but similar to the $40 \%$ prevalence observed in lactating women in rural Zimbabwe [21]. With a mean BMI within acceptable limits, a significantly high proportion $(40.3 \% ; p<.05)$ of mothers had marginal serum retinol levels and breast milk deficient in retinol. In an earlier study done to investigate their vitamin A status, iron stores, and body composition, a close relationship was found between serum retinol, hemoglobin status, and serum ferritin [22]. In a similar study that investigated micronutrient deficiencies in Indonesian lactating women, it was observed that vitamin A deficiency led to an increased risk of anemia and iron deficiency [6].

The percentages of lactating women and breasted infants (six months old or older) with no consumption of animal sources of vitamin A were $39.2 \%$ and $33.3 \%$, respectively. Despite an average lactation period of eight months, $89.5 \%$ of the breastfed infants received foods of animal origin with high vitamin $A$ content fewer than three times weekly. Through focus group discussions, the investigators learned that breastfed Nandi infants were introduced to diluted cow's milk within the first month of life. By the age of two months the infants were no longer exclusively breastfed. Complementary feeding with nonmilk foods such as ripe bananas, avocado, and thin millet porridge was started from the age of two months. Unless a woman became pregnant again, breastfeeding usually continued until the child was about 18 months old. The initial pattern of breastfeeding on demand begins to be replaced by supplementary feeding made 
up of maize or millet porridge. As shown in this study intake of fruits and soft vegetables is likely to be low.

During the survey period, the yellow fruits and vegetables available in the market were papaya and mango, while pumpkin and sweet potato were available in home gardens. Appropriate and adequate complementary foods introduced from the age of six months protect breastfed infants from vitamin A deficiency $[23,24]$. The percentages of infants six months old or older receiving papaya and mango at least once a week were $2.1 \%$ and $16.7 \%$, respectively. Animal sources of vitamin $A$ were consumed three times a week by $10.4 \%$ of the infants.

Although they were available in the local market at reasonable prices, the least-used foods for infant supplementary feeding were papaya, small whole fish, and liver. Cod liver oil, a good source of vitamin $\mathrm{A}$, was consumed at least once weekly by only $8 \%$ of the infants. Most mothers knew about cod liver oil but were unable to afford it for their infants. The risk of vitamin A deficiency in breastfed infants six months old or older was high, because $89.5 \%$ did not receive foods high in vitamin $A$ three times weekly [4]. For infants less than six months old, the main dietary source of vitamin $A$ was breast milk deficient in retinol. For this age group, vitamin A requirements can only be met if the infants receive breast milk with retinol levels above $1.05 \mu \mathrm{mol} / 1[4,12]$.

The vitamin A content of breast milk is closely related to maternal vitamin $A$ status and dietary intake of foods with high vitamin A content [25]. When lactating women have low serum retinol, breast-milk retinol tends to be low $[4$, 8]. This in turn diminishes the value of breast milk as a key source of dietary vitamin A for the breastfed infant. In the Nandi community, the observed high (40.3\%) prevalence of marginal serum retinol and breast milk deficient in retinol may have been due to the fact that none of the women had received any vitamin $A$ supplementation and their intake of foods with high vitamin $A$ content was low. This left a majority (77.4\%) of the breastfed infants six months old or older receiving breast milk with an inadequate retinol content $(<1.05$ Hmol/1) to maintain and build their liver stores $[4,12]$. The prevalence of stunting in these breastfed infants was $12.2 \%$. At the community level it has been suggested that when the prevalence of breast-milk retinol of less than 1.05 $\mu \mathrm{mol} / \mathrm{l}$ is greater than or equal to $25 \%$ and the level of stunting is greater than or equal to $30 \%$ in children under five years of age then vitamin A deficiency is a potential problem of public health significance $[4,26]$. Nandi infants may not be severely stunted, but nearly a quarter of them experience growth faltering at an early age. 
In addition to receiving breast milk deficient in retinol, infants six months old or older $(65.8 \% ; \mathrm{N}=48 / 73)$ did not frequently receive appropriate supplementary plant and animal sources of vitamin A. A study investigating infant-feeding practices in Kenya, Mexico, and Malaysia reported that though Kenyan mothers continued to breastfeed for up to 12 months, early supplementation of their breastfed infants with milk and/or other foods was a common practice [27]. In our study population, all infants were breastfed on demand. Breast-milk retinol concentration was found to be low regardless of the duration of lactation. On the other hand, a study investigating factors influencing vitamin A status of lactating Bangladeshi women observed that women with a lactation period of at least six months had significantly lower serum vitamin A levels than women with a lactation period of less than six months. Duration of lactation had an important influence on the vitamin A status of the women [28].

In our study population, \% creamatic was identified as a predictor of breast-milk retinol, but when \% creamatic was controlled for, intake of sweet potatoes became the main predictor. In turn, dark-green leafy vegetables and breast-milk retinol were the main predictors of serum retinol. Sweet potatoes are a popular snack food and are generally available throughout the year. All homesteads plant dark-green leafy vegetables that are abundant only during the rainy season. A study investigating vitamin A deficiency in rural lactating Zimbambwe women also found dark-green leafy vegetables to be the main source of vitamin $A$. Retinol-containing foods and yellow fruits and vegetables were rarely consumed. In these women, vitamin A and iron deficiencies were identified as problems of public health significance [21]. Similarly, in lactating Bangladeshi women, intake of vitamin A was identified as a predictor of breast-milk retinol [28].

We did not obtain data on the prevalence of clinical vitamin A deficiency in the breastfed infants. The mothers were not willing to let us draw blood from their infants, and accurate assessment of infant morbidity was not possible. The theoretical cutoff of breast-milk retinol $<1.05 \mu \mathrm{mol} / 1$ has not been confirmed locally but is based on observations made in a population of mothers in central Java, Indonesia. To carry out a three-day precise weighing dietary assessment with biochemical analyses of serum and breast milk posed important financial, logistical, and technical constraints. This limited our sample size to 88 lactating mother-infant pairs. We found the Helen Keller International food-frequency method simple and fast to use. The data collected, though not quantitative, proved to be useful in assessing community risk for low intake of vitamin A rich foods. 
In summary, despite adequate local availability, mothers and children did not frequently receive foods high in vitamin $\mathrm{A}$ content. This low intake requires nutritional improvement, as is supported by the biochemical findings among this group of lactating Nandi women. With the apparently low serum retinol during a period of abundance of foods high in vitamin $A$ content, the Nandi women studied may not be able to maintain an optimal vitamin $A$ status during lactation. This may diminish the importance of breast milk as a dietary source of vitamin $\mathrm{A}$ for the breastfed infant. This study suggests that increasing vitamin $\mathrm{A}$ intake in women of childbearing age may be adequate to ensure that young children receive sufficient amounts of vitamin $A$. For this study, the low intake of foods high in vitamin $A$, combined with the high prevalence of marginal serum retinol and breast milk deficient in retinol, identifies vitamin A deficiency as a problem of public health significance for the Nandi community.

\section{Recommendations}

Baseline data for monitoring change in vitamin A status over time have been provided, and a modified food-frequency questionnaire that will prove useful in monitoring the impact of conmunity-based vitamin A deficiency interventions has been developed. As a determinant of breast-milk retinol, the \% creamatic method is recommended as a simple and easy technique for assessing improvements in breast-milk vitamin $A$. We recommend that intervention strategies involve a mix of measures that will result in improved vitamin $A$ status. For a long-term permanent solution to the problem, we recommend food-based approaches. To increase the dietary intake of vitamin A-containing foods by vulnerable groups, nutrition and social marketing interventions should be considered.

\section{Acknowledgments}

This study was supported by the MUNDO Moi University and Maastricht University project. I an grateful for the facilitation role played by the Dean Prof. B. O. Khwa-Otsyula and the former Dean of the Faculty of Health Sciences, Prof. H. N. K. arap Mengech. Special thanks go to the assistant chief and the Nandi women of Kokwet. We also give special thanks to Mr. L. C. Kimile for assistance in sample collection and the KEMRI labs for support in sample analysis. 


\section{References}

1. Global prevalence of vitamin A deficiency. Micronutrient Deficiency Information Systen (MDIS) Working Paper No. 2,1995 Geneva: World Health Organization WHOF NUT/95.3.

2. Fourth report on the world mutrition situation. Nutrition throughout the life cycle 2000 ; Geneva: ACO/SCN in collaboration with IFPRI.

3. Gross R, de Romana GL, Tomaro J. A life-cycle approach to multimicronutrient supplementation: rationale and programme concept. Food Nutr Bull 2000;21:270-4.

4. World Health Organization. Indicators for assessing vitamin A deficiency and their application in monitoring and evaluating intervention programmes. World Heath Organization. Geneva; 1996. WHO/NUT/96.10.

5. Role of vitamin A in iron deficiency anemia. New York: Raven Press. Nestlé Nutrition Workshop Series 1992; Vol 30.93-101.

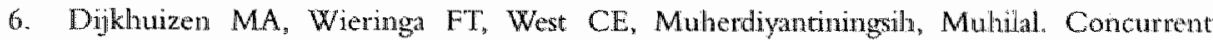
microntrient deficiencies in lactating mothers and their infants in Indonesia. Am J Clin Nutr $2001 ; 73: 786-91$.

7. Safe vitamin $A$ dosage during pregnancy and lactation. The micronutrient initiative, World Health Organization. Geneva; 1998. WHO/NUT/98.

8. Underwood BA. Maternal witamin A status and its importance in infancy and early childhood. Am J Clin Nutr 1994;59(2 suppl):517S-22S.

9. Hussey $G_{x}$ Klein $M$. A randomized, controlled trial of vitamin $A$ in childiren with severe measles. N Engl J Med 1990;323:160-4.

10. West KP Jr, Pokhrel RP, Katz J, LeClerq SC, Khatry SK, Shrestha SR, Predhan EK, Tielsch JM, Pardey MR, Sommer A. Efficacy of vitamin A in reducing preschool child mortality in Nepall. Lancet 1991;338:67-71.

11. Effectiveness of vitamin A supplementation in the control of young child morbiclity and mortality in developing countries. Nutrition Policy Discussion Paper No. 13; 1993; $\mathrm{ACC} / \mathrm{SCN}$.

12. Stoltzfus R. Underwood BA. Breast-milk vitamin $A$ as an indicator of the vitamin $A$ status of women and infants. Bull World Health Organ 1995;73:703-11.

13. Newman V. Viramin A and breast-feeding: a comparison of data from developed and developing countries. Food Nutr Bull 1994; 15:161-76

14. Rosen D, Haselow $N$, Sloan $N$. How to use the MIKI food frequency method to assess community risk of vitamin A deficiency. HKI Vitamin A Technical Assistance Program. 1993. New York.

15. Sloan $N$, Rosen D, de la Pag $T$, Arita $M_{n}$ Temaliwa $C$, Solomons $N$. Identifying areas with vitamin A deficiency: the validity of a semiquantative food frequency method. Anu J Public Health 1997;87:186-91.

16. Bender DA. The Vitamins, In: Introduction to human nutrition. Gibney MJ, Vorster HH, Kok FI, eds. Oxford, UK: Black well Publishing; 2002:125-32.

17. Stoltzfus RJ, Hakimi M, Miller KW, Rasmussen KM, Dawiesah S, Habicht JP, Dibley MJ. High dose vitamin $A$ supplenentation of breast-feeding Indonesian mothers: effects on the vitamin A status of mother and infant. J Nutr 1993;123:666-75.

18. Muslimatun $S$. Nutrition of Indonesian women during pregnancy and lactation: a focus on vitamin $A$ and iron. PhD thesis, Wageningen Uniwersity, The Netherlands, 2001.

19. Prentice A, Prentice AM, Whitehead $\mathbb{R G}$. Breast-milk fat concentration of rural African wonen. 1. Short-term variations within individuals. Br J Nutr 198: $: 45: 483-94$. 
20. Lucas $A_{*}$ Gubs JA, Lyster RL, Baum JD. Creamatocrit: simple clinical technique for estimating fat concentration and energy value of human mik. Br Med J 1978;22:1018-20.

21. Ncube TN, Malaba $L_{\text {n }}$ Greiner $T$, Gebre-Medhin M. Evidence of grave vitamin A deficiency anong lactang women in the semi-arid rural area of Maklaza in Zimbabwe. A population-based study. Eur I Clim Nurr 2001,55:229-34.

22. Etcyang $\mathrm{GA}$, wan Marken Lichtenbelt WD, Oloo A, Saris WHM Serum netinol, iron status and body composition of lactating women in Nandi; Kenya. Anin Nutr Metal $2003,47276-83$

23. Mahalanabit D. Breast feeding and witamin $A$ deficiency among children attending a diarthoea treatment center in Bangladesh: a case-control study. Br Med I 1991,303:493-6.

24. Brown KH, Akhtar NA, Robertson AD, Ahmed MG. Lactational capacity of marginally nourished mothers: relationships between maternal nutritional status and quantity and proximate composition of milk. Pediatrics 1986,78:909-19.

25. Allen LH. Maternal micronutrient malnutrition: effects on breast milk and infant nutrition and priorities for intervention. SCN News 1994, No.11.

26. de Onis $M$, Monteiro $C$, Akre J, Glugston $G$. The worldwide magnitude of protein-energy malnutrition: an overview from the WHO Global Database on Child Growth. Bull World. Health Organ 1995;71:703-12.

27. Dianond HJ, Ashworth A. Infant feeding practices in Kenya, Mexico and Malaysia. The rarity of the exclusively breast-fed infant. Hum Nutr Appl Nutr 1987;41:51-64.

28. Ahmed F, Azim A. Aklyaruzzaman M. Vitamin A deficiency in poor, unban, lactating women in Bangladesh: factors influencing vitamin A status. Public Health Nutr 2003;6:447-52. 
bis

Assessment of body composition and breast milk volume in lactating mothers in pastoral communities in Pokot, Kenya, using deuterium oxide

G.A. Ettyang, WD. van Marken Lichtenbelt. F. Esamai, W.M.M. Saris, K. R. Westerterp 


\section{Abstract}

Background and objective: In sub-saharan Africa, the practice of breast-feeding infants is common. Records documenting the intake of breast milik amongst infants is limired, This study evaluated the association between maternal body composition and the intake of breast milk in infants from the pastoral communities within Pokot, Kenya .

Method: The study was conducted in 10 lactating mothers who were participating in a longitudinal study aimed at determining maternal body composition, iron stores and vitamin A status during the third trimester pregnancy and four months after they had given birth. Maternal and infant anthropometric measurements were made, and maternal blood samples were taken to determine serum retinol and ferritin levels. Infant milk intake and maternal fat free mass (FFM) and percent body fat (\%BF) were measured using "the dose to the mother method". A measured deuterium oxide $\left(2 \mathrm{H}_{2} \mathrm{O}\right)$ dose was given to the mother. Urine and breast milk from the mother, and saliva samples from the infant, were collected on days 1,8 and 14 after dosing.

Results: The mean (SD) maternal and infant weight was $49.5(0.8)$ and $4.956(.874) \mathrm{kg}$, respectively, and the infant weight/age mean (SD) Z score was $-1.750(.077)$. Throughout the study, the infants gained an average of $20(4)$ $\mathrm{g} /$ day in body weight and their average milk intake was $555(22) \mathrm{ml} /$ day. The energy intake of the infant was $1602(148) \mathrm{kJ} /$ day and was lower $(\mathrm{p}<0.05)$ than the $2404(423) \mathrm{kj} /$ day estimated by the FAO/WHO/UNU. The mean (SD) maternal FFM, \%BF, BMI, Hb, Hct, ferritin and retinol were $32.8(3.1) \mathrm{kg}$, $17.24(7.0), 18.5(1.01) \mathrm{kg} / \mathrm{m}^{2}, 11.5(1.3) \mathrm{g} / \mathrm{dl}, 33.9(0.1), 16.2(0.1) \mu \mathrm{g} / 1$ and $0.894(0.16) \mu \mathrm{mol} / \mathrm{l}$, respectively.

Conclusion: Data on volume of breast milk consumed by the infants suggests, at least for this group of infants, that adequate growth may not be achieved. There is a possibility that lactating mothers practicing exclusive breast-feeding and living under harsh conditions may experience periods of low breast milk volume. Body composition and biochemical findings among this group of Pokot mothers indicate dietary inadequacies that require nutritional intervention.

\section{Introduction}

In countries of sub-saharan Africa, the practice of breast-feeding infants is common. Records documenting the intake of breast milk amongst infants is limited even though breast milk plays an important role in meeting the energy requirements for infant growth $[1,2]$. Current guidelines for these countries 
recommend exclusive breast-feeding up to at least 6 months old[3]. Particularly evident, is the inadequacy of crucial data evaluating the nutritional adequacy of exclusive breast-feeding during the first 4-6 months of infant life. The accuracy, cheapness and ready availability of deuterium oxide $\left(\mathrm{D}_{2} \mathrm{O}\right)\left({ }^{2} \mathrm{H}_{2} 0\right)$ has led to its extensive use in measuring body composition [4] and in estimation of infant breast milk intake $[5,6]$. The method offers an opportunity to determine maternal body composition and breast milk output at the same time. Studies that have used the $\mathrm{D}_{2} \mathrm{O}$ dillution method to investigate the milk intake of breast-fed infants from developing countries are very few [7-8]. In sub-saharan Africa, only one body composition validation study in ten lactating women living in Nandi, a rural community in Kenya, has been done by Ettyang et al [9].

Lack of data from developing countries seriously hinders the evaluation of the nutritional adequacy of human milk intake amongst exclusively breast-fed infants. Evidence to date clearly indicates that few women exclusively breast-feed beyond 4 months [10]. Environmental factors adversely affect the maternal food intake thus putting them at risk for underweight as well as reducing the volume of breast milk they may produce. Numerous socio-economic and cultural factors influence their decision to supplement human milk. In developing countries, maternal work demands are among the factors that determine the need and timing of complementary feeding.

The present study was conducted in West Pokot, a part of Kenya where environmental and life style factors have adversely affected maternal and child nutritional status [11]. Undernutrition amongst the worst affected pastoral and farming households is a function of declining food availability and is exacerbated by chronic food insecurity. In view of poor rains, conflict and other hazards, the security of food is increasingly fragile. Therefore, the aim of this study was to evaluate the association between the intake of breast milk of pastoral infants who were exclusively breast-fed and the body composition of their mother; body composition was measured using the isototopic method. In addition, the relationship between the energy cost of growth and energy density of the breast milk was examined.

\section{Materials and methods}

\section{Study community}

The study was conducted in the West Pokot district of Kenya.. The women, all from the pastoral community living in the Chepkobeh location, were participants in a longitudinal. study aimed at determining the prevalence of 
under-nutrition, low iron stores and vitamin A deficiency during the third trimester pregnancy and at 4 months after birth. Maternal body composition and breast milk intake of the infants were measured in 10 lactating women. The selection criteria included: exclusive breast feeding, having an infant aged 2-4 months, maternal parity $<4$ months, birth weight of more than $2500 \mathrm{~g}$, and no congenital abnormalities. From all women in the longitudinal population that met this critetia, 10 were randomlly selected for this study. Approval for the research was obtained from both the Moi ethical and research committee and the government of Kenya. The objectives and procedures of the study were explained to the women. Only women who gave informed consent were studied. Given the logistic requirements and the difficult terrain, the 10 mothers and infants that were selected were invited to sleep one night at the home of one of the villages' traditional birth attendants. Procedures for the collection of samples were explained and mothers asked to return to the same home on days 8 and 14 .

\section{The deuterium ${ }^{2} \mathrm{H}_{2} \mathrm{O}$ ) dilution method}

The volume of breast milk consumed can be estimated from measurements of the rate of water turnover after the oral administration of a measured $\mathrm{D}_{2} \mathrm{O}$ dose to either the mother or the infant. Estimation of the infant breast milk intake by the "dose-to-the-mother" method has been described by Coward et al [5] and validated in ten infants from a nutritional recovery center in Santiago Chile by Infante et al [12]. One advantage of the $\mathrm{D}_{2} \mathrm{O}$ technique is that the measurement of body composition can also be made. Use of the method avoids inclusion of infant water intake from other sources in the calculation of breast milk intake. It also allows for breast milk intake to be studied without interfering with the normal feeding pattern of the child. In this study, $\mathrm{D}_{2} \mathrm{O}$ was used as a tracer to follow the movement of water (trace) into and out of the body water pools of the mother and her breast-fed infant [5]. By giving $\mathrm{D}_{2} \mathrm{O}$ to the mothers, we were able to measure the volume of milk consumption in their breast-fed infants. The basic measurement obtained was a value that is related to the effects of all feeds consumed by the infant over a period of 14 days; therefore, the results are comparable to other isotope dilution studies done in other parts of the world.

\section{Collection of urine samples}

The stock mixture of $\mathrm{D}_{2} \mathrm{O}$ was prepared from separate (un)labeled water accordingly to the Mastricht protocol [4]. A background urine sample was collected in the evening, 5-10 minutes before the $D_{2} \mathrm{O}$ intake. The mothers were given a standard dose of $70 \mathrm{ml}$ of water with 5 APE deuterium [13]. The next morning, one to three hours before the final urine sampling, the mothers 
were asked to completely empty their bladder; this urine was not collected. A second urine specimen was collected one hour later for analysis. As much as possible, the time between drinking the deuterium and the last urine sampling was 10 hours ( \pm 10 minutes). The urine samples were frozen and stored at $-70 \mathrm{C}$ until transported to the analytic laboratory in Maastricht.

\section{Breast milk and saliva samples}

A $100 \mu \mathrm{l}$ sample of expressed breast milk from the mother and a saliva sample from her infant were collected at the time of urine sample collection (Day 0). She was given an accurately weighed dose of $\mathrm{D}_{2} \mathrm{O}$. At least three further milk and saliva samples were collected to provide estimates of $\mathrm{D}_{2} \mathrm{O}$ enrichment at days 1,8 , and 14 . Sample collection on day 0 was done to ensure that the dose of $\mathrm{D}_{2} \mathrm{O}$ reached equilibrium overnight within the mother [4]. The samples were frozen in glass toped vials at $-70^{\circ} \mathrm{C}$ and transported to the analytic laboratory in Maastricht.

\section{Anthropometry and blood collection}

The mother's body weight was measured to the nearest $0.1 \mathrm{~kg}$ using an electronic scale (SECA). Height was measured to the nearest $0.1 \mathrm{~cm}$ using a stadiometer. Body mass index $\left(\mathrm{BMI} \mathrm{kg} / \mathrm{m}^{2}\right)$ was computed from Weight in $\mathrm{kg}$ $/$ (Height $\mathrm{x}$ Height in meters). Biceps, triceps, suprailiac and subscapular skinfold thickness were measured using a Holtain skinfold thickness caliper (UK); all measurements were done in triplicate by the same investigator14]. The infant's body weight was measured to the nearest $0.1 \mathrm{~kg}$ with a baby weighing scale and height was measured to the nearest $0.1 \mathrm{~cm}$ with a height stadiometer. Infants were weighed again at the end of the 14-day period. Five $\mathrm{ml}$ venous blood samples were stored on ice for transportation to the laboratory. On arrival, serum was separated from blood by centrifugation at room temperature, and at $3000 \mathrm{rpm}$ for $15 \mathrm{~min}$. Thereafter, the serum samples were store at $-70^{\circ} \mathrm{C}$ until analyzed for retinol and ferritin.

\section{Biochemical analysis}

A Coulter counter (model 560) was used to determine hemoglobin ( $\mathrm{Hb}$ ) and Haematocrit ratio ( $\mathrm{Hct}$ ). Retinol levels in serum were assayed using high-performance liquid chromatography (HPLC). Measurements of serum ferritin (SF) were performed using the enzyme-linked immunosorbent assay (ELISA Boehringer Mannheim Immundiagnostike Mannheim, Germany). Nutritional anaemia was assessed using both $\mathrm{Hb}$ and Hct [15]. The lactating mothers were categorized as having anaemia if their $\mathrm{Hb}$ levels were $<12 \mathrm{~g} / \mathrm{dl}$ or their Hct ratio was $<37$. Depletion of iron stores was based on the levels of SF concentration; $<12 \mu \mathrm{g} / \mathrm{l}$ indicates severe depletion; $12-29 \mu \mathrm{g} / 1$ marginal deple- 
tion and $\geq 30 \mu \mathrm{g} / \mathrm{I}$ indicates normal stores. Vitamin A status was based on serum retinol concentration; $<0.35 \mu \mathrm{mol} / 1(10 \mu \mathrm{g} / \mathrm{dl})$ indicates vitamin $\mathrm{A}$ deficient and $<0.70 \mu \mathrm{mol} / 1(20 \mu \mathrm{g} / \mathrm{dl})$ reflects marginal deficiency.

\section{Determination of body composition, breast milk volume and infant energy intake.}

After preparation with the Pt equilibration technique [16] the urine samples were analyzed with an isotopic ratio mass spectrometry (Aqua Sira VG. UK, Cheshire). Deuteriun was measured in hydrogen gas. Hydrogen gas was produced from the sample online by the hot uranium technique. The ${ }^{2} \mathrm{H}$ enrichment in 5 to $7 \mu$ of milk and saliva water samples was measured by reductions of the water to hydrogen gas and subsequent ${ }^{2} \mathrm{H}$ analysis using an isotopic ratio mass spectrometry [17]. The fat free mass (FFM) was calculated as TBW/ 0.724 as suggested by van Raaij [18]. Maternal body fat (BF) and \%BF was calculated from body weight (BW) by difference. Thus, $\mathrm{BF}=\mathrm{BW}-\mathrm{FFM}$ and $\% \mathrm{BF}=(\mathrm{BF} \times 100) / \mathrm{BW}[13]$. Milk volume was assessed assuming a proportion of $96 \%$ of water after complete reduction of its solids [5]. Estimation of gross energy intake from the breast milk was based on $2.9 \mathrm{~kJ} / \mathrm{g}(0.67 \mathrm{kcal} / \mathrm{g})$ [1.9].

\section{Statistical analyses}

Data were analyzed with the SPSS/PC statistical package (Version 9.2 1998). Means, standard deviations and median were calculated for all outcome measurements. Independent samples Student's t-test was used to determine the significance of the differences between means. The Chi-square was used to compare the difference between proportions. Pearson's correlation tests were performed to examine the relationships between body composition, breast milk volume, serum retinol and measures of iron status.

\section{Results}

General and biochemical data for the mothers measured during the $3^{\text {rat }}$ trimester of pregnancy as well as during the lactation period(2-4 months are birth), are reported as mean \pm (SD) and shown in Table 1 . Although not significant, body weight during pregnancy was reduced from $51.9(3.1) \mathrm{kg}$ to $49.5(0.8) \mathrm{kg}$ during lactation. Hb increased slightly from $9.9(2.5) \mathrm{g} / \mathrm{dl}$ to $11.5(1.3) \mathrm{g} / \mathrm{dl}$. There were significant $(p<0.05)$ reductions in BMI from $19.8(1.3)$ to $18.5(1$.$) . The level of$ serum ferritin significantly ( $p<0.05$ ) reduced from $23.4(0.1) \mu \mathrm{g} / \mathrm{l}$ during pregnancy to $16.2(0.1) \mu \mathrm{g} / 1$ during lactation. Serum retinol levels significantly $(\mathrm{p}<$ $0.05)$ increased during lactation as compared to during pregnancy $[0.894(0.16)$ 
Table 1: General and biochemical data of the 10 Pokot mothers measured during preganncy and lactation.

\begin{tabular}{lll}
\hline & $\begin{array}{l}\text { Pregnancy } \\
\text { (3rd Trimester) }\end{array}$ & $\begin{array}{l}\text { Latation } \\
(\text { at } 2-4 \text { Mondhs })\end{array}$ \\
\hline Parity & 3 & 4 \\
Weight $(\mathrm{kg})$ & $51.9 \pm 3.1$ & $49.5 \pm 0.8$ \\
BMI & $19.8 \pm 1.3$ & $18.6 \pm 2.7$ \\
MUAC & $22.7 \pm 1.2$ & $21.8 \pm 0.9$ \\
Hb $(\mathrm{g} / \mathrm{dl})$ & $9.9 \pm 2.5$ & $11.5 \pm 1.3 * \star$ \\
Hct & $32.0 \pm 4.5$ & $33.9 \pm 4.9$ \\
Ferritin $\mu \mathrm{g} / 1$ & $23.4 \pm 0.1$ & $16.2 \pm 0.1 \star$ \\
Retinol $\mu \mathrm{mol} / 1$ & $.735 \pm .290$ & $.894 \pm .160 \star$ \\
\hline
\end{tabular}

Values are mean $\pm S D{ }^{*} p<0.05$ based on paired $t-$ test $^{*}{ }^{\star \star} p<0.01$ based on paired $t-$ test ${ }^{*} \mathrm{BMI}$ - body mass index (Weight $(\mathrm{kg}) /$ Height $^{2}\left(\mathrm{~m}^{2}\right) ; \mathrm{MUAC}$ - nid upper arm circumference.

Table 2: Body composition of lactating Pokot and Nandi mothers.

\begin{tabular}{lcl}
\hline & Pokot study & Nandi Study \\
\hline Total body water & $24.0 \pm 2.3$ & $31.8 \pm 3.4$ \\
Total body water \% & $48.5 \pm 4.1$ & $52.0 \pm 7.8$ \\
Fat Free Mass(kg) & $32.8 \pm 3.1$ & $44 \pm 4.7^{\star \star}$ \\
Body Far(kg) & $8.7 \pm 3.8$ & $16.7 \pm 8.8$ \\
$\%$ Body Fat & $17.3 \pm 7.0$ & $26.2 \pm 8.1 \star \star$ \\
BMI & $18.5 \pm 1.0$ & $23.4 \pm 4.0^{\star \star}$ \\
MUAC & $22.7 \pm 1.16$ & $23.4 \pm 4.0^{\star \star}$ \\
Average skinfold thickness & $5.3 \pm 1.16$ & $9.9 \pm 6.7 \star$ \\
Biceps (mm) & $14.7 \pm 3.4$ & $16.7 \pm 6.7$ \\
Triceps (mm) & \\
\hline
\end{tabular}

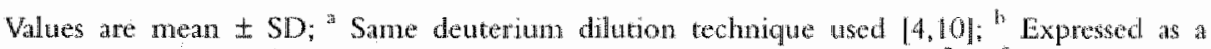
percentage of body weight; BMI - body mass index (Weight $(\mathrm{kg}) / \mathrm{Height}^{2}\left(\mathrm{~m}^{2}\right)$ : MUAC - Mid upper arm circumference; ${ }^{\star} p<0.05$ based on independent samples t - test: ${ }^{\star *} p<0.01$ based on independent samples $t$ - test.

vs. $0.736(0.29) \mu \mathrm{mol} / \mathrm{l}$, respectively]. Pregnancy levels of Hct were significantly correlated with infant milk intake per day ( $.699 \mathrm{p}<0.05)$ and with lactation $\mathrm{Hb}(\mathrm{r} .639 \mathrm{p}<0.05)$. Pregnancy levels of retinol were significantly correlated with FFM $(r=-.919 p<0.05)$ and with \% body fat $(r=.767 p<0.05)$ during lactation.

A shown in Table 2, \% body water of the Pokot mothers is lower than that of the lactating mothers in the Nandi study [48.5(4.1) vs. $52.0(7.8) \%$, respectively] 
Table 3. Breast mulp intake in infants and water tornover rates and body content of their mothers for the Pokot - Kenya, the Gambia and Papua New Guinea.

\begin{tabular}{|c|c|c|c|}
\hline & $\begin{array}{l}\text { Pokot } \\
\text { stady }\end{array}$ & $\begin{array}{l}\text { Gambia * } \\
\text { sudy }\end{array}$ & $\begin{array}{l}\text { Papua New Guined } \\
\text { * study }\end{array}$ \\
\hline No. of aldidren & 10 & 4 & 17 \\
\hline Age range (months) & $2-4$ & $0-4$ & $0-4$ \\
\hline Total body water $\%$ & $48.5 \pm 4.1$ & $59.7 \pm 2.7$ & $50.9 \pm 1.9$ \\
\hline Material water turnower $1 /$ day & $4.77 \pm 0.95$ & $5.93 \pm 0.25$ & $3.65 \pm 0.19$ \\
\hline $\begin{array}{l}\text { Breast milk intake } \\
\mathrm{ml} / \mathrm{day} \\
\mathrm{ml} / \mathrm{g}\end{array}$ & $\begin{array}{l}552 \pm 22 \\
115 \pm 5 \\
\end{array}$ & $\begin{array}{l}752 \pm 18 \\
152 \pm 9 \\
\end{array}$ & $\begin{array}{l}670 \pm 46 \\
140 \pm 7 \\
\end{array}$ \\
\hline
\end{tabular}

* Values reported by Coward et al [5]; Values are mean $\pm \mathrm{SE}$.

Table 4: Notritional status and estimated average dhily breast milk volume and energy intake of the Pokot infant.

\begin{tabular}{|c|c|}
\hline Males & 6 \\
\hline Fenales & 4 \\
\hline Birth weight $(\mathrm{kg})$ & $2.94 \pm 0.323$ \\
\hline Age at evaluation (months) & $3.690 \pm 1.26$ \\
\hline Weight at evaluation $(\mathrm{kg})$ & $4.956 \pm 0.874$ \\
\hline Weight gain (g/day) & $20 \pm 4$ \\
\hline Weight/Age & $-1.750 \pm 0.77 \star$ \\
\hline Volume of Milk intake (ml/day) & $552 \pm 22$ \\
\hline Energy from milk intake $(\mathrm{kJ} / \mathrm{d} \text { ay })^{\text {a }}$ & $1602 \pm 148$ \\
\hline Energy from milk intake $(\mathrm{kJ} / \mathrm{kg} / \mathrm{day})^{\text {" }}$ & $333 \pm 154$ \\
\hline Unfant encrgy requirinent $(\mathrm{kJ} / \mathrm{day})^{\text {b }}$ & $2404 \pm 423$ \\
\hline
\end{tabular}

Values are mean $\pm \mathrm{SD}$; Z score from National Center for Health Statistics (NCHS); Based on an energy content of breast milk of $2.9 \mathrm{~kJ} / \mathrm{g}(0.67 \mathrm{kcal} / \mathrm{g})[19] ;{ }^{\text {to }}$ Based on FAO/WHO/UNU recommendation

[10]. The Pokot mothers \% body fat of $17.3(7.0)$ is lower compared to $26.4(6.4)$ for the Nandi mothers. The Pokot mothers BMI of $18.5(1.0)$ may be indicative of a prolonged low energy intake.

Data on water turnover rates in Pokot mothers compared to values reported by Coward et al [4] for lactating mothers from Gambia and Papua New Guinea are shown in Table 3. During the study period, Pokot women had a relatively low mean (SD) total body water \% of $48.5(4.1)$ compared to the value of $59.7(2.7)$ 
and $50.9(1.9)$ for the women in Gambia and Papua New Guinea, respectively. The $4.77(0.95) \mathrm{l} / \mathrm{day}$ water turnover observed in Pokot lactating mothers was lower than that reported for the women in Gambia [5.93(0.25) 1/day]. The estimated intake of breast milk by the Pokot infants $[552(22) \mathrm{ml} /$ day] was lower compared to the milk intakes of $752(18) \mathrm{ml} /$ day for the Gambia infants and $670(46) \mathrm{ml} / \mathrm{d}$ for the Papua New Guinea infants.

Table 4 shows the nutritional status and estimated average daily breast milk volume and energy intake of the Pokot infant. The mean (SD) new born weight taken within 7 days of birth was $2.94 \pm 0.323 \mathrm{~kg}$. At $2-4$ months of age the mean (SD) Z score of $-1.750(.077)$ weight/age is below the $50^{\text {th }}$ percentile (National Centre for Health Statistics). The Mean (SD) weight gain of 20 (40) $\mathrm{g} /$ day corresponds to a mean (SD) milk intake of $552 \pm 22 \mathrm{ml} /$ day. This may not be sufficient to provide for normal growth during the first $2-4$ month period after birth. The mean (SD) energy intake of $1602 \mathrm{~kJ} /$ day is significantly lower $(\mathrm{p}<0.01$ ) compared to the FAO/WHO/UNU estimated 2404(423) $\mathrm{kJ} /$ day energy requirement of this age group. Only $20 \%(2)$ of the infants met their energy requirements. The energy supplied by milk is $66 \%$ lower than the recommended intake.

\section{Discussion}

The deuterium dilution technique is proving to be useful for field studies examining body composition $[4,20]$ and infant breast milk intake [5-8]. The evaluation of breast milk intake is of particular importance for setting future breast feeding recommendations and to investigate the effect of diet and environmental factors on maternal capacity for adequate lactation. The evaluation of body composition during field studies in developing countries is of particular importance for identifying intervention strategies aimed at improving nutrient intake. Establishing the volume of breast milk intake is of particular relevance to the estimation of adequacy of nutrient intake of the exclusively breast fed infant $[10]$.

The advantages of the deuterium dilution technique [4] are the non-invasive character of the measurements, the relative ease with which it can be applied to both the mothers and infants and the possibility of combining this type of evaluation with other nutritional indices providing valuable information for nutritional interventions. The main disadvantage may be the complexity of the laboratory measurements because it requires a mass spectrometer and trained 
personnel that are currently not available in Kenya or other developing countries.

To our knowledge this is one of the very few milk intake studies carried out in 2-4 month old infants in Africa and the first in a pastoral community in Kenya. Previous Kenyan breast milk intake studies were carried out in farming communities and used the test weighing technique [21]. Studies conducted in lactating mothers in the Gambia and Papua New Guinea did not take into account maternal body composition [5].

A variety of information becomes available when $\mathrm{D}_{2} \mathrm{O}$ are given to the mother. Maternal water tumnover rate in the Pokot mothers is lower than that found in Papua New Guinea. This may be due to the effect of different levels of activity and different environmental conditions that promote water losses [5]. Comparisons between Pokot and Gambia mothers show that in the Gambia infant's water consumption was also derived from sources other than breast milk. The opposite happens for the Pokot lactating mother. Breast-feeding is almost completely exclusive and the infant derives little water from sources other than breast milk.

Among the Otomi Indians of Mexico, lactation performance was reported to be significantly correlated with maternal body size and composition [22]. Physically, the Otomi and Pokot mothers have a similar mean height of $1.47 \mathrm{~m}$ and a body weight of $50.5 \mathrm{~kg}$. The Otomi mothers BMI of 23.4 is higher. The Pokot mothers mean(SD) of 18.6(1.3) is indicative of a low energy intake [23]. Expressed as a percentage of body weight the estimates of BF were higher at $23.6(6.4) \%$ and more comparable to $26.2(8.1) \%$ observed in the Nandi lactating mothers The mean (SD) $\mathrm{Hb}$ of $11.5(1.3) \mathrm{g} / \mathrm{d}$ l. during lactation is below the WHO cut off point of $12 \mathrm{~g} / \mathrm{dl}[24]$. When simple correlation tests were used, maternal pregnancy $\mathrm{Hb}$ levels were significantly correlated to pregnancy $H$ ct ratio. This suggests that iron status was likely to be an important determinant of $\mathrm{Hb}$ and hence anaemia. Serum retinol levels were marginal and may indicate a risk of low dietary intake of vitamin A [25].

The method recommended by Coward et a] [5] was used to calculate infant milk-water intake. In this study, it is clear that on average, milk intake for this group of infants may be insufficient to provide the necessary energy for normal growth during the first $2-4$ months of life $[1,2,26]$. This fact is relevant for many developing countries where stress is put on promotion of exclusive breast feeding for the first 6 months of life [3]. The intake of the infants is $66 \%$ lower 
than the $485 \mathrm{~kJ} / \mathrm{kg} /$ day FAO/WHO/UNU recommendation [1]. The infants" energy intake and pattern of growth based on weight/age is not comparable with those recommended for this age group. If this low level of energy intake is continuous then adequate growth may not be sustained.

Determining maternal boy composition and infant breast milk intake combined with other nutritional parameters is critical if we aim to prevent deficiencies that may cause impaired health and well being later in life. The biochemical findings among the Pokot mothers indicate dietary inadequacies that require nutritional improvement. The volume of breast milk produced suggests that for this group of infants, the current levels of breast milk that they consume, may not achieve adequate growth.

\section{References}

1. FAO/WHO/UNU. Energy and protein requirenents: report of the joint FAO/WHO Ad Hoc RII Expert Committee. WHO Technical Report Series 724. Geneva: WHO, 1985

2. Lucas A, Ewing G, Roberts SB, Coward WA. How nuch energy does the breast fed infant consumes and expands? BMJ 1987;295:75-78.

3. ACC/SCN: 4th Report - The World Nutrition Situation: Nutrition throughour the Life Cycle. CFAPTER 3: Breastfeeding and complementary feeding 2000 (IFPRI $\mathrm{ACC} / \mathrm{SCN}$ ).

4. Westerterp KR Wouters $\mathrm{L}$ van Marken Lichtenbel WD: The Maastricht protocol for the measurement of body composition and energy expenditure with labeled water. Obes Res 1995 [suppl] 3: 49-57.

5. Coward WA, Cole TJ, Sawyer MB. Prentice AM. Breast-milk intake measurement in mixed-fed infants by administration of deuterium oxide to their mothers. Hum Nutr Clin Nutr. $1982 ; 36(2): 141-8$.

6. Fjeld CR, Brown $\mathrm{KH}$, Schoeller DA. Validation of the deuterium oxide nethod for measuring average daily milk intake in infants Am I Clin Nutr 1988; 48 (3).671-679

7. Butte NF Villalpando $S$, Wong WW, Flores-Huerta $S$ et al. Human milk inake and growth faltering of rural Mesoamerindian infants. Am I Clin Nutr 1992;55(6):1109 f 6 .

8. Caire G, Calderon de la Barca AM, Bolanos AV et all Measurement of deuterium oxide by infrared spectroscopy and isotope ratio mass spectrometry for quantifying daily milk intake of breast fed infants and maternal body fat food Nut Bull 2002;23(3) 38-41

9. Ettyang GA, van Marken Lichtenbelt WD, Saris WHM., Westerterp KR. Assessment of body conposition in lactating mothers in a rural African commenity using deuterium oxide dilution. Souch African J Clin Nutr 2004; 17 (1):10 15

10. Butte NF Nutrient adequacy of exclusive breast feeding for the term infant during the frost six months of life. Word Health Organization 2002 WHO Geneva Switzerland.

11. Central Bureau of Statistics: The first report of poverty in Kenya incidence and depth of poverty. Ministry of Planning and National Development (CBS) June Vol. 11998

12. Infante $C$, Hurtado J, Salazar $G$, Pollastri $A$, Aguirre $\mathbb{E}$, Vio F 'The dose-to-mother method to measure milk intake in infants by deuterium dilution: validation study. Eur I Clin $\mathbb{N u t r}$ $1991 \mathrm{Mar}^{2} 45$ (3): 121-9. 
13. Westerterp KR: Body composition, water turnover and energy turnover assessment with labelled water. Proce of the Nutr Soc 1999,58:945-951.

14. Cibson RS. Arthropometric measurement of body composition; in Gibson RS: Principles of Nutritional Assessment New York; Oxford Universily Press 1990 pp 187 - 208

15. Cook JD, Finch CA: Arsessing iron status of a population. An J Chn Nutr 1979; $32: 2115-2119$

16. Scringeout CM Rollo MM Mudambo SMKT Handley LL Prosser SJ A simplified method for deuterium/hydrogen isotope ratio measurements on water samples of biological origin. Biological Mass Spectrometry 1993; 22;383-387

17. Wong WW Lee LS Klem PD. Deuterium and 18 oxygen measurements on microlutre samples of urine; plasma, saliva and human milk. Am J Clin Nutr 1987;45:905-913

18. RaaijJMA van Peek MEM Vermaart-Miedema SH Schonk CM Hautvast JGAJ: New equations for estimating body fat mass in pregnancy from body density or total body water Am I Clin Nutr 1988; $48: 24-29$.

19. Sehmi j K National food composition tables and the planting of satisfactory diets 1993. Government of Kenya Press Nairobi Kenya

20. Van Marken Lichtenbelt WD Westerterp KR Wouters L: Deuterium dilution as a method for determining total body water: effect of test protocol and sampling time. Brit I of Nutr $1994 ; 72: 491-497$

21. Jansen A.A, Horelli H T Quinn VJ. Food and Nutrition in Kenya. A historical Review 1987 Government of Kerrya Press Nairobi Kenya

22. Villalpando SF Butte NF Wong WW Flores-Huerta S Hernandez-Beltran MJ Smith EO Garza C: Lactation performance of rural Mesoamerindians Eur J Clin Nutr 1992; 46: $337-48$.

23. Shetry PS: Adaptation to low energy intakes: the responses and limits to low intakes in infants, children, and aduls. Eur J Clin Nutr 1999; 53 Supp 1: S14-33

24. WHO: The prevalence of anaemia in women: a tabulation of available information. $2^{\text {nd }} \mathrm{Ed}$. World Health Organisation 1992 Genewa.

25. Underwood BA: Maternal vitamin A status and its importance in infancy and early childhood. Am J Clin Nutr 1994; 59 (Supp): 517S-524S.

26. Salazar G, Vio F, Garcia C, Aguirre E, Coward WA. Energy requirements in Chilean infants. Arch Dis Child Fetal Neonatal Ed. 2000 Sep; 83(2): F120-3 
Differences in body composition, iron stores and vitamin A status between pastoral and farming women in West Pokot, Kenya, during late pregnancy and lactation

G.A. Etyang, W.D. Wan Marken Lichtenbelt, E Esamal. W.H.M. Saris 


\section{Abstract}

Objective: To investigate the difference in pregnancy outcome, iron stores, vitamin A status and body composition during late pregnancy and early lactation of women living in two Pokot communities with different living conditions.

Setting: A rural farming as compared to a pastoral community in West Pokot, Kenya.

Study design: A longitudinal study carried out from October 2001 to August 2002.

Subjects: At baseline the women were in third trimester of pregnancy. Follow up measurements were taken 4 months after the birth of the womens' infant. Complete data was collected from 113 pastoral and 110 farming women.

Methods: Maternal body composition was estimated from the measurements of weight, height, skinfold and arm circumference. Serum ferritin and retinol concentrations were measured. Birth weight of the infant was measured within 7 days of delivery and thereafter, the infants growth was monitored for a period of 4 months.

Results: The estimated relative risk of having a newborn infant weighing $<2.5$ $\mathrm{kg}$ was 2.3 times greater for women from the farming community than for those from the pastoral community. For the women from the pastoral as compared to farming community, $\mathrm{Hb}$ concentrations measured during pregnancy were significantly $(\mathrm{p}<0.05)$ lower and the estimated relative risk of having a low $\mathrm{Hb}$ concentration was 2.6 times greater for the pastoral women. Serum ferritin concentrations were significantly higher during the third trimester of pregnancy $(p<0.05)$ as well as 4 months post-birth $(p<0.01)$, for the pastoral women. Serum retinol concentrations of pastoral and farming women were not significantly different during pregnancy or lactation. For the pastoral as compared to the farming women, the prevalence of having a serum retinal concentration $<0.700 \mu \mathrm{mol} / 1$ during either pregnancy or lactation, was not different. In both pastoral and farming women, $\%$ body fat during lactation was associated with serum retinol concentration during lactation whereas for pastoral women, \% body fat during pregnancy was associated with $\mathrm{Hb}$ concentration measured during lactation. Pregnancy outcome for the pastoral women was related to parity as well as bicep and tricep skinfolds. For farming women, pregnancy outcome was associated with parity, height and $\%$ body fat. In both pastoral and farming women, serum ferritin concentration was related to parity and $\mathrm{Hb}$ concentration, and for the farming women they were also related to the number of years of formal education. For the farming wonnen, serum retinol concentration was related to bicep skinfold during lactating. The serum retinol concentrations of the pastoral women was related to fat free mass, $\mathrm{Hb}$, and 
retinol concentrations during pregnancy as well as to BML and 30 body fat during lactation:

Conclusion: As compared to women from a pastoral community, women from a farming community in West Pokot, Kenya, have poorer body composition and lower iron and vitamin stores during pregnancy. In addition, the weight of their infants is lower. These findings may be associated with differences in living conditions, which are usually harsher in farming than in pastoral communities.

\section{Introduction}

In many rural societies in sub-sahara Africa, the status and quality of life of women are inseparably linked to the environment and socio-cultural systems. The very few studies that have looked at maternal nutritional status $[1]$, pregnancy outcome [2-3] and infant growth [4-5] within sub-sahara Africa, have all suggested that lifestyle affects the health of mothers and their children in unique ways. These harsh environments and frequent droughts have left pregnant and lactating women frequently exposed to low levels of food intake. The resulting maternal deficiencies in micronutrients such as iron and vitamin $A$ have well recognized health consequences [6-9]. Accordingly, it is speculated that maternal malnutrition during pregnancy and lactation may effect the weight of the child at birth or within the first 4 months of life, and in later life it may increase the risk of low-infant weight related diseases[10-14].

Communities living in the remote semi-arid areas of tural Kenya may have similar ethnic backgrounds but lead very different ways of life i.e pastoral or farming. In both lifestyles, women tend to be overworked due to too many demands on their time. For the pastoral woman, herding the family goats is a key responsibility. In farming communities, the family's food security depends on the woman's ability to dig, plant, weed, and harvest food crops. They have access to too few resources to adequately cope with their circumstances. One example is the very limited access to health services. In Kenya, a good example of this are the Nilo-hamitic Pokot community with Kalenjin ethnicity. This community was originally entirely agricultural (e.g. cattle, sheep, goats) and were influenced by the hamitic culture. This marked the beginning of their venture into a pastoral life style. Over the years, the community was divided into two distinct groups. By approximately 1895 , the agricultural group continued to live on the higher escarpments whereas the pastoralists moved to the lower altitude grazing grounds (their present location) [15]. 
Communities with Kalenjin ethnicity tend to lead an agricultural life style resulting in a predominantly cereal based diet [16]. Similarly, for the Pokot farming community, white maize and millet are the main staple foods. In a drought year, when these crops fail, household food security is jeopardized [17]. A common way of coping is to reduce the amount of food eaten. The result is chronic under-nutrition. The pastoral women living in the lower altitude hot savannah climate are more vulnerable to endemic malaria [18]. From 1999 to 2002 , consecutive droughts led to dwindling livestock numbers and income from the sale of these animals is controlled by men. Though consumption may be frequently limited, meat and blood remain the key foods in the diet of the pastoral woman. For this reason, a pastoral as compared to farming lifestyle is more likely to have a more positive effect on maternal nutritional status during pregnancy and lactation. The objective of this longitudinal study was therefore to investigate nutritional aspects in two rural communities that are ethnically similar, but with distinctly different lifestyles. We looked at differences in pregnancy outcome, iron stores, vitamin A status and body composition of women at third trimester of pregnancy and again at four months after the delivery of their infant.

\section{Materials and methods}

\section{General description of the study area}

The study was conducted, in the sub-locations of the West Pokot district; namely, Ortum, Morbus, Sobokwo, Kerelwa and Shepkobegh. In these locations, the pastoral Pokot communities mainly comprise of older men, women, and children whose livelihood depends on caring for some livestock; mainly goats, at the more permanent homesteads. The young men are constantly on the move with their cattle seeking grass and water. For the Pokot farming communities, due to limited annual rain fall an extensive system of furrow irrigation for the cultivation of maize, sorghum, and millet has been developed. A prolonged severe drought during the last two years has left families in both types of communities at risk of starvation. The poor household food security has become a priority issue for both the government and the world food program (WFP). Increasingly the prevalence of HIV/Aids and endemic malaria are becoming health problems of public health significance.

\section{Population under investigation}

The longitudinal study was carried-out from October 2001 until August 2002. Approval for the research was obtained from both the Moi ethical and research committees, and the government of Kenya. At the time of the study, a compre- 
hensive census of households with preginant and lactating women, and children under the age of five, had just been compiled by the chief and village elders. This was done in preparation for possible future government food distribution. With this type of data available, each of the five sub-locations was considered to be a study cluster with an average of 10-12 villages each. Using multi-stage sampling, 8 pastoral and 6 farming Pokot villages were randomly selected for the study.

From the 14 villages an updated register of pregnant women was compiled with the help of the village elders and the traditional birth attendants (TBA) who resided in each village. Estimation of gestational age was based on the last menstrual period and it was verified by infant's date of birth. A total of 310 pregnant women were registered. In the two communities, the inclusion criteria for participation in the study were that the women were in the third trimester of her pregnancy (estimated to be between 28 and 36 weeks of gestation). The pregnant women were presumed to be healthy. The women that met the criteria received a detailed explanation concerning the objectives and procedures of the study. They were required to give informed consent before participating in the longitudinal study. Of those examined, 122 from the pastoral community and 128 from the farming community, were recruited for the study (Fig 1). The TBA and a research assistant maintained a record of birth dates and made notification to the study team. Body weiglits were taken on the day that the infants were born, or within 7 days of birth. All infants were weighed once a month during the first four months of life. This was done by a member of the study team, either at the nearest health center, or in the mothers' village if distance to a health center was too great or was difficult to access due to the terrain.

\section{Anthroponetry and blood collection}

A pre-coded questionnaire was used to collect baseline demographic characteristics and pregnancy history. Maternal body weight was measured to the nearest $0.1 \mathrm{~kg}$ using a calibrated electronic scale (SECA Corporation Weighing and Measuring System Colombia USA) and height was measured to the nearest 0.1 $\mathrm{cm}$ with a stadiometer. Body mass index (BMI) was calculated from $\mathrm{Wt} / \mathrm{Ht}^{2}$ $\left(\mathrm{kg} / \mathrm{m}^{2}\right)$. A Holtain skinfold thickness caliper (UK) was used to measure (in triplicate) bicep, tricep, suprailiac and subscapular skinfold thicknesses; skinfold measures were then used to calculate maternal fat mass (FM), \% body fat (\%BF) and fat free mass (FFM) [19]. Mid-upper arm circumference (MUAC) was measured using a non-extensible tape measure (UNICEF Version). The same investigator made all repeated measurements. Infant body weight was measured to the nearest $0.1 \mathrm{~kg}$ using a baby weighing scale (SECA 770 Corporation weighing and Measuring System Colombia USA). Infant growth was moni- 
tored once every montli over the first 4 months of life. At all times, the infants body weight was measured without dothing.

A non-fasting venous blood sample $(5 \mathrm{ml})$ was collected from each woman during the third trimester of pregnancy, and approximately at four months after delivery. The $5 \mathrm{mll}$ blood sample was divided into a trace element free and an EDTA vacuumed blood tube (Becton Dickinson, Franklin Lakes NJ, USA). The samples were stored on ice for transportation to the Kapenguria District Hospital laboratory. At Kapenguria District Hospital and within 3-5 hours of sample collection the serum was separated (centrifuged for $15 \mathrm{~min}$ at 3000 rpmi, alliquoted and frozen overnight at $-20^{\circ} \mathrm{C}$. The next day the frozen samples were transported on dry ice to the Moi University laboratories in Eldoret where they were stored at $-70^{\circ} \mathrm{C}$ until analysis for serum retinol and ferritin concentrations.

\section{Biochemical analysis}

A Coulter counter, model 560 (Coulter electronics Ltd. Luton, Beds, England) was used to determine hemoglobin (Hb) and Haematocrit ratio (Hct). Serum retinol concentration was assayed using high-performance liquid chromatography. Serum ferritin concentration (SF) was measured by ELISA using a commercial kit (Boehringer Mannheim Immundiagnostike Mannheim, Germany). A cut off of $\mathrm{Hb}<110 \mathrm{~g} / 1$ was considered low and possibly linked to anaenia [10,19]. Depletion of iron stores was based on the concentration of SF concentration: severe $<12 \mu \mathrm{g} / \mathrm{l}$; marginal $12-29 \mu \mathrm{g} / 1$ and normal $\geq 30 \mu \mathrm{g} / 1$ [20]. Vitamin $\mathrm{A}$ status was based on serum retinol concentration: deficient, $<0.35$ $\mu \mathrm{mol} / 1(10 \mu \mathrm{g} / \mathrm{dl})$ and marginal, $0.35-0.70 \mu \mathrm{mol} / 1(20 \mu \mathrm{g} / \mathrm{dl})[21]$

\section{Statistical analysis}

All statistical analyses were performed using the SPSS software package (Windows version 11.1) and a $p$ value of $<0.05$ was considered significant. Normality of data distribution was checked by visual evaluation using a histogram and the Kolmogorov-Sminnov test of normality. Pearson chi-square and independent sample t-tests were used to compare groups for significant differences. Pearson correlation coefficients, stepwise and backward linear regression analyses were used to determine the relationship between supposed factors related to \% body fat, new born infant weight, serum ferritin and retinal concentrations. General independent variables were: age, total number of live births and number of years of formal schooling. Body composition variables were: pregnancy and lactation height, weight, lactation BMI, \% BF, FF mass, MUAC and skinfold thickness measurements. Biochemical variables included: concentrations of $\mathrm{Hb}$; Hot; serum retinol; serum ferritin including categoricall. 
variables for deficiency status. A total of three models were developed where dependent variable inclusion was set at a p value of 0.05 and exclusion at $0.01 \mathrm{In}$ the $\% \mathrm{BF}$ model, all variables were entered but controlling for weight, height, skinfold thickness measurements, MUAC and BMI. For pregnancy outcome, only third trimester variables were entered in the model. All variables were included in the serum ferritin model.

\section{Results}

\section{Number of subjects enrolled in the study}

From pastoral and farming villages a total of 250 women in their third trimester of pregnancy were enrolled in the study. From the original cohort, 116 women from pastoral and 114 from farming villages were examined at $\sim 4$ months after delivery of their infant. Complete data was obtained from 113 women from the pastoral communities and 110 women from the farming communities (Figure 1). The percentage of women enrolled in the study who had no formal schooling was $53 \%$ from the pastoral communities and $54 \%$ from the farming communities. Women who were primiparous were $10.7 \%$ vs $8.5 \%$, those with more than 4 children were $22 \%$ vs $22.7 \%$ and those with the youngest child < 24 months old were $39 \%$ vs $24 \%$ from pastoral and farming communities respectively Descriptive statistics for maternal body composition, pregnancy outcome, and biochemical characteristics in pastoral and farming Pokot women during the period of third trimester pregnancy and at four months after delivery, are shown in Table 1

\section{Body composition and pregnancy outcome}

The prevalence of a low lactation BMI $(<1.8 .5)$ in pastoral and farming communities was $23 \%$ and $26.4 \%$ respectively (table 2 ). After fou months if lactation the mean \% BF was significandy $\left(p<0.05, \chi^{2}\right)$ lower in pastoral women (table 1).

Pregnancy outcome, as assessed on the basis of the mean (SD) infant weight that was measure within 7 days of birth, was $2.856(.314) \mathrm{kg}$; $60 \%$ of the infants were male and $40 \%$ were female. The percentage of infants weighing $<2.5 \mathrm{~kg}$ was $16.8 \%$ in the pastoral and $31.3 \%$ in the farming, communities respectively. In the farming community, the mean birth-weight of the infants was significantly lower $(p<0.01$, t-test) than that for the infants born in the pastoral community (Table 1). In the farming community, a significant $(p<0.05)$ proportion of the newborns had a weight of $<2.5 \mathrm{~kg}$ (Table 2). The estimated relative risk of weighing $<2.5 \mathrm{~kg}$ was 2.3 times greater for infants born to women living in the farming community than for those in the pastoral community. In both commu- 


\section{0 eligible Pokot women}

$28-36$ wh pregnant; $18-38$ y of age; mean parity 4

Meant(SD): yrs in school $2.3(2.9)$; age of youngest child

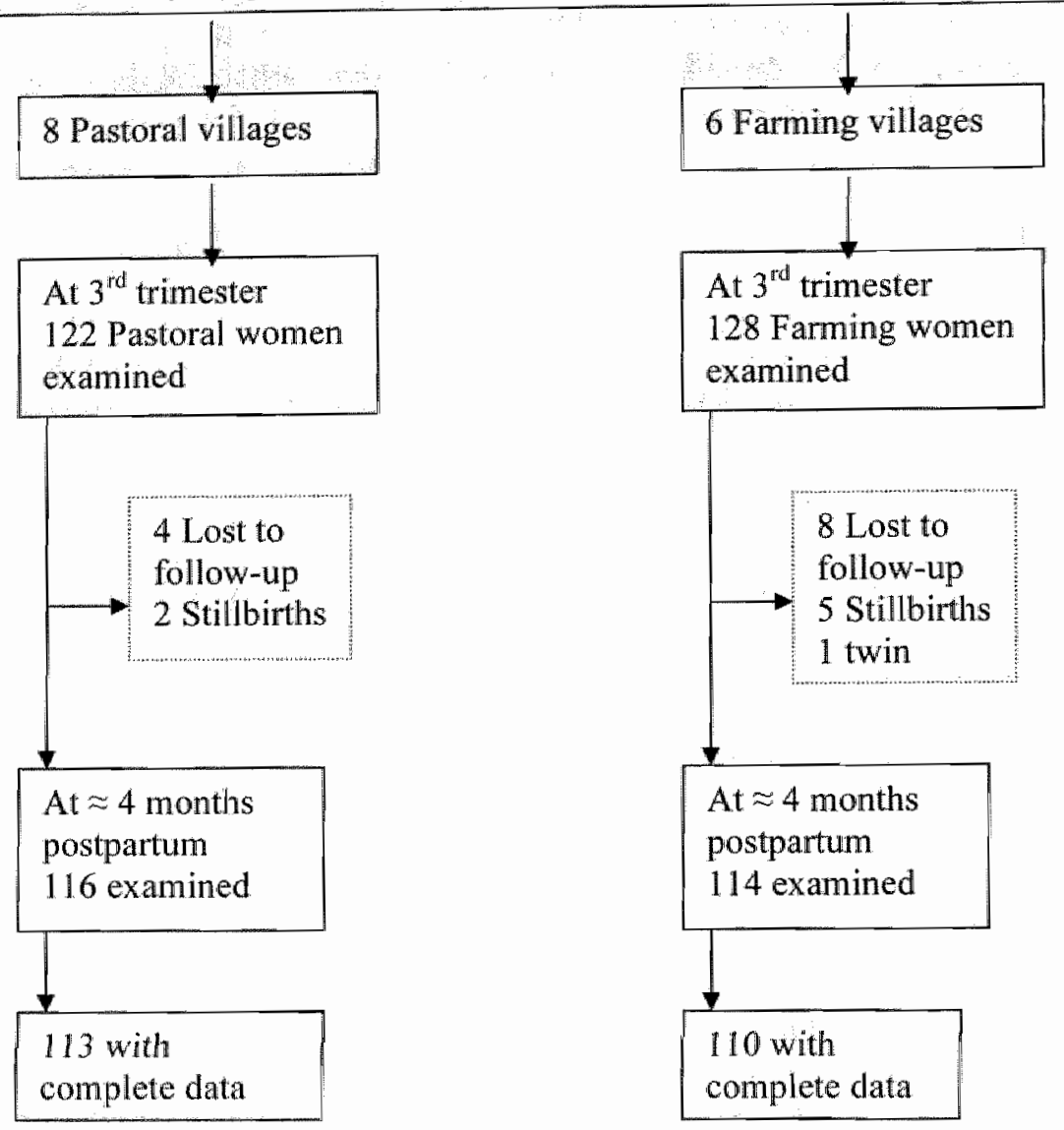

Figure 1 Vligible subjecs at recrutment and follow-up in the longitudinal stady.

nities, $65 \%$ of infants with a low birth-weight may be attributed to living in the farming community. In the farming conmunity, the number of still-born babies was 5 as compared to 2 in the pastoral community.

Iron and vitamin A status

During the third trimester of pregnancy, the mean hemoglobin concentration was significantly $\left(p<0.05, \chi^{2}\right)$ lower in the pastoral as compared to farming women (Table 1). The percentage of pregnant women with low $\mathrm{Hb}$ concentrations ( $<110 \mathrm{~g} / 1$ ) was $42.2 \%$ in pastoral community and $21.8 \%$ in the farming 
Table 1. Body composition, biochemical characteristics and pregnancy outeome in pastonal and farming Pokot women during the period of third trimester pregnancy and at fowr month after delivery

\begin{tabular}{|c|c|c|}
\hline & $\begin{array}{l}\text { Pastoralists } \\
\text { mean }(5 \text { th, } 95 \text { th percentiles) }\end{array}$ & $\begin{array}{l}\text { Farmers } \\
\text { mean }(5 \text { th, } 95 \text { th percentiles) }\end{array}$ \\
\hline Age & $26.8(19.37)$ & $26(18,38)$ \\
\hline Education & $2.0(0,7)$ & $2.0(0.8)$ \\
\hline Parity $^{2}$ & $3(0,7)$ & $3(0,8)$ \\
\hline Height (cm) & $160(150,170)$ & $160(149,170)$ \\
\hline \multicolumn{3}{|l|}{ Weight (kg) } \\
\hline Pregnancy & $51.9(43.5,61.9)$ & $51.6(38.7,63.3)$ \\
\hline Lactation & $50.0(40.0,62.5)$ & $51.1(37.8,63.0)$ \\
\hline \multicolumn{3}{|l|}{$B M I\left(W t / h t^{2}\left(\mathrm{~kg} / \mathrm{mi}^{2}\right)\right.$} \\
\hline Lactation & $19.7(16.7,23.3)$ & $19.8(16.0,25.2)$ \\
\hline \multicolumn{3}{|l|}{ BF } \\
\hline Pregnancy & $21.7(15.9,27.9)$ & $22.7(160,32.5)$ \\
\hline Lactation * & $24.2(14.4,35,9)$ & $25.9(17,3,35.9)$ \\
\hline \multicolumn{3}{|l|}{ FFM } \\
\hline Pregnancy & $40.5(34.3,46.9)$ & $39.7(32.2,46.6)$ \\
\hline Lactation & $37.7(31.9,43.6)$ & $37.6(30.0 .43 .3)$ \\
\hline Infant weight $(\mathrm{kg})^{3}$ * & $2.9(2.3,3.5)$ & $2.8(2.1,3.4)$ \\
\hline \multicolumn{3}{|l|}{ Hemoglobin (g/l) } \\
\hline Pregnancy $\star$ & $119(86,150)$ & $124(99,149)$ \\
\hline Lactation & $118(99,131)$ & $119(99,142)$ \\
\hline \multicolumn{3}{|l|}{ Het Ratio } \\
\hline Pregnancy & $33(25,39)$ & $32(23,41)$ \\
\hline Lactation & $34(30,37)$ & $34(30,38)$ \\
\hline \multicolumn{3}{|l|}{ Serum ferritin $(\mu \mathrm{g} / 1)$} \\
\hline Pregnancy* & $25.8(18.1,34.5)$ & $24.4(18.0,34.0)$ \\
\hline Lactation & $18.5(11.9,27.2)$ & $16.9(11.6,26.4)$ \\
\hline \multicolumn{3}{|l|}{ Serum retinol $(\mu \mathrm{mol} / \mathrm{l})$} \\
\hline Pregnancy & $0.915(0.22,1.82)$ & $0.917(0.27,1.55)$ \\
\hline Lactation & $1.092(0.35,1.90)^{\circ}$ & $1.111(0.34,1.97)$ \\
\hline
\end{tabular}

'Pastoral: pregnancy $n=122$, Lactation $n=113$, Farmers: pregnancy $n=128$, Lactation $n=110_{*}^{2}$ Total number of live births; ${ }^{3}$ New born intant weight taken within 7 days of birth; BMI: Body mass index; \% BF: Percent Body fat; FFM: Fat free mass; * pastoral and farming groups significandy different $\mathrm{p}<0.05,{ }^{*} \mathrm{p}<0.01$ (Independent samples $\mathrm{t}-\mathrm{te}$ t).

community (Table 2). In the pastoral community, a significant $\left(p<0.01, \chi^{2}\right)$ proportion of pregnant women had a reduced $\mathrm{Hb}$ concentration during the third trimester of pregnancy. The estimated relative risk of having a low $\mathrm{Hb}$ concentration was 2.6 times greater for pastoral. women than for women in the 
Table 2. Prevalence of low body mass index, serum retinol, serwm ferritin and infant bir th weight in pastoral and farming Pokot women during the period of third trimester pregnancy and at four months after delivery.

\begin{tabular}{|c|c|c|c|c|c|c|}
\hline & \multicolumn{3}{|c|}{ Pastoralists } & \multicolumn{3}{|c|}{ Farmers } \\
\hline & \multicolumn{3}{|c|}{ Prewalence: } & \multicolumn{2}{|c|}{ Prevalence } & \multirow[b]{2}{*}{ Mean $(95 \% \mathrm{Cl})$} \\
\hline & in: & $\%$ & Mean $(95 \% \mathrm{Cl})$ & $\mathrm{n}$ & 8 & \\
\hline \multicolumn{7}{|l|}{$\mathrm{BMI}<18.5$} \\
\hline Lactation & 26 & 23.0 & $17.2(17.2,17.3)$ & 29 & 26.4 & $16.9(16.7,17.1)$ \\
\hline \multicolumn{7}{|l|}{ Pregnancy outcome ${ }^{2}$} \\
\hline Weight $<2.500 \mathrm{~kg}^{\star \star}$ & 19 & 16.8 & $2.37(2.36,2.40)$ & 35 & 31.3 & $2.29(2.26,2.32)$ \\
\hline \multicolumn{7}{|l|}{ Hamoglobin $(\mathrm{g} / \mathrm{l})^{3}$} \\
\hline 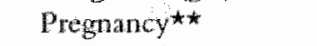 & 49 & 42.2 & $100(98,101)$ & 27 & 21.8 & $104(102,106)$ \\
\hline Lactarion* & 49 & 43.4 & $109(108,110)$ & 31 & 7 & $106(103,109)$ \\
\hline \multicolumn{7}{|l|}{ Ferritin $<32 \mu g / 1$} \\
\hline Pregnancy & 95 & 77.0 & $24.0(23.7,24.5)$ & 110 & 85.9 & $23.1(22.8,23.5)$ \\
\hline Lactation & 111 & 98.0 & $18.2(17.8,18.6)$ & 109 & & $16.7(16.3,17.1)$ \\
\hline \multicolumn{7}{|l|}{ Retinol $<0.70 \mu$ mol $/ 1$} \\
\hline Pregnancy & 34 & 27.9 & $0.42(0.41,0.45)$ & 31 & 24.2 & $0.50(0.47,0.53)$ \\
\hline Lactation & 33 & 29.2 & $0.54(0.51,0.56)$ & 34 & 30.9 & $0.53(0.50,0.55)$ \\
\hline
\end{tabular}

"Pastoral: pregnancy $n=122$; Lactation $n=113$; Farmers: pregnancy $n=128$; Lactation $n=110$; BML: Body mass index (wt/ht $\left.{ }^{2}\left(\mathrm{~kg} / \mathrm{mm}^{2}\right)\right)^{2}$ New born infant weight taken within 7 days of birth; ${ }^{3}$ Hemoglobin: Pregnancy $H b<110 \mathrm{~g} / 1$; Lactation $<120 \mathrm{~g} / \mathrm{l}$; * Pastoral and farming groups significantly different $p<0.05, \star \star\left(p<0.01, x^{2}\right)$.

farming community. As compared to the women from the farming community, the mean serum ferritin concentration of the pastoral women was significantly higher during the third trimester of pregnancy $\left(p<0.05, \chi^{2}\right)$ as well as 4 months after delivery $\left(p<0.01 \chi^{2}\right)$. During the third trimester of pregnancy and four months post-delivery, the mean serum retinol concentration and the reduced vitamin A status were not significantly different between the two communities (Tables 1 and 2).

\section{Determinants of \% body fat and new bom infant weight}

An analysis of variance based on stepwise regression is shown in Table 3. Lactation $\%$ body fat as the dependent variable was related to lactation serum retinol and pregnancy \% body fat $(\mathrm{p}<0.01)$ that explained $20 \%$ of the total variation in $\%$ body fat of the lactating women in the farming community. These two factors, in addition to $\mathrm{Hb}$ concentration during lactation, explained $19.5 \%$ of the total variation in \% body fat of the lactating women in the pastoral community. In both communities, the correlation coefficients show a positive linear relationship. Using backward regression with birth weight as the dependent variable, parity $(p<0.05)$, bicep $(p<0.05)$ and tricep $(p>0.05)$ skinfold measure- 
Table 3. Coefficients (B) and significance levels (p) fron stepwise regression analyses of percent body fat at four months post-delivery as the dependent wrible for 113 pastoral and 140 farming Pokot women.

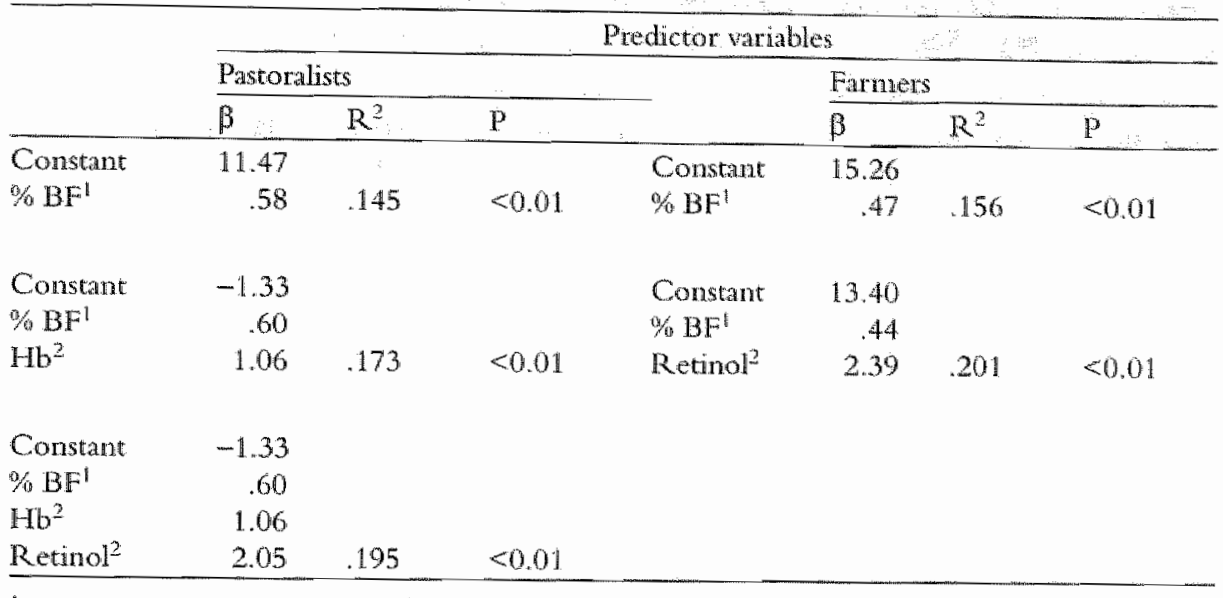

'At third trimester pregnancy; ${ }^{2}$ At four months post-delivery; $\%$ BF: Percent body fat.

Table 4. Coefficients $(\beta)$ and significance levels ( $p$ ) from backward regression analyses of pregnancy outcome as the dependent variable for 113 pastoral and 110 faming Pokot women.

\begin{tabular}{|c|c|c|c|c|c|c|c|}
\hline & \multicolumn{7}{|c|}{ Predictor variables } \\
\hline & \multicolumn{3}{|c|}{ Pastoralists } & & \multicolumn{3}{|l|}{ Farmers } \\
\hline & $\beta$ & $\mathrm{R}^{2}$ & $p$ & & $\beta$ & $\mathrm{R} 2$ & $\mathbb{P}$ \\
\hline Constant & $2.63 \star \star$ & & & Constant & .42 & & \\
\hline Parity & $.04^{\star}$ & & & Parity & -.03 & & \\
\hline \multirow{2}{*}{$B S \mathbb{F}$} & $.04 \star$ & .050 & $<0.05$ & Height & $.01 \star \star$ & & \\
\hline & & & & $\% \mathrm{BF}$ & $.02^{\star \star}$ & .087 & $<0.01$ \\
\hline Constant & $2.77^{\star}$ & & & Connstant & .92 & & \\
\hline Paricy & $.04 \star \star$ & & & Pariby & -.03 & & \\
\hline $\mathrm{BSF}$ & .05 & & & Height & $.02^{\star *}$ & & \\
\hline \multirow[t]{2}{*}{$\mathrm{TSF}$} & -.02 & .061 & $<.05$ & Weight & -.07 & & \\
\hline & & & & $\% \mathrm{BF}$ & $.02^{\star \star}$ & .085 & $<0.01$ \\
\hline
\end{tabular}

* Significance of the predictor wariable $p<0.01 *$ * $p<0.05$ t-test, 'Based on measurements done at the period of third trimester pregnancy; B SF Biceps skin fold thickness; "T SF Triceps skin fold thickness.

ments were all related and able to explain $6 \%$ of the total variation in the birth weight of the pastoral infants (Table 4). In the farming community, $\%$ body fat $(p<0.05)$, height $(p<0.05)$, weight $(p>0.05)$ and parity $(p>0.05)$ were able to explain $8.5 \%$ of the total variation in the birth weight of infants (Table 4). Birth-weight of the infants was positively correlated with the third trimester of 
Table 5. Coefficients ( $\beta$ ) and significance levels (p) from stepwise regression analysis of sermm ferritin concentrations for 113 pastoral and 110 faming Pokot women four months after delvery.

\begin{tabular}{|c|c|c|c|c|c|c|c|}
\hline & \multicolumn{7}{|c|}{ Predictor variables } \\
\hline & \multicolumn{3}{|c|}{ Pastoralists } & & \multicolumn{3}{|c|}{ Farmers } \\
\hline & $\beta$ & $\mathbf{R}^{2}$ & $\mathrm{p}$ & & $\beta$ & $\mathrm{R}^{2}$ & $\mathrm{P}$ \\
\hline Constans & 1681 & & & Constant & 16.08 & .068 & $<0.01$ \\
\hline Pariry & .58 & .055 & $<0.01$ & Education & .40 & & \\
\hline Constant & 16.81 & & & Constant & 14.77 & & \\
\hline Parity & .58 & & & Edducation" & .45 & & \\
\hline \multirow[t]{5}{*}{$\mathrm{Hb}$} & -11.10 & .098 & $<0.01$ & Parity $^{2}$ & .38 & .104 & $<0.01$ \\
\hline & & & & Constant & 23.11 & & \\
\hline & & & & Educationat $^{4}$ & .43 & & \\
\hline & & & & Parity ${ }^{2}$ & .40 & & \\
\hline & & & & $\mathrm{Hb}$ & -.70 & .164 & $<0.01$ \\
\hline
\end{tabular}

1. Number of years of formal schooling; 2 Total number of live births.

pregnancy maternal weight $(r=0.167, p<0.05)$ and bicep skin fold thickness $(r=0.138, p<0.05)$ but negatively correlated with the infant being born in the farming community $(r=-0.163, p<0.05)$.

\section{Determinants of serum ferritin and retinol concentrations}

Stepwise regression identified parity and $\mathrm{Hb}$ concentration as variables that were able to explain $9.8 \%$ of the total variation in the serum ferritin concentrations of lactating pastoral women (Table 5). For the farming women, the number of years of formal schooling, as well as parity and $\mathrm{Hb}$ concentration, were found to explain $16.4 \%$ of the total variation in their serum ferritin concentrations (Table 5). Maternal height ( $\mathrm{r}=-0.208, \mathrm{p}<0.01$ ), bicep skinfold thickness $(r=-0.140, p<0.05)$ and fat free mass $(r=0.144, p<0.05)$ were all negatively correlated with serum fertitin concentrations measured four months after the birth of the infant.

\section{Discussion}

The Pokot community values their traditional way of life and they have consistently remained largely unaffected by the forces of modernization [15]. Cattle occupy a central part in the economic and social life of the community. Although the farming and pastoral communities of Pokot reflect different ecological situations, their basic cultural outlook is the same. About $85 \%$ of the Pokot people are pastoralists. They move in seasonal cycles to search for water and pasture for their stock. The agricultural people of Pokot are grouped into sprawling villages made up of more permanent homesteads. 
In our study, the loss of infants at birth was 2 for the pastoral and 5 for the farming community (Figure 1). Therefore, the estimated relative risk of death of these infants was 2.4 times greater for infants born in the farming community than for those born in the pastoral community and this probably reflects their harsher living conditions. Between 1989 and 2003, the infant mortality rate (IMR) for Kenya, increased from 60 to 78 per 1000 births. The increase depicts the deterioration in quality of life over the last 20 years [18]. West Pokot is in the Rift Valley Province and the IMR for women from this region who have no education is reported to be 73.3 per 1000 births [18].

In the pastoral community, the sheer number of cattle that one has is a critical factor that determines the frequency of consumption of milk, blood and meat. These foods are more energy dense and their availability is more sustained than in the farming community, especially during a drought year. Income gained from the sale of animals is used to buy maize. The main food crops for the farming community are white maize, sorghum, millet and beans. Although some areas have irrigation systems, which are communally controlled and maintained, in a drought $r$ seasonal availability of food is reduced and household food insecurity becomes more acute. No cash crops are grown in the area and sources of cash for purchase of maize is limited especially in households where non of the members are in formal employment. [15].

In this study, the mean birth weight of the infants $(2.9 \mathrm{~kg})$ is quite similar to the mean birth weight that has been reported for infants born to Turkana pastoral women (2.9 kg) [3]. Available data on infant birth weight tends to be based on deliveries conducted in hospitals and health centers. For Kenya, such data estimate that the incidence of infants having birth weights of less than $2.5 \mathrm{~kg}$ is approximately $9.3 \%$ [18]. An estimate of $11 \%$ has been made for other developing countries. Due to insufficient data, there are no estimates for the East African region $[10]$ and therefore our data provide valuable information. Out community based data confirms the magnimde of the problem of having infants with low birth weights; In West Pokot; the estimated incidence of $16.8 \%$ and $31.3 \%$ for pastoral and farming communities, respectively, is considerably higher than the national hospital based estimate. In this study, there is a possibility that the incidence of having infants with a low birth weight was over-estimated due to the field conditions under which gestational age was determined. We did not have an effective method for identifying premature births. This may be monitored more rigorously in future studies, but we acknowledge that the estimated risk of having an infant weighing less $<2.50 \mathrm{~kg}$ was 2.3 times greater for infants born to women living in the farming community than for those in the pastoral 
community. A low birth weight in a socio-economically deprived community such as the Pokot farming community leads to negative health consequences that reverberate throughout the life cycle of an individual $[10,14]$. To date, the West Pokot district is one of the top-ten poorest districts in Kenya with about $43 \%$ of its population living on the poverty line and $49 \%$ below the poverty line. Literacy levels have remained low. It is estimated that only $1.1 \%$ of individuals are formally employed [15].

Compared to the pastoral women, this level of poverty is more apparent anong the Pokot farming women where maternal stature was found to be positively associated and maternal weight was negatively associated to infant birth weight (Table 4). Other studies have reported that under-nutrition, manifested by decreased maternal height and reduced pre-pregnancy weight, and pregnancy weight gain are among the strongest predictors for infants having a reduced birth weight [12]. A longitudinal study of farming pregnant women in the semi- arid Machakos District of Kenya found that birth weight was influenced by weight gain and maternal stature [22]. In an Indonesian study, birth weight predictors were gestational age, maternal weight and infant gender [23].

In both pastoral and farming communities a large proportion of births took place at home. The early identification of infants with a low birth weight is essential. for any comprehensive initiative aimed at improving child survival. Determination of third trimester maternal weight status requires monthly weight monitoring. In this study, third trimester MUAC [13] required minimal contact and was therefore used. Alternative anthropometric measurements to identify infants with a reduced birth weight have been proposed [24]. In Ethiopia, chest and head circunference have been used to identify infants with a reduced birth weight and these anthropometric measures may be a useful alternative that could be used by the traditional birth attendants in both pastoral and farming Pokot communities [25].

In the present study's population, the serum retinol and $\mathrm{Hb}$ concentrations had a positive significant effect on maternal lactation fat stores (Table 3). In a Nandi community where the food supply is relatively secure, research examining the relationship between body composition, vitamin $A$ and iron status in lactating women had identified serum retinol concentrations as a negative predictor of lactation \% body fat [16]. This difference in the nature of effect may be due to the fact that the West Pokot district is more vulnerable to household food insecurity [17]. The lactation phase of the reproductive cycle is energy demanding and body composition (\% BF and FFM) are proxies reflecting the adequacy of 
energy and protein intake. This in turn, may also effect the mothers iron and vitamin A status.

The prevalence of a low maternal $\mathrm{Hb}$ concentration $(<110 \mathrm{~g} / \mathrm{l})$ during the third trimester of pregnancy was significantly higher in pastoral pregnant women: The relative risk was about 2.6 times higher for women living in the pastoral community than for those in the pastoral community. Here the problem may not be related to nutrition inadequacy but due to the fact that the pastoral women living in the lower altitude hot savannah climate are more vulnerable to endemic malaria. The problem is that infection such as malaria or HIV may induce an acute phase response which may increase serum ferritin concentrations and decrease hemoglobin concentrations. This might be the case for the pastoral Pokot women in our study. Chronic infection is another potential confounder of the biochemical iron indices that were used and unfortunately we were unable to collect data on acute phase proteins such as CRP. Not considering the effects of the acute phase response, results in a distorted estimate of the prevalence iron deficiency [26]. Our data need to be interpreted with this in mind.

In this study $25 \%$ of the Pokot women were found to have a serum retinol concentrations of less than $0.70 \mu \mathrm{mol} / \mathrm{l}$ during pregnancy. In a national demographic survey carried out in $2003,11.6 \%$ of pregnant women were reported to be night blind [18]. This is considered to be a proxy indicator of vitamin A deficiency as a public health problem. Just as reported for iron indices [26-27], surveys to estimate vitamin A deficiency should also include measurements of serum C-reactive protein. This may have affected our estimates for serum retinol. A study by Sapin et al [28] found that healthy well-nourished pregnant women who reached full-term had the same absolute quantities of retinol as non-pregnant women, whereas the lower concentration of retinol in pregnant women who had reached full-term was due to expansion in plasma volume. This could be the reason why our mothers had a measurable increase of serum retinol during lactation.

In conclusion, the Pokot farming way of life was associated with negative changes in maternal body composition, iron stores and vitamin A status during the period of third trimester pregnancy and at four months after delivery. These factors may therefore have partially determined pregnancy outcome. The estimated relative risk of having a infant with a birth weight of less than $2.5 \mathrm{~kg}$ was 2.3 times higher for infants born to women living in the farming community than for those in the pastoral community. Both pastoral and farming women were equally affected by the high prevalence of vitamin A deficiency and low iron stores. Although we recommend that intervention strategies need to aim at 
preventing a reduced maternal body composition and infant weight we also point out that associations do not prove causality. The clearly attained body composition status, serum retinol and ferritin concentrations especially for the farming women are the result of complex interactions between physiological factors to which some women appear to be predisposed to and diet and high level physical activity. Factors with direct causal impacts may include low caloric intake and indirectly the reported low iron stores and high prevalence of vitamin $A$ deficiency.

\section{Acknowledgements}

This study was carried out within the frame work of the Moi University and Maastricht University MHO/NUFFIC project. We are grateful for the facilitation role played by the dean Prof. B.O. Khwa-Otsyula and the former dean of the Faculty of Health Sciences, Prof. H.N.K. arap Mengech. -Special thanks go to the chief, the village committees and the mothers of West Pokot communities. Special mention is made of Ms H Chesopo who provide invaluable support in sample collection and to Mr. M. Sang and Mr.L.C Kinile for facilitating sample analysis.

\section{References}

1. Pike IL. Age, reproductive history, seasonality, and maternal body composition during pregnancy for nonadic Turkana of Kenya. Anu J Human Biol. 1999;11:658-672

2. Leslie PW, Campbell KL \& Litte M.A. Pregnancy loss in nomadic and setted women in Turkana, Kenya: a prospective study. Human Biol. 1993; 65:237-54

3. Pike UL. Pregnancy outcome for nomadic Turkana pastoralists of Kenya. Am J Phys Anthropol, 2000; 113:31-45

4. Litle MA Gray SI \& Leslie PW. Crowth of nomadic and setted Turkana infants of northwest Kerrya. An J Phys Anthropol. 1993;92:273-89

5. Nathen MA Fratkin EM \& Roth EA. Sedentisn and child health among Rendile pastoralists of Northern Kenya. Soc Sei Med. 1990; 43: 504-15

6. Mejia LA. Role of vitamin A in iron deficiency anemia. Fomon SI \& Zlotkin S. Nestle Nutrition Workshop Series Vol. 30. 1992 Nutritional Anemias 93-101. Raven Press, New York:

7. Dijkluizen MA, Wiaringa FT, West CE, Muherdiyntiningsil \& Muhilal. Concurrent micronutrient deficieacies in lactating mothers and their infants in Indonesia. Am J Clin Nutr 2001:73;786-791

8. Suharno D, West CE, Muhilal Karyadi D \& Hautwast JGAJ. Supplementation with vitamin A and iron for nutritional anaenia in pregnant women in West Jaxa, Indonesia. Lancet $1993 ; 342: 1325-1328$.

9. Muslimatun S, Schmidt M, Schultink W, West CE, Hatvast GAJ, Gross R \& Muhilal. Weekly supplementation with iron and vitamin $A$ during pregnancy increases hemoglobin 
concentration but decreases serum ferritin concentration in Indonesian pregnant women. ] Nutr 2001;131;85-90

10. ACC/SCN. Fourth report on the world nutrition situation. Nutrition throughout the life cycle. Geneva: $2000 \mathrm{ACC} / 5 \mathrm{CN}$ in collaboration with IFPRI

11. De Onis $M$, Bloeener M \& Villar J Levels and patterns of intraterine growth teardation in developing countries. Eur J Clin Nutr 1998; 52:5-15.

12. Prada IA \& Tsang RC. Biollogical mechanisms of envirommentally induced causes of IUGR. Eur J Clin Nutr. 1998;52: S21-S28

13. James WPT, Mascie- Taylor CGN, Norgan NG, Bistrian BR, Shetty PS \& Ferno-Luzzi A. The value of MUAC in assessing chromic energy deficiency in third world adults. Eu I Chin Nurr 1994;48:883-894

14. Allen LH, Lunga aho MS, Shaheen M, Harrison GG, Neunann C, Kirksey A Matemal body mass index and pregnancy outcone in the Nutrition Collaboratiwe Research Support Program. Eur J Clin Nutr 1994; 48: S68-76: discussion 576-7.

15. Pkosing D, Krop S, Lopetakou W, Sikamov P, The Pokot land claims in Trans Nzoi District $(1896-2002)$. Presented to The Constitucion of Kenya Review Commission (CKRC). hattp://www kenyaconstitution.org. April 2002

16. Etryang GA, van Marken Lichtenbelt WD, Oloo A, Saris WHM. Serum retinol, iron status and body composition of lactating women in Nandi, Kenya. Am Nutr Metab $2003 ; 47: 276-283$.

17. CBS: The first report on poverty in Kenya Incidence and depth of poverty. Ministry of Planning and National Development 1998.

18. CBS: The Kenya Demographic and Health Survey. http://www cbs.go.ke 2003

19. Gibson R. Principles of Nutritional assessment 1990 Oxford University Press.

20. Yip, $\mathbb{R}$ (1994) Iron deficiency Contemporary scientific issue and international programmatic approaches. J Nutr 1994;124:1479S-1490S

21. WHO. Indicators for assessing vitamin A deficiency and their application in monitoring and evalluating intervention programmes. 1996 WHO/NUT/96.10 Genewa:

22. Kusin JA, Kardjati S \& Renqvist UH. Maternal body mass index: the functional significance during reproduction. Eur J Clin Nutr 1994; 48: \$56-67.

23. Muslimatuns S. Nutrition of Indonesian women during pregnancy and lactation; a focus on vitamin $A$ and iron. 2001. PhD Thesis. Wageningen University, The Netherlands.

24. WHO. Collaborative study of birth weight surrogates. Use of a simple anthropometric measurement to predict birth weight, Bulletin of the World Health Organization $1993 ; 71: 157-163$.

25. Raymond EG, Tafari N, Troendle IF \& Clemens ] (1994) Development of practical screening tool to identify pre-term low birth weight neonates in Ethiopia. Lancet. 1994;344:524-527.

26. Thurnham D I, McCabe G P, Northrop-Clewes C A $\&$ and Nestel Pefects of sub clinical infection on plasma retinol concentrations and assessment of prevalence of vitamin $A$ deficiency: meta-analysis. Lancet 2003;362:2052-2058.

27. Wieringa F T, Dijkhuizen M A, Clive E. West C E, Northop-Clewes C. A \& Muhial Estimation of the Effect of the Acute Phase Response on Indicators of Micronutrien Status in Indonesian Infants J Nutr.2002;132:3061-3066.

28. Sapin V, Alexandre MC, Chaib $S$, Boumazeau JA, Sanvan P, Borel Pacquetin B, Grolien $P$, Lemery D, Dastugue B \& Azais BVEffect of vitamin A status at the end of term pregnancy on the saturation of retinol binding protein with retinol. Am / Clin Nutr 2000; $71: 537-543$. 


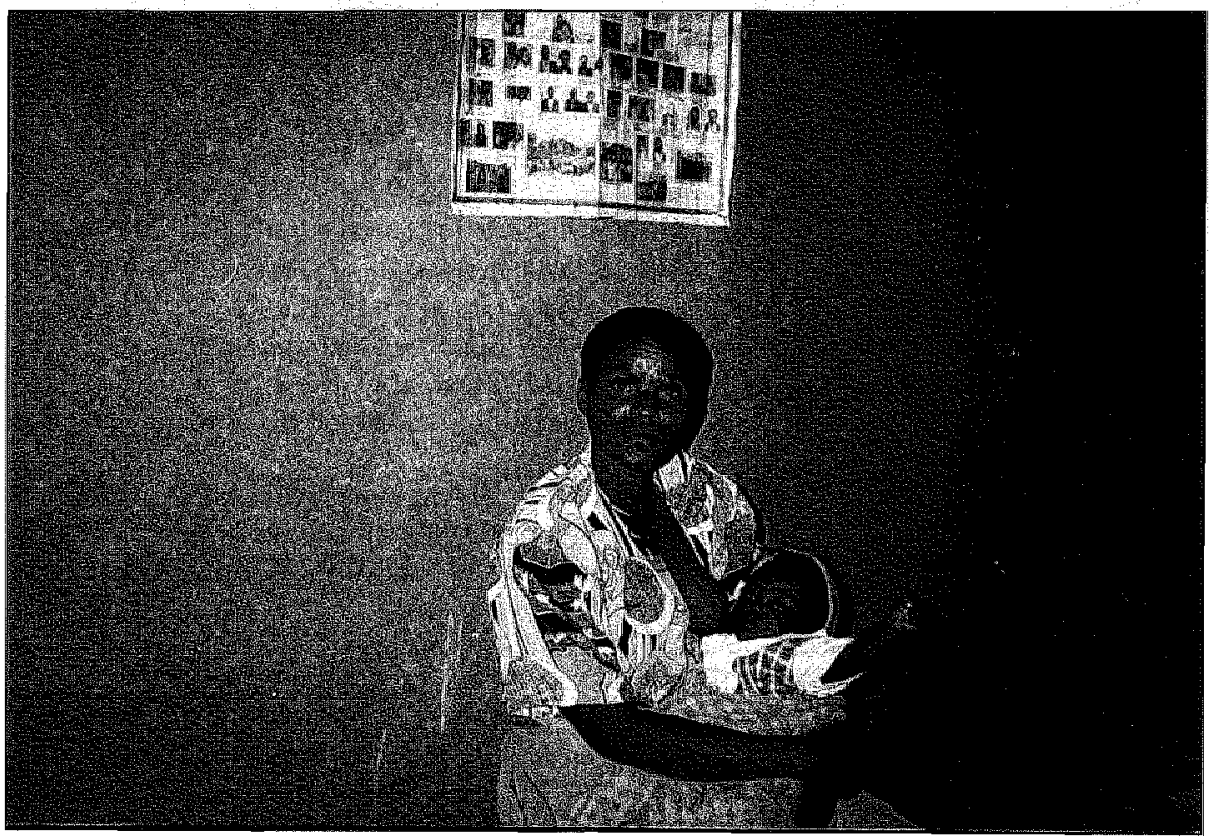


$\sqrt{1}$

Factors underlying the prevalence of low infant weight at birth and up to 4 months of age, in pastoral and farming communities of West Pokot, Kenya

G.A. Ertyang, WD van Marken Lichtenbeh, Fa Esmai, W.M.M. Surs

Conditionally accepted for publication Joumal of Public Health Nutrition 


\section{Abstract}

Objective: To determine the prevalence of infants being born with a reduced body weight and to identify risk factors associated with a reduced weight at birth and up to the age of 4 months, in farming and pastoral communities in West-Pokot.

Design: Longitudinal study conducted from October 2001 to August 2002. Setting: Rural farming and pastoral communities of West Pokot, Kenya Subjects: Data was collected for 109 farming and 112 pastoral newborn infants and their mothers during the third trimester pregnancy and at four months after birth.

Methods: Infant birth weight was measured within 7 days of birth and then every month thereafter until 4 months of age. Maternal serum ferritin, serum retinol and breast milk retinol concentrations were measured. Maternal anthropometric measurements were taken and general questionnaire data was collected.

Results: Pastoral infants had a significantly higher birth weight $(\mathrm{P}<0.05)$ and a higher weight/age $z$ score at 4 months of age $(P<0.05)$. At the age of four months, the percentage of infants in farming and pastoral communities with a Wt/Age $z$ score of less than -2.00 were $16 \%$ and $21 \%$, respectively. The estimated relative risk of Wt/Age $z$ score $<-2.00$ was 1.5 times higher for four month old infants born to women living in the farming community as compared to those in the pastoral community. Weight of infants in both pastoral and farming communities deviated below the NCHS/WHO reference population. The mean (SD) breast-milk retinol concentration for pastoral (985(.408) $\mu \mathrm{mol} / \mathrm{l})$ as compared to the farming women $(1.000(.451) \mu \mathrm{mol} / \mathrm{l})$ was not significantly different. At four months post-delivery, the prevalence of a breast-milk retinol concentration of less than $1.05 \mu \mathrm{mol} / 1$ and a serum retinol concentration of less than $0.70 \mu \mathrm{mol} / \mathrm{l}$ was $46 \%(52 / 112)$ and $29.2 \%(33 / 112)$ for pastoral and 50.9\% (56/109) and 30.9\% (34/109) for farming women, respectively. Predictors of weight at four months of age for the pastoral infants were their birth weight as well as maternal weight during the third trimester of pregnancy and mid-upper arm circumference four months post-delivery. For the infants born in the farming community, these predictors were birth weight as well as maternal $\%$ body fat during the third trimester and a serum retinol concentration of less than $0.70 \mu \mathrm{mol} / 1$. In the pastoral community, the predictors of breast milk retinol concentration were a pregnancy serum retinol concentration of less than $0.70 \mu \mathrm{mol} / 1$ and $\%$ body fat four months post-delivery. For the farming women, the predictors were age, serum ferritin concentration during pregnancy and body mass index four months after delivery. Maternal weight during the third trimester of pregnancy and at 4 months postpartum was posi- 
tively correlated to the neonatal weight/age $\mathrm{z}$ score $(\mathrm{r}=.174 \mathrm{p}<0.001)$ and to infant growth $(r=.182 \mathrm{p}<0.01)$.

Conclusion: During the first four months of life, the infants in the farming community were more likely to be underweight than their counterparts in the pastoral community. Women living in pastoral and farming communities had a breast milk vitamin $A$ status that was inadequate to meet infant nutritional requirements and to build up infant liver stores. To achieve a measurable effect, future nutritional interventions need to ensure that the Pokot women enter pregnancy with a good nutritional status and that this is maintained throughout lactation.

\section{Introduction}

In developing countries $11 \%$ of infants born at term have a reduced birth weight [1]. Maternal nutritional status [2,3], socio economic related factors [4] and life-style have been reported to influence the birth weight of infants [5] as well as their subsequent growth [6]. Of great concern for women in developing countries is the inadequate maternal weight during pregnancy [7]. This has been reported to be associated with acute nutritional stress during pregnancy [8] that prevents infants from attaining their full growth potential $[2,3,7]$.

Maternal vitamin A status plays a critical role in the health and growth of infants [9] and its deficiency during pregnancy has been reported to have a negative impact on maternal iron status [10]. In turn, iron deficiency is associated with a higher risk of pre-term delivery and a low birth weight [11]. For exclusively breast-fed infants, breast milk is the sole source of vitamin A. Vitamin A intake and status during the third trimester of pregnancy, have been shown to effect breast milk retinol concentrations [12]. Determination of breast milk vitamin $A$ concentration reflects the nutritional status of the mother and the infant [13]. This is because mothers who are lactating and vitamin A deficient may not have enough vitamin $A$ in their breast milk to maintain and build body reserves in their rapidly growing infants [9]. Although a comparison of data from developed and developing countries has been reported [14], data on breast milk vitamin $A$ concentration and maternal nutritional status postpartum is scarce and mostly done in the far East [15].

High levels of infants with a birth weight of less than $2.5 \mathrm{~kg}$ and an infant growth $z$ score of less than -2.0 are considered a trigger for public health action requiring population wide interventions aimed at reducing the prevalence of under-weight in new born infants $[1,7,8]$. In Kenya there is very limited data 
that relates maternal lifestyle, pregnancy weight patterns, and iron and vitamin $A$ status to pregnancy outcome and infant growth. Accordingly, the aim of this study was to determine the prevalence and to identify the risk factors associated with being underweight from birth to 4 months of age, in infants bon to mothers in Pokot pastoral and farming communities.

\section{Subjects and method:}

\section{Study area and population under study}

The longitudinal study was carried out in West Pokot from October 2001 to August 2002. During this time, we found within the West-Pokot area, that a fairly comprehensive census of households with pregnant and lactating women and children under the age of five years was available at sublocational and village level. The study area included the five sub-locations of Ortum, Morbus, Sobokwo, Kerelwa and Chepkobegh. Using multistage sampling, 8 pastoral and 6 farming villages were randomly selected for the study. An updated register of pregnant women was compiled with the help of the village elders and the traditional birth attendants (TBAs) who reside in each village. Estimation of gestational age was based on the last menstrual period and verified by the birth date of the infant. A total of 310 women were registered as pregnant. In the two communities, the inclusion criteria for participation in the study were that the women were in the third trimester of their pregnancy (estimated to be between 28 and 36 weeks of gestation) and that they were healthy. Those examined and recruited for the study were 122 and 128 from the pastoral and farming communities, respectively. At follow-up, 230 lactating women were examined. On hundred and twelve women from the pastoral community and 109 from the farming community had complete data collected about them (Figure 1). The TBA and a research assistant maintained a record of birth dates and made notification to the study team. Due to remoteness and difficult terrain, two data collection centers were established in the pastoral community; the farming community had only one due to its easier accessibility. Birth weights were measured soon after birth or as much as possible within 7 days. For each infant, growth was monitored monthly during the first four months of life. This was done at the nearest health center and by the study team. Approval for the research was obtained from both the Moi University ethical and research committee and the government of Kenya. The women received detailed explanation concerning the objectives and procedures of the study, and their written consent to participate in the study was obtained prior to their inclusion. 


\section{Anthropometry, blood and breast milk collection}

A pre-coded questionnaire was used to collect demographic and pregnancy history data. At follow-up, additional data on frequency of breast feeding was also collected. The mother"s body weight was measured to the nearest $0.1 \mathrm{~kg}$ using a calibrated electronic scale (SECA Corporation Weighing and Measuring System Colombia, USA) and height was measured to the nearest $0.1 \mathrm{~cm}$ with a stadiometer. Body mass index (BMI) was calculated from $\mathrm{Wt} / \mathrm{Ht}^{2}\left(\mathrm{~kg} / \mathrm{m}^{2}\right)$. A Holtain skinfold thickness caliper (UK) was used to measure in triplicate, biceps, triceps, suprailiac and sub-scapular skin fold thicknesses and from these measures maternal fat mass (FM), fat free mass. (FFM) and \% body fat (\%BF) were estimated [16]. Mid-upper arm circumference (MUAC) was measured using a non-extensible tape measure (UNICEF Version). Repeated measurements were carried-out by the same investigator. The infant's body weight was measured to the nearest $0.10 \mathrm{~kg}$ with a baby weighing scale (SECA 770 Corporation weighing and Measuring System Colombia USA) and growth was monitored monthly for the first four months of life. At all times, infants were weighed without clothing.

A non-fasting venous blood sample of $5 \mathrm{ml}$ was collected from each woman during the third trimester pregnancy and at about four months after delivery. The blood was divided into a trace element free and an EDTA vaccutainer (Becton Dickinson, Franklin Lakes NJ, USA). The samples were stored on ice for transportation to the Kapenguria District Hospital laboratory. Within 3-5 hours of blood collection, the serum was separated (1.5 min at $3000 \mathrm{rpm}$ ), aliquoted and frozen overnight at $-20^{\circ} \mathrm{C}$ at the Kapenguria District Hospital. The next day, the frozen samples were transported on dry ice to the Moi University laboratories in Eldoret where they were stored at $-70^{\circ} \mathrm{C}$ until analysis for serum retinol and ferritin concentrations.

Breast milk was collected during the day from the breast that had not been uised to feed the infant within the previous hour [13]. The mothers used manual expression to collect $10-150 \mathrm{ml}$ of breast milk. The breast milk was stored in foiled glass bottles and transported to the laboratory in a cool box with ice packs. Two aliquots were frozen at $-70^{\circ} \mathrm{C}$ and analysis was carried-out within 1 year of collection, at Moi University laboratories in Eldoret Kenya.

\section{Biochemical analysis}

A Coulter counter, model 560 (Coulter electronics Ltd. Luton, Beds, England), was used to determine hemoglobin ( $\mathrm{Hb}$ ) and Haematocrit ratio $(\mathrm{Hct})$ concentrations. Serum retinol concentration was assayed using high-performance 
liquid chromatography (HPLC). Serum ferritin concentration (SF) was measured by ELISA, using a commercial kit (Boehringer Mannheim Immundiagnostike Mannheim, Germany). Depletion of iron stores was based on the levels of SF concentration: severe $<12 \mu \mathrm{g} /$; marginal $\mathbb{1} 2-29 \mu \mathrm{g} / 1$ and normal $\geq 30 \mu \mathrm{g} / 1[17,18]$. Vitamin $A$ status was based on the serum retinol concentration: deficient, $<0.35 \mu \mathrm{mol} / 1(10 \mu \mathrm{g} / \mathrm{dl})$ and marginal, $0.35-0.70$ $\mu \mathrm{mol} / \mathrm{l}(20 \mu \mathrm{g} / \mathrm{d}$ ) [19]. Milk fat was determined by using the field-tested [20] "creamatocrit" micro-method [21]. The percentage of cream, or creamatocrit, was read from the Haematocrit capillary tube. Fat and energy values were calculated arithmetically as follows: Fat $(\mathrm{g} / \mathrm{l})=$ creamatocrit $(\%)-0.59 / 0.146$; energy in $\mathrm{kcal} / \mathrm{l}=(290+66.8 \mathrm{x}$ creamatocrit percent $)$. The breast milk vitamin $\mathrm{A}$ concentration was expressed as a ratio to the $\%$ fat concentration (i.e $1.5 \mu \mathrm{mol} / 1$ vitamin $A \div 5 \%$ fat $=0.3 \mu \mathrm{mol} / \%$ fat) $[13,19]$. The breast milk retinol levels were assayed using a high-performance liquid chromatography. Risk of low intake was based on a cut off of $\leq 1.05 \mu \mathrm{mol} / 1 \llbracket[13,19]$.

\section{Statistical analysis}

Normality of data distribution was checked by visual evaluation using a histogram and the Kolmogorov-Smirnov test of normality. Pearson chi-square and independent samples t-test analysis were used to compare groups for significant differences. Monthly attained infant growth was assessed based on the growth reference standards recommended by the WHO, and analyzed using the Epi Infor 2000 Version 1.1 .2 programme. Pearson correlation coefficient and stepwise linear regression analysis were used to determine the relationship between factors speculated to be related to infant growth and breast millk retinal level. General independent variables were: age, total number of live births and number of years of formal schooling. Body composition variables were: pregnancy and lactation height, weight, lactation BMI,\% BF, FFM, MUAC and skin fold thickness measurements. Biochemical variables included: $\mathrm{Hb}, \mathrm{Hct}$, serum retinol, serum ferritin including categorical variables for deficiency status. Infant variables included weight within 7 days of birth and monthly weight up to the age of four months. A total of two models were developed. To create variables for each model, dependent variable inclusion was set at a $\mathrm{p}$ value of 0.05 and exclusion at 0.01 . The SPSS software package (Windows version 11.1) was used for all statistical analyses and a $p$ value of $<0.05$ was considered significant. 


\section{Results}

\section{Maternal nutritional status}

In the study, we enrolled 250 Pokot women who were in their third trimester of pregnant, aged between 18-38 years, mean parity of 4 (Figure 1) (2). Pokot women pregnant for the first time, were $9.6 \%$, and those with $<4$ pregnancies carried to term were $53.3 \%$. Anthropometric and biochemical characteristics of the study population from pastoral and farming communities are shown in Table 1. The mean (SD) breast milk retinol concentration of $0.985(0.408)$ $\mu \mathrm{mol} / 1$ for pastoral and $1.000(0.451) \mu \mathrm{mol} / 1$ for farming women were not significantly different. Four months after delivery, the prevalence of breast milk retinol concentration of $<1.05 \mu \mathrm{mol} / 1$ and serum retinal concentration of $<$ $.700 \mu \mathrm{mol} / \mathrm{l}$ were $46 \%(52 / 112)$ and $29.2 \%(33 / 112)$ for the pastoral women

Table 1: Characteristics of women and infants living in pastoral and farming communicies of West Pokot. ${ }^{1}$

\begin{tabular}{|c|c|c|}
\hline & $\begin{array}{l}\text { Pastoralists } \\
\text { mean }\left(5^{\text {th }}, 95^{\text {th }} \text { percentile) }\right.\end{array}$ & $\begin{array}{l}\text { Farmers } \\
\text { mean }\left(5^{\text {th }}, 95^{\text {bl }} \text { percentile }\right)\end{array}$ \\
\hline Maternal & . & \\
\hline Age & $26,8(19,37)$ & $26(18,38)$ \\
\hline $\begin{array}{c}\text { BML }\left(\mathrm{kg} / \mathrm{m}^{2}\right) \\
\text { Lactation }\end{array}$ & $19.7(16.7,23.3)$ & $19.8(16.0,25.2)$ \\
\hline $\begin{array}{l}\text { BF } \\
\text { Pregnancy } \\
\text { Lactation * }\end{array}$ & $\begin{array}{l}21.7(15.9 .27 .9) \\
24.2(14.4,35.9)\end{array}$ & $\begin{array}{l}22.7(16.0,32.5) \\
25.9(17.3,35.9)\end{array}$ \\
\hline $\begin{array}{l}\text { Seruma ferritin }(\mu \mathrm{g} / \mathrm{l}) \\
\text { Pregnamcy* } \\
\text { Lactation }\end{array}$ & $\begin{array}{l}25.8(18.1,34.5) \\
18.5(11.9,27.2)\end{array}$ & $\begin{array}{l}24.4(18.0,34,0) \\
16.9(11.6,26.4)\end{array}$ \\
\hline $\begin{array}{l}\text { Serum retinol (jmol/ } 1 \\
\text { Pregnancy } \\
\text { Lactation }\end{array}$ & $\begin{array}{l}0.91(0.22,1.82) \\
1.09(0.35,1.90)\end{array}$ & $\begin{array}{l}0.92(0.27,1.55) \\
1.11(0.34,1.97)\end{array}$ \\
\hline BM retinol $(\mu \mathrm{mol} / \mathrm{l})$ & $.98(.36,1.86)$ & $1.00(.36,1.80)$ \\
\hline $\begin{array}{l}\text { New born infant } \\
\text { Weight }(\mathrm{kg})^{2 *} \\
\text { Wt/Age }\end{array}$ & $\begin{array}{l}2.93(2.34,3.52) \\
-0.97(-1.91,-0.02)\end{array}$ & $\begin{array}{l}2.80(2.11,3.42) \\
-1.17(-2.30,-0.08)\end{array}$ \\
\hline $\begin{array}{l}\text { Infant at } 4 \text { months } \\
\text { Weight }(\mathrm{kg})^{\|} \\
\text {Wt } / \mathrm{Age}^{\star}\end{array}$ & $\begin{array}{l}5.23(3.45,6.49) \\
-0.86(-2.77,1.24)\end{array}$ & $\begin{array}{l}5.00(2.94,6.63) \\
-1.18(-3.32 .0 .89)\end{array}$ \\
\hline
\end{tabular}

${ }^{1}$ Pastoral: pregnancy $n=122$; Lactation $n=112$; Farmers: pregnancy $n=128$; Lactation $n=109 ; 2$ New born infant weight taken within 7 days of birth: "Weiglt for age $Z$ scores based on WI-1O reference population (1997); BM: Breast milk retinol; BMI- Body mass index; $\%$ BF: Percent Body fat; * Pastoral and farming groups significandy different $p<0.05,{ }^{*}$ p $<0.01$; (Independent. samples $t-$ test). 

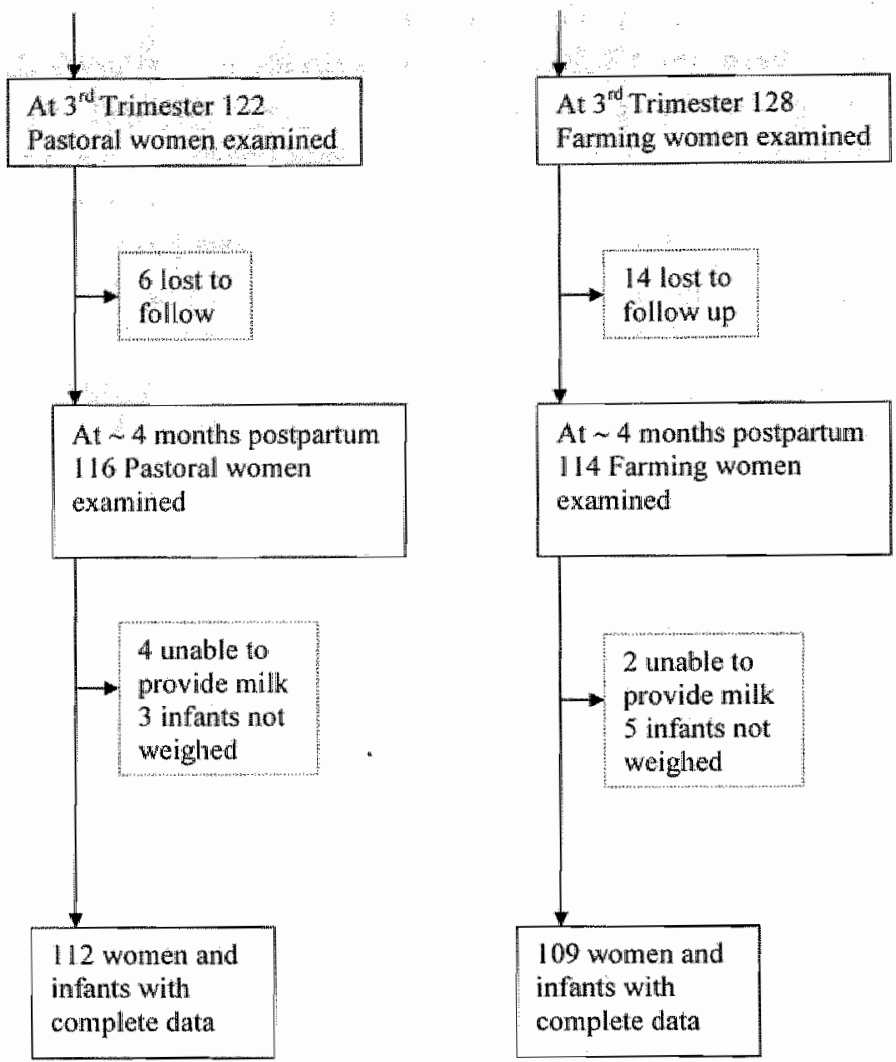

Figure 1. Eligible subjects at recruiment and follow-up in the longitudinal study:

and $50.9 \%(56 / 109)$ and $30.9 \%(34 / 109)$ for farming women, respectively (Table 2).

\section{Prevalence of infant underweight}

The mean \pm SD weight of new born Pokot infants was $2.9(0.363) \mathrm{kg}$ for pastoral infants and $2.8(0.414) \mathrm{kg}$ for farming infants. In the farming community, the mean birth weight of newborns was significantly lower $(p<0.01)$ than for newborns in the pastoral community (Table 1). Newborns with a weight of $<2.5 \mathrm{~kg}$ were $16.8 \%$ for the pastoral community, and $31.3 \%$ for farming community (Table 2) The estimated relative risk of having a newborn with a weight of $<2.5 \mathrm{~kg}$ was 2.3 times greater for infants born to women living in the farming community than for those in the pastoral community. At $\sim 4$ months of 
Table 2: Prevalence of under weight and low serum and breast millk retinol concentrations in infants and lactating women living in pastoral and farming Polsot communites.

\begin{tabular}{|c|c|c|c|c|c|c|}
\hline & \multirow{2}{*}{\multicolumn{3}{|c|}{$\begin{array}{l}\text { Pastoralists } \\
\text { Prevallence }\end{array}$}} & \multirow{2}{*}{\multicolumn{3}{|c|}{$\begin{array}{l}\text { Farmers } \\
\text { Prevalence }\end{array}$}} \\
\hline & & & & & & \\
\hline & $n$ & $\%$ & Mean $(95 \% \mathrm{Cl})$ & $\mathrm{n}$ & $\%$ & Mean $(95 \% \mathrm{CD})$ \\
\hline \multicolumn{7}{|l|}{ Pregnancy cutcome ${ }^{2}$} \\
\hline Weight $<2.5 \mathrm{~kg}^{*}$ & 19 & 16.8 & $2.37(2.36 .2 .40)$ & 35 & 313 & $2.29(2.26,2.32)$ \\
\hline \multicolumn{7}{|l|}{ Infant weight ${ }^{3}$} \\
\hline Wt/Age $<-2.00^{4} \star \star$ & 18 & 16.1 & $-2.57(-2.7,-2.44)$ & 23 & 21.1 & $-2.92(-3.07,-2.78)$ \\
\hline \multicolumn{7}{|l|}{ Retinal $<0.70 \mu \mathrm{mol} / \mathrm{l}$} \\
\hline Pregnancy & 34 & 27.9 & $0.42(0.41,0.45)$ & 31 & 24.2 & $0.50<0.47,0.53$ \\
\hline Lactation ${ }^{5}$ & 33 & 29.2 & $0.54(0.51,0.56)$ & 34 & 30.9 & $0.53(0.50 .0 .55)$ \\
\hline
\end{tabular}

BM retinol $<1.05 \mu \mathrm{mol} / 1$

\begin{tabular}{lllllll} 
Lactation $^{5}$ & 52 & 46 & $0.669(0.648,0690)$ & 56 & 50.9 & $0.651(0.629,0.673)$ \\
\hline
\end{tabular}

${ }^{1}$ Pastoral: pregnancy $n=122 ;$ Lactation $n=112 ;$ Farmers; pregnancy $n=128$; Lactation $n=109 ;{ }^{3}$ New born infant weight taken within 7 days of birth; ${ }^{3}$ Infant weight at 4 months; ${ }^{4}$ Weight for age $z$ score based on WHO Ref population (1997); ${ }^{5}$ Four months after delivery; * Pastoral and farming groups significantly different $p<0.01$ (Chi square).

age, infants in farming and pastoral communities with a Wt/Age $z$ score $<-2.00$ were $16.1 \%$ and $21.1 \%$ respectively (Table 2 ). The estimated relative risk of $\mathrm{W} t /$ Age $\mathrm{z}$ score $<-2.00$ was 1.5 times greater for infants born to women living in the farming community than for those in the pastoral community. In the two communities, $55 \%$ of the low Wt/Age of four month old infants may be attributable to living in the farming community.

\section{Infant growth pattems}

Infant growth patterns are shown in Figure 2. Infants from the pastoral community had higher weight/age $z$-scores during the first four months of life (Figure 2). Compared to the NCHS/WHO reference population, in all the groups the weight/age $z$ scores were lower at two months. Though there was slight improvement, the $\mathrm{z}$ scores start dropping at 4 months. At this age, Pokot infants who were severely underweight (weight/age $\mathrm{z}$ scores $<-2.00$ ) were $19.1 \%$. Infants in pastoral and farming communities who were below this cut off point were $8.4 \%$ and $10.7 \%$ respectively. Compared to four montl]x old pastoral infants, the estimated relative risk of severe under weight was 1.5 times higher for infants born in a farming community. Weight of infants in both pastoral and farming communities deviated below the NCHS/WHO reference population; 


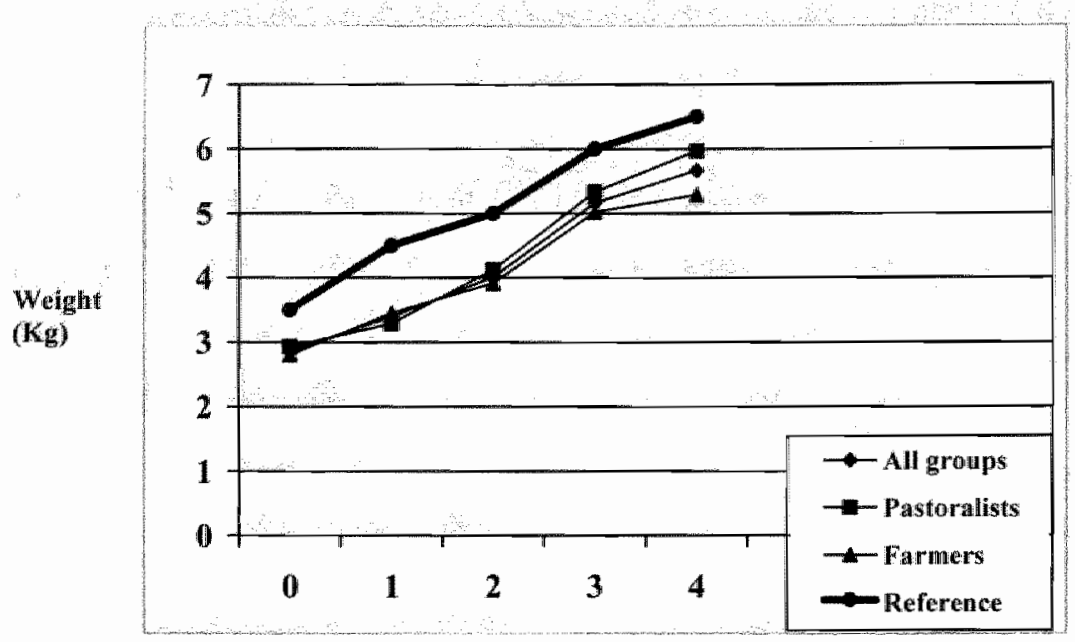

Age in months

Figure 2. Mean weight of infants from $0-4$ months in the Pastoral and farming communities and reference values based on the WHO/National Center for Health Statistics infant growth reference standards.

infants from both the pastoral and farming communities started life much lighter (Figure 2).

\section{Determinants of infant weight at four months}

An analysis of variance based on stepwise regression is shown in Table 3. Using infant weight at four months as at dependent variable, newborn infant weight taken within 7 days of birth, maternal third trimester pregnancy and lactation mid upper arm circumference were the factors that explained $30.5 \%$ of the total variation in the weight of four month old pastoral infants (Tablle 3). In acldition to newborn infant weight third trimester pregnancy $\%$ body fat and serum retinol concentrations of $<0.70 \mu \mathrm{mol} / 1$ were factors that explained $21.3 \%$ of the total variation in the weight of four month old infants in the farming community (Table 3). Third trimester pregnancy weight was positively correlated to neonatal weight/age $z$ score $(r=.174 \mathrm{p}<0.001)$ and to infant growth $z$ score $(r=0.212 p<0.001)$. Also positively correlated to infant growth were lactation weight $(\mathrm{r}=0.182 \mathrm{p}<0.01)$, BMI $(\mathrm{r}=0.184 \mathrm{p}<0.001)$ and being a pastoral infant $(r=0.132 \mathrm{p}<0.05)$.

\section{Deteminants of breast milk retinol.}

In the farming community, the predictor variables able to explain $10.3 \%$ of the total variation in pastoral women's breast milk retinol, were pregnancy serum 
Table 3. Coefficients $(\beta)$ and significance levels $(p)$ fron stepwise regression andyses of weight as the dependent variable for 112 pastoral and 109 farming infants who were aged 4 mondhs.

\begin{tabular}{|c|c|c|c|c|c|c|c|}
\hline & \multicolumn{6}{|c|}{ Predictor variables } & \multirow[b]{3}{*}{$P$} \\
\hline & \multicolumn{3}{|c|}{ Pastoralists } & & \multicolumn{2}{|c|}{ Farmers } & \\
\hline & $\beta$ & $\mathrm{R}^{2}$ & $\mathrm{P}$ & & $\beta$ & $R^{2}$ & \\
\hline Counstant & 0.07 & & & Constant & 1.34 & & \\
\hline NBI Wt: & 1.79 & .217 & $<0.01$ & NBI We ${ }^{1}$ & 1.27 & .133 & $<0.01$ \\
\hline Constant & -2.45 & & & Constant & -.24 & & \\
\hline NBI Wt & 1.68 & & & NBI We & 1.21 & & \\
\hline $\mathrm{MP} \mathrm{Wt}^{2}$ & 0.06 & .257 & $<0.01$ & $\% \mathrm{BF}^{3}$ & 0.07 & .187 & $<0.01$ \\
\hline Constant & 2.45 & & & Constant & 0.07 & & \\
\hline NBI Wt ${ }^{1}$ & 1.67 & & & NBI Wi & 1.21 & & \\
\hline$M P \mathrm{Wt}^{2}$ & 0.08 & & & $\% \mathrm{BF}^{3}$ & 0.07 & & \\
\hline L MAC ${ }^{4}$ & -.28 & 305 & $<0.01$ & Retinol "s & -.57 & .213 & $<0.01$ \\
\hline
\end{tabular}

${ }^{1}$ NBI Wt: New born infant weight taken within 7 days of birth; ${ }^{2}$ MP Wt: Maternal third trimester pregnancy weight; ${ }^{3} \% \mathrm{BF}$ : Third trimester \% body fat; ${ }^{4} \mathrm{~L}$ MAC: Lactation mid upper arm circamference, ${ }^{5}$ Pregnancy serum retinol $<.700 \mu \mathrm{mol} / \mathrm{l}$.

Table 4. Coefficients $(\beta)$ and significance levels $(p)$ from stepwise regression analyses of breas: milk retinol concentration as the dependent variable, for 112 pastoral and 109 farming women who were lactating.

\begin{tabular}{|c|c|c|c|c|c|c|c|}
\hline & \multicolumn{7}{|c|}{ Predictor variables } \\
\hline & \multicolumn{4}{|c|}{ Pastoralists } & \multicolumn{3}{|c|}{ Farmers } \\
\hline & $\beta$ & $\mathbb{R}^{2}$ & $\mathrm{P}$ & & $\beta$ & $\mathrm{R}^{2}$ & $\mathrm{P}$ \\
\hline $\begin{array}{l}\text { Constant } \\
\text { P SR }\end{array}$ & $\begin{array}{r}1.21 \\
.26\end{array}$ & .051 & $<0.01$ & $\begin{array}{l}\text { Constant } \\
\text { Age }\end{array}$ & $\begin{array}{r}.57 \\
0.03\end{array}$ & .133 & $<0.01$ \\
\hline $\begin{array}{l}\text { Constant } \\
\mathrm{PSR} \\
9 \mathrm{BF}\end{array}$ & $\begin{array}{l}.700 \\
.27 \\
2.08\end{array}$ & .103 & $<0.01$ & $\begin{array}{l}\text { Constant } \\
\text { Age } \\
\text { L SR }\end{array}$ & $\begin{array}{l}-.98 \\
0.03 \\
-.03\end{array}$ & .158 & $<0.01$ \\
\hline & & & & $\begin{array}{l}\text { Constant } \\
\text { Age } \\
\text { L.SF } \\
\text { P. SF }\end{array}$ & $\begin{array}{r}1.27 \\
.03 \\
-.04 \\
-.34\end{array}$ & .190 & $<0.01$ \\
\hline & & & & $\begin{array}{l}\text { Constant } \\
\text { Age } \\
\text { L SF } \\
\text { P SF } \\
\text { L BMI }\end{array}$ & $\begin{array}{r}2.01 \\
.03 \\
-.03 \\
-.35 \\
-.04\end{array}$ & .210 & $<0.01$ \\
\hline
\end{tabular}

P SR: Pregnancy serum retinol <. $700 \mu$ mol $/ \mathrm{ml} ; \%$ BF: Lactation \% body fac; L SR: Lactation serum retinol; L SF: Lactation serum fertitin; P SF: Pregnancy serum ferritin < $32 \mu \mathrm{g} / \mathrm{l}$; L BMI: Lactation body mass index 
retinol $<0.700 \mu \mathrm{mol} / 1$ and $\% \mathrm{BF}$ four months after delivery (Table 4). In the lactating women from the farming community, the predictor variables explaining $21 \%$ of the variation in breast milk retinal concentration were age, serum ferritin concentration during pregnancy; and BMI four months after delivery (Table 4). The total number of pregnancies carried to term was negatively correlated to both breast milk vitamin $\mathrm{A}$ status $(r=-0.138 \mathrm{p}<0.05)$ and a pregnancy $\mathrm{Hb}$ status of $<1.10 \mathrm{~g} / 1(\mathrm{r}=-0.178 \mathrm{p}<0.01)$.

\section{Discussion}

The findings of this study contribute to knowledge relating matemal nutrition to pregnancy outcome and infant growth for purposes of creating sound advice on which to base child and mother health programmes. Newborn infant weight is considered to be an important determinant of infant mortality and morbidity. Maternal malnutrition is usually assumed to be a causal factor in infant mortality and morbidity, but other environmental factors are also involved. We had an opportunity to investigate the underlying factors for the occurrence of infant under weight in Pokot communities who were of similar ethnicity but who led different lifestyles. We found that predictors of weight in four month old pastoral and farming infants was their newborn infant weight, maternal weight during the third trimester of pregnancy and mid upper-arm circumference four months after delivery. For the infants born in the farming community, these were newborn birth weight, third trimester pregnancy \% body fat, and serum retinol concentrations of $<0.70 \mu \mathrm{mol} / 1$ (table 4 ).

These predictors of infant growth are comparable to those identified in a study of Brazilian infants that investigated fat changes in low income lactating mothers and the growth of their breastfed infants [22]. In this study, they found that birth weight and the fat concentration of the breast milk were the strongest predicators of growth in the first three months of life. Simillarly maternal weight during pregnancy (which represents the maternal long-term nutritional situation) was the most important determinant of newborn birth weight in chronically malnourished women from the Central African Republic [23]. In our study, maternal weight during the third trimester of pregnancy was positively correlated to neonatal weight/age $z$ score.

The National Center for Health Statistics (NCHS) anthropometric reference standards were used to assess attained growth based on weight/age (WA). At four months of age, infants in farming and pastoral communities with a W/t/Age $z$ score $<-2.00$ were $16 \%$ and $21 \%$ respectively. The estimated relative risk of 
Wt/Age $z$ score $<-2.00$ was 1.5 times higher for infants born to women living in the farming community than for those in the pastoral community. The recent national demographic and health survey reports that the prevalence of children having a Wt/Age $\mathrm{z}$ score of $<-2.00$ was $21.2 \%$ and was not significantly different to the one found in the farming community [24].

In Kenya, early infancy growth faultering that is sustained chrough the second year of infant life has been reported in infants in a semi-arid area of Embu district [25]. Though low weigh for age (WA) is commonly identified with protein- energy- malnutrition (PEM) it is also importantly associated with micronutrient malnutrition and risks of infection [26] and mortality [27]. Analysis of infant malnutrition by Shrimpton $e t$ al [28] showed a downward trend in mean WA from the age of 3 months following the initiation of supplemental or complementary feeding. It is assumed that the fluids and solids introduced to infants during this early period of life, tend to be of lower nutritional quality than the breast milk that they replace. Deficient nutrient intake may therefore be said to reinforce the malnutrition-infection cycle and contributes to overall poor health and sub-optimal growth.

In our study population, the infants were exclusively breastfed on demand with very little supplemental and complementary feeding being introduced. The mean breast milk retinol concentration of $0.985 \mu \mathrm{mol} / \mathrm{l}$ for pastoral and 1.00 $\mu \mathrm{mol} / \mathrm{l}$ for farming women, were not significantly different. In our situation, it is possible that the infant population may have been breastfed on breast milk that was already deficient in vitamin A. At four months of age, the prevalence of breast milk retinol concentrations of $<1.05 \mu \mathrm{mol} / \mathrm{l}$ and serum retinol concentrations of $<0.700 \mu \mathrm{mol} / \mathrm{I}$ were $46 \%(52 / 112)$ and $29.2 \%(33 / 112)$, respectively for pastoral women, and $50.9 \%(56 / 109)$ and $30.9 \%(34 / 109)$, respectively, for the farming women. These values reflect a vitamin A deficient population [9].

Where a single micronutrient deficiency is identifed, it is inevitable that PEM and other micronutrient deficiencies will also be present. In infants, PEM manifests as growth retardation. $U p$ to $80 \%$ of the infant mortality incidence that is associated with under-nutrition, is attributable to mild and moderate malnutrition [27]. Treating or preventing a single nutrient will not restore full health. Balanced macro- and micro-nutrient intake with protection against serious and prolonged infections remains the foundation for adequate growth and development in childhood. 
In our study, accurate assessment of food intake was logistically difficult. We therefore selected a nutrient that is associated with optimal pregnancy outcome and infant growth to provide grounds for the speculation that, the deficiency of this key nutrient may compromise overall maternal health and infant growth Breast milk is recognized as the only food that could singly provide all the nutrients required to support optimal growth in early infancy [9]. In the pastoral community, the predictors of breast millk retinol concentration were maternal serum retinol concentrations of $<.70 \mu \mathrm{mol} / \mathrm{l}$ during pregnancy and maternal \% body fat four montlis after delivery. For the farming wonen, these were age, serum ferritin concentration during pregnancy and body mass index four months after delivery.

During the 1980's and 90 's, emphasis was on implementation of various measures to control severe vitamin A deficiency. The more widespread problem of sub-clinical deficiency has remained relatively untouched. Evidence from. Nepal shows that pregnancy is a period in life when there is increased risk of vitamin $A$ deficiency and it has been shown as in children that there is an increased mortality risk [28]. To date it appears that lactation has not been similarly investigated although there are suggestions of vulnerability to infant as well as the mother $[13,29]$. The results of our study and the vitamin A iron interaction [10] should draw attention to the fact that lactating women are as equally vulnerable as their infants. Women need vitamin $A$ in increased amounts during pregnancy in order to support fetal growth and development, and to replace vitamin $A$ losses from their breast-milk during lactation. The need for vitamin A during lactation is greater than during pregnancy.

Severe drought during the past two years has left families in the Pokot pastoral, and in particular in farming communities, at severe risk of hunger. While men in the pastoral community roam the patched land looking for pasture for the cows, the women remain in more permanent homesteads. They spend most of their day looking after goats; a source of income critical for purchase of cereal. from the local markets. Prolonged drought in the farming community has had a devastating effect on household food security. Famine has become a reality since the patched land can no longer produce enough food for the family. With almost no cash crop, income for purchase of food is scarce.

Based on the fact that the Pokot women's way of life and their nutritional health are intricately intertwined, a number of recommendations can be made. A greater understanding and awareness of the specific roles that women play in both pastoral and farming communities, will help in the design and implemen- 
tation of household level intervention strategies aimed at bringing about changes in matemal and child nutrition. For any meaningful improvement in the Pokot infant's growth, one must first deal with those ways in which the health and nutrition of a woman are adversely affected by the existing lifestyles. Women need to be provided with the necessary resources that will enable them to fulfill their roles of ensuring household food security for their families.

In conclusion, a significant proportion of infants in the farming community had a birth weight of $<2.5 \mathrm{~kg}$ and an infant weight/age $z$ score of $<-2.00$. Maternal weights during the third trimester of pregnancy and at 4 months postpartum, were associated with neonatal weight and subsequent infant growth. Birth weight reflecting maternal nutritional status during pregnancy was the most important predictor of infant growth. Both pastoral and farming lactating women had breast milk vitamin A status that was inadequate to meet infant nutritional requirements and to build up their liver stores. Their marginal iron stores and the effect of their lifestyle on infant growth indicate that to achieve a measurable effect, future nutritional interventions need to ensure that women enter pregnancy with a good nutritional status, and that this is maintained throughout lactation

\section{Acknowledgments}

This study was carried out within the frame work of the Moi University and Maastricht University MHO/NUFFIC project. We are grateful for the facilitation role played by the dean Prof. B.O. Khwa-Otsyula and the former dean of the Faculty of Health Sciences, Prof. H.N.K. arap Mengech. Special thanks go to the chief, the village committees and the mothers of West Pokot communities. Special mention is made of Ms H Chesopo who provided invaluable support in sample collection and to Mr. M. Sang and Mr.L.C Kimile for facilitating sample analysis.

\section{References}

1. Prada JA, Tsang RC. Biological mechanisms of environmentally indenced catuses of IUGR Eur J Clin Nutr 1998; 52: $521-\$ 28$

2. Strauss RS, Dietz WH. Low maternal weight gain in the second on third trimester increases the risk for intrauterine growth retardation. J Nutr. 1999;129:988-993

3. Abraham B, Altiman SL, Picket KE. Pregnancy weight gain: stll controversial. A J Clin Nutr $2000,71: 1233 \mathrm{~S}-1242 \mathrm{~S}$

4. Kramer MS. Socioeconomic determinants of intratuterine growtin retardation. Eur J Clin Nutr. 1998;52:(S1) $\$ 29-\$ 32$ 
5. Pike IL. Pregnancy outcome for nomadic Turkana pastoralists of Kenya. Am J Phys Aatmopol. 2000; 13:31-45

6. Litte MA, Gray S1, Leshe PW. Growth of nomadic and settled Turkana infants of northwest Renya. Am J Phys Anthropol 1993;92:273-89

7. ACC/SCN. Fourth report on the world nutrition situation. Nutrition throughout the life cyde 2000 . Geneva: ACC/SCN in collaboration wh TPPRI.

8. De Ons $M$, Bloeener $M$, Villar J. Levels and patterns of intrauterine growth retardation in developing countries. Eur J Clin Nut. 1998; 52:5-15.

9. Underwood BA. Maternal vitamin A status and its importance in infancy and early childhood. Am J Clin Nutr 1994; 59:517\$-522S.

10. Surhano D, West CE, Muhilal, Karyadi D, Hautvast JGAJ: Supplementation with vitamin A and iron for nutritional anaemia in pregnant women in West Java Indonesia. Lancet $1993 ; 342: 1325-1328$

11. Scholl TO, Reilly T. Anemia fron and pregnancy outcome.J Nutr. 2000;130:443S-447S

12. Ortega RM, Andres P, Martinez RM, Lopez-Sobaler AM. Vitamin A status during the third trimester of pregnancy in Spanish women influence of concentrations of vitanuin A in breast milk. Am J Clin Natr. 1997;66:564-568

13. Stoltzfus $R$, Underwood B. Breast milk vitamin A as an indicator of the vitamin A status for women and infants. WHO Bulletin 1995; 73:703-711

14. Newman V. Vitamin A and breast- feeding: a comparison of data from developed and developing countries. Food Nutr Bull 1994;15:161-176

15. Muslimatun S, Schmidt MK, West CE. Schultink W, Hautvast GAJ, Karyadi D. Weekly vitamin $A$ and iron supplementention during pregnancy increase vitamin $A$ concentration of breast milk but not iron status in Indonesian lactating women. I Nutr. 2001;131:85-90.

16. Gibson R. Principles of Nutritional assessment. 1990. Oxford Uniwersity Press.

17. Yip R. Iron deficiency: Contemporary scientific issue and international programmatic approaches. J Nutr 1994;124:1479S-1490S.

18. UNICEF/UNU/WHO/MI. Preventing iron deficiency in women and children: Technical consensus on key issues. 1999 International Nutrition Foundation and Micronutrient Initiative.

19. WHO. Indicators for assessing witamin A deficiency and their application in monitoring and evaluating intervention programmes. 1996 WHO/NUT/96.10 Geneva:

20. Prentice $A_{\text {, Prentice }} M_{*}$, Whitehead $\mathbb{R}$. Breast-milk fat concentration of rural African women. Short-term variations within individuals. B J Nutr 1981, 45:483-494.

21. Lucas $A$, Gibbs $\int_{i}$ Lyster $R$, Baum J. Creanacocrit: simple clinical technique for estimating fat concentration and energy walue of human milk. B M J 1987; 22:1019-1020

22. Dorea $J G$. Subcutaneous fat changes in low-income lactating mothers and growth of breast -fed infants J An Coll Nutr 1995; 14 9(1):61-5

23. Andersson R, Bergstrom S. Maternal nutrition and socio-economic status as determinants of birth weight in chromically malnourished African women. Trop Med Int Health 1997: $2(11): 1080-7$

24. CBS. The Kenya Demographic and Health Survey 2003 hatp://www cbs go.ke

25. Newmann $\mathrm{CG}$, Harrison GC. Onset and exolution of stunting in infants and children. Examples from the Human Nutritio Collaborative Research Support Progranume. Kenya and Egypt studies. Eur J Clin Nutr 1994;48 (1):S90-S102

26. Tomkins A, Watson F Malnutrition and infection: a review. Geneva: UN/ACC/SCN 1989 Geneva Switzerland.

27. Pelletier D, Frongillo EA, Habicht JP. Epudemiologic evidence for a potentiating effect of malnutrition on child mortality. Am J Pub Health 1995;83:1130-1133 
28. Christian $\mathrm{P}$, West $\mathrm{KP} J \mathrm{r}$ Khantry $\mathrm{S}$. Night blindness during pregnancy and subsequent mortality among women in Nepal: Effects of vitumin $\mathrm{A}$ and b-carotene supplementation. Am I Epidemiology 2000;152:542-547

29. Ertyang GA, van Marken Lichtenbelt WD, Oloo A, Saris WHM. Serum retinol, iron status and body composition of lactating women in Nandi, Kenya. Ann Nutr Metab $2003 ; 47: 276-283$.. 


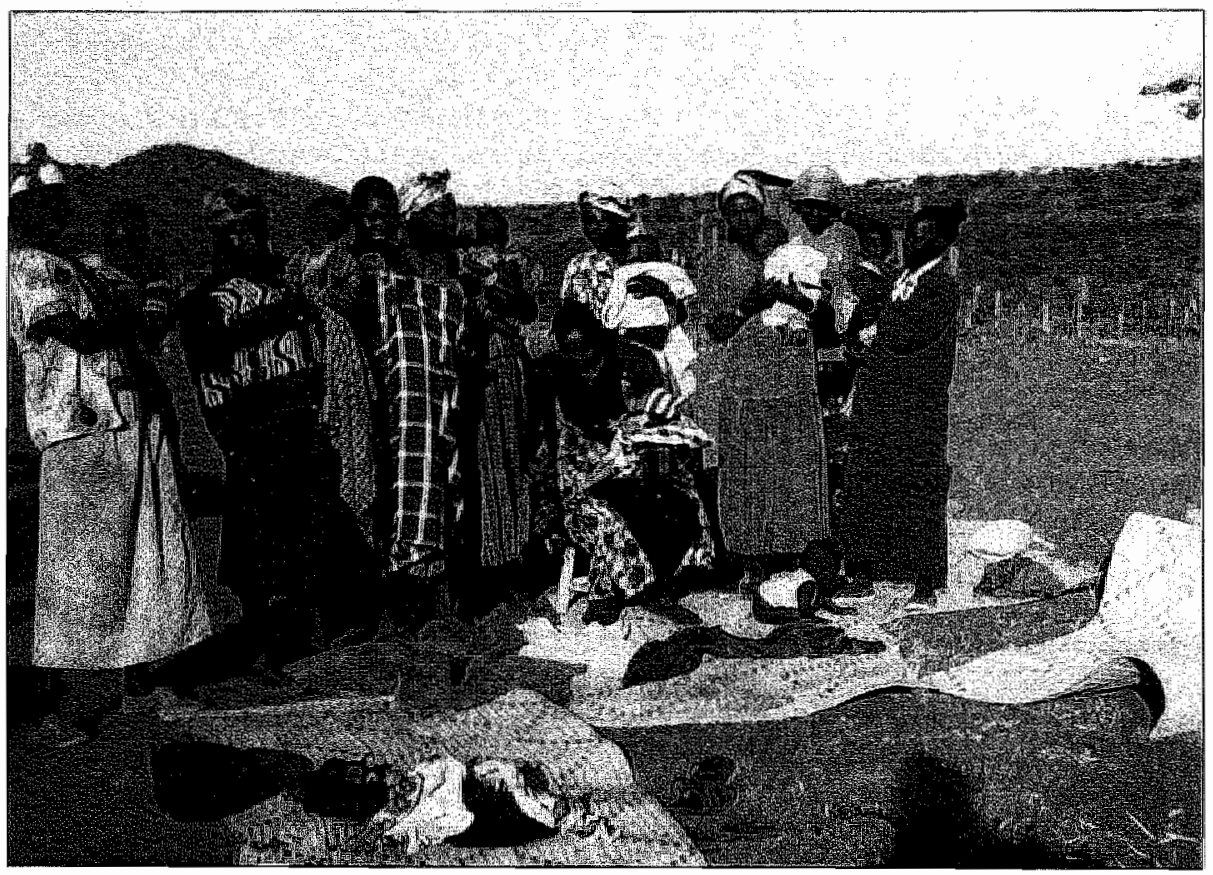




\section{General discussion}

In sub-saharan Africa, under-nutrition among the worst affected pastoral and farming households tends to be a function of declining food availability which is exacerbated by chronic food insecurity and prevalent infection. The magnitude and implications of the resulting reduced food intake cannot be brought into focus without directed attention towards two very vital factors. One, the little addressed issue of how the existing socio-economic and environmental conditions determine outcomes of under-nutrition, and two, the relatively untouched bigger problem of sub-clinical deficiency. Children under the age of five continue to remain in the spotlight mainly because the negative effect of under-nutrition on their growth and development is viewed as more urgent, and to some extent, more dramatic as the problems manifests early. On the other hand, women in sub-saharan Africa, despite exposure to chronic under-nutrition continue to fulfill stressful physiological obligations such as pregnancy and lactation. Among other things, optimal nutrition during these critical periods of a woman's life are generally affected adversely by the existing cultural and socio-economic systems.. Policy makers in the public health-system need to put more emphasis on strategies that aim to substantially reduce the prevalesce of macro- and micro-nutrient deficiencies in poor rural pregnant and lactating women in sub-salharan Africa.

The overwhelming aim of most of the reported nutritional benefits derived from the numerous laboratory based research and clinical trials is to contribute to the design of more specific, targeted government policies and implementation of community level approaches of tackling the root causes of under nutrition in specific vulnerable groups.

For a long time, a lot of emphasis was put in the implementation of various short-term measures to control severe micronutrient deficiency disorders. Yet the prevention of the multiple nutrient deficiencies that occur as a result of reduced food intake require life-long, adequate provision of mutrients. One reason for this trend has been the lack of community based data that describes 
the distribution of under-nutrition within and between specific communities and across vulnerable groups.

Accordingly, there is a three-fold purpose which this chapter seeks to fulfill and that includes: 1) taking the opportunity to point out the lessons learnt and the conclusions made from the research carried out in Nandi and West Pokot districts; 2) to highlight the implications from the research findings for public health prevention of under-nutrition in pregmant and lactating women; and 3) to identify and prioritize areas of future work. This will be done in light of the three objectives presented in the introduction of this thesis and rephrased as questions that were addressed.

A. Investigate factors underlying the prevalence of low body composition, iron stores, serum and breast milk vitamin $A$ in rural women.

B. Assess application in rural African field conditions and contribute to improved methods for assessing body composition and infant breast milk intake.

C. Investigate the role of lifestyle on maternal nutritional status during periods of pregnancy and lactation as well as on the first four months of infant growth.

Are low body composition, poor iron stores and prevalent vitamin $A$ deficiency a significant public health problem in lactating rural mothers?

\section{Lessons learnt and conclusions}

A high prevalence of vitamin A and iron deficiency was observed in lactating women. A reduced fat mass were directly related to these indicators of malnutrition [chapter 2$]$. The reduced fat mass observed in women of reproductive age is an outcome of inadequate food intake. Based on recent estimates of energy needs, humans can adapt to a range of energy intakes but at a cost whenever there are sustained deviations from required levels. This fact greatly diminishes support for the debate that has surrounded the "small is beautiful" proposition and the "adaptation to lower energy intakes view point" [1,2]. Socially acceptable and necessary levels of physical activity require adequate food intake. During chronic under-nutrition, the resulting maternal deficiencies in micronutrients such as iron and vitamin $A$, especially during the periods of pregnancy and lactation, are known to reinforce the severe effects of the malnutrition infection cycle and reduced work capacity $[3,4]$. 
Iron deficiency during lactation is a residual from that resulting from pregnancy and delivery. In Nandi women with a lactation period of $<4$ months, the Hct and serum retinol concentrations were highly significant factors that explained up to $41 \%$ of the total variation in reduced iron stores [chapter 2]. For Pokot women from the farming community, these factors were maternal education, parity and $\mathrm{Hb}$ compared to only parity and $\mathrm{Hb}$ for those living in a pastoral community [chapter 7]. Serum retinol levels in individuals are tightly regulated, they are indicative of vitamin A status in individuals only when body reserves are depleted or surpassed [5]. We found both Nandi and Pokot lactating women to be at high risk of vitamin A deficiency.

\section{Implications for public health}

Vitamin $A$ is a generic term for a group of retinoids with similar biological activity. The term includes retinal, retinol, retinoic acid and substances considered to be pro-vitamin $A$, because they can be transformed into retinol. Among the pro-vitamin $A$ compounds, $\beta$ carotene has the highest potential vitamin $A$ activity [5]. But compared to animal sources of vitamin $A$, the bioefficacy of a carotene in foods is reported to be low [6]. A food frequency survey completed by the Nandi lactating women, revealed a minimal intake of plant and animal sources of vitamin A even though availability was not a major limiting factor [chapter 3 ]. Though we have not reported on the dietary intake of the Pokot mothers it is likely to be low as well. Very often poor women cannot afford animal sources of vitamin $A$. Reduced intakes of animal sources of vitamin A may therefore be a significant factor in prevalent vitamin A deficiency. As shown for the Pokot lactating women [chapter 7] iron and vitamin A deficiency, combined with low maternal fat stores and heavy workloads, have negative effects on maternal nutritional status and as suggested by Allen [7] and on pregnancy outcome.

\section{Future research}

To make a significant change, interventions need to encourige consumption of both animal and plant sources of vitamin A [8]. In order to monitor and evaluate impact of these interventions Vitamin A measurement of plasma retinol concentrations is likely to be used. In communities living in Nandi and West Pokot districts where malaria is endemic, plasma retinol is likely to be reduced in clinical and sub-clinical infection. Due to this, there may be under estimation of the prevalence of vitamin A deficiency 19]. Hence in community interventions where improvement in vitamin A status is an outcome measure, this factor needs to be taken into account. Information about acute-phase proteins will enable plasma retinol concentrations to be corrected where sub-clinical infection exists, and will also allow the healthy sub-group to be identified. 
Is matemal breast milk adequate to maintain and build retinol reserves of the breast-fed infant?

\section{Lessons leant and conclusions}

Partially breast-fed infants may not receive appropriate foods with thigh vitamin A content and although exclusive breastfeeding is advocated, most breast milk is deficient in retinol there by further heightening the risk of vitamin A deficiency [Chapter 4]. Vitamin A content of breast milk is strongly influenced by maternal nutritional status [5]. It is therefore, not surprising to find lower amounts of vitamin $A$ in human milk, in regions were under-nutrition is wide-spread and mothers less frequently consume vitamin $A$ containing foods. Consequently, the concentration of vitamin $A$ in mature milk of women in Nandi and West Pokot was extremely low. In communities where vitarnin A deficiency is common, mature milk typically contains around $1 \mu \mathrm{mol} / 1$ of vitamin A (range from 0.4-1.8 $\mathrm{mmol} / \mathrm{l}$ ). In the Nandi [Chapter 2] and Pokot [Chapter 7] Jactating women, we observed a mean (SD) of $0.9(0.7) \mu \mathrm{mol} / 1$ and $1.0(0.7) \mu \mathrm{mol} / \mathrm{l}$ breast milk vitamin $\mathrm{A}$, respectively. Studies conducted in Indonesia have reported slightly lower values of $0.6(0.29) \mu \mathrm{mol} / 1[10]$. These observed reduced levels may be a direct result of the reduced intake of vitamin A of the mothers. As demonstrated in supplementation trials [11-13], breast milk vitamin $A$ will increase if the mothers intake of vitamin $A$ is increased.

\section{Implications for public health}

Nutritional status of lactating women in sub-saharan Africa has not been studied systematically, yet both the mother and her infant could gain from improved nutrition[14-16]. Retinoids are stored in the liver as esters and storage increases in the fetal liver during late gestation. The placenta regulates the passage of a sufficient anount of vitamin $A$ from mother to fetus in order to meet physiological requirements but not to build up a substantial body reserves. This tight regulation is believed to result in low hepatic reserves of vitamin $A$ at birth; even in infants born to well nourished mothers $[17,18]$. After birth, vitamin $A$ is transferred to the infant through breast milk. Infants of women with inadequate vitamin $A$ status are born with reduced reserves of vitamin $A$ and thus their vitamin $A$ status is likely to be protected for shorter periods than the status of infants born with higher reserves. Even when the breast milk vitamin A content is less than optimal, as is the case for Nandi and Pokot lactating women, a mother's milk is the best dietary source of vitamin A for a young infant. Breast milk protects the infant against infectious disease that may deplete vitamin A stores [19]. According to Stoltzfus and Underwood [20], the best evidence that vitamin $A$ levels in human milk corresponds to maternal vitamin $A$ status comes from areas where vitamin $A$ deficiency is endemic; in 
these populations, there is a significant improvement in the concentration of milk after maternal supplementation.

\section{Future research}

We have evidence to show that the reduced vitamin $A$ intake by the mother is an initial problem. Therefore, future research should be focused on how to improve the mothers vitamin $A$ intake. This can be done in a number of ways. For a long-term permanent solution to the problem, we recommend food-based approaches. To increase the dietary intake of vitamin A-containing foods by vulnerable groups, nutrition and social marketing interventions should be considered. The $\%$ creamatic method is recommended as a simple and easy technique for monitoring and evaluating impact of these interventions.

Under mul field conditions, how feasible and useful is the application of the deuterium oxide $\left(\mathrm{D}_{2} \mathrm{O}\right)$ dilution method for measuring maternal body composition and infant breast milk intake?

\section{Lessons leamt and condusions}

Compared to the deuterium oxide $\left(\mathrm{D}_{2} \mathrm{O}\right)$ dilution method, the skinfold technique may result in lower prediction of $\%$ body fat [chapter 3 ]. There is a possibility that lactating mothers practicing exclusive breast-feeding and living under harsh conditions may experience periods of reduced breast milk volume [chapter 5].

Information on the body composition of populations or individuals is important because body composition is an indicator of nutritional status. The WHO promote $\mathrm{BMI}$ as a crude indicator for weight judgment. The cut-off values are based on the relation of BMI with mortality and with risk factors for disease found in Caucasian populations [21]. While appropriate for large population surveys, the relationship between BMI and \% body fat differs among ethnic groups. There is a growing perception that because of differences in body build, frame size and possibly also other variables, there are differences in the relationship between BMI and body fat \% among ethnic groups. Africans often have higher bone density than Caucasians [22].

Body assessment techniques can be described as either mechanistic or descriptive [23]. Of these two techniques, the descriptive methods are easier to apply in field conditions that exist in rural communities of sub-saharan Africa. They include use of skinfold thicknesses that basically rely on a statistical relationship between easy measurable body parameter (s) and the body components of 
interest. Where peripheral subcutaneous fat may be almost absent, the use of skin fold thickness can be a very misleading indicator of total body fat [22]. In our study we followed Pokot mothers longitudinally and decided to use skinfold thickness measurements to determine the changes in \% body fat during periods of third trimester pregnancy and at four months after delivery. We acknowledged the fact that the statistical relationships used in the Durnin and Wontersley equation [24] for estimation of body fat are based on a Caucasian population. Analternative for determination of body composition was the use of deuterium oxide $\left(\mathrm{D}_{2} \mathrm{O}\right)$. The ready availability of $\mathrm{D}_{2} \mathrm{O}$ has led to its extensive use in body composition research [25] and in the estimation of infant breast milk intake $[26,27]$.

Compared to developed countries, studies on human milk intake of exclusively breast-fed infants from developing countries are very few [28-30] and in sub-saharan Africa hardly any have been done using $\mathrm{D}_{2} \mathrm{O}$. Prolonged exclusive breast feeding carries a risk of nutritional deficiency even in privileged populations. A longitudinal study done in three different ecological zones in Embu Kenya [31], concludes that when lactation is started with relatively poor fat stores, the result of this may be production of insufficient milk volume for promotion of optimal infant growth. Our sample was small because of the $\mathrm{D}_{2} \mathrm{O}$ technique used and only pastoral mothers were selected for the study. The low $\%$ body fat and breast milk volume observed in Pokot lactating mothers needs further verification.

\section{Implications for public health}

The likely variability $(5.8 \%-17.5 \%)$ observed in the skin fold thickness technique results in a lower accuracy of the prediction of \% body fat [chapter 3]. Accurate assessment of body composition indices continue to be necessary because determining changes in body size and composition provides important information on the consequences of lowered energy intake especially if sustained at low levels as is the case in rural communities of the developing world. 'This may be an important factor for community based nutritional interventions that are aimed at improving the body composition of vulnerable groups, such as pregnant and lactating women, or subjects with severe under nutrition.

Within the developing countries of the world, breastfeeding is the method of choice for feeding infants. The lack of data from developing countries seriously impedes evaluation of the human milk intake of exclusively breast fed infants. Evidence to date clearly indicates that few women exclusively breast feed beyond 4 months post-delivery [30]. Numerous socio-economic and cultural 
factors including maternal work demands, influence the decision to supplement human breast-milk.

\section{Future research}

Physical activity and maternal lactation capacity are among numerous factors that determine the need and the timing of complementary feeding. Particularly evident is the inadequacy of crucial data for evaluating the nutrient adequacy of exclusive breast feeding for the first 4-6 months of infant life. The $\mathrm{D}_{2} \mathrm{O}$ method offers the opportunity to simultaneously determine maternal body composition and breast milk output [26]. From our experience in Nandi and West Pokot, we suggest that the $\mathrm{D}_{2} \mathrm{O}$ method can be combined with other socio-economic, cultural and biological indicators thus providing a better understanding of the determinants of maternal body composition and breast-feeding patterns. This is likely to be possible if use of the Fourier transformed infrared spectrophotometer (FTIS) to measure $\mathrm{D}_{2} \mathrm{O}$ sample enrichment is made [29]. This new development should facilitate wider use of $\mathrm{D}_{2} \mathrm{O}$.

\section{During periods of pregnancy and lactation how can pregnancy outcome and infant grouth be affected by differences in matemal diet and life under harsh conditions?}

\section{Lessons leamt and conclusions}

Compared to pastoralists, the Pokot farming life-stylle with a much higher risk of experiencing a reduced food intake, was associated with negative changes in maternal body composition and micronutrient status during pregnancy and therefore it may partially determine pregnancy outcome [chapter 6]. During the first four months of life, infants in the farming community were more likely to be underweight than their counterparts in the pastoral community [chapter 7].

It was estimated in 1997 that about $53 \%$ of the rural and some $50 \%$ of the urban population of Kenya could be deemed poor. They have consumption and expenditure valued at less than Ksh. 1,239 (\$ 16.6) per AE per month [32]. West Pokot is regarded to be among the top-ten poor districts in Kenya. The harsh environmental conditions and the differences in pastoral and farming life-styles could be an important factor associated with this high poverty incidence. In both communities, frequent droughts may lead to the inadequate nutrient intake experienced by the women, and in turn, this may lead to poor pregnancy outcome and infant growth. Compared to the pastoral women, the effect of this level of poverty is more apparent among the Pokot farming women where maternal stature was found to be a positive predictor of newborn birth weight 
and maternal weight was a negative predictor of birth weight. The Pokot farming life-style was associated with negative changes in maternal body composition, iron stores and vitamin A status during the third trimester of pregnancy as well as four months after delivery

We did not have an effective method for identifying premature births. This could be evaluated more rigorously in future studies but we note that, the estimated relative risk of having a newborn birth weight of $<2.5 \mathrm{~kg}$ was 2.3 times higher for infants born to women living in the farming community than for those in the pastoral community. A reduced newborn birth weight in a socio-economically deprived community such as the Pokot farming community, leads to negative health consequences that reverberate throughout life [33].

Infant growth is the most commonly used functional outcome measure of nutrient adequacy. Its normal progression is dependent on many needs being met and many physiological processes proceeding normally. Optimal infant nutrient status relies on both exogenous sources and endogenous stores of nutrients. For breastfed infants these are met by human milk and endogenous nutrient stores transferred to the infant from the mother during gestation. In our study, we found that predictors of weight in four month old pastoral and farming infants were their birth weights, maternal weight during the third trimester of pregnancy and mid upper-arm circumference four months after delivery. For the infants born in the farming community these were birth weight, maternal $\%$ body fat and a serum retinol concentration of $<0.70 \mu \mathrm{mol} / 1$ during the third trimester of pregnancy. Thus, maternal body composition during the third trimester and micronutrient status were related to pregnancy outcome.

Similarly maternal weight during pregnancy, representing the maternal long-term nutritional situation was the most important determinant of birth weight in chronically malnourished women from the Central African Republic [34]. A Kenyan study [31] done in three different populations and ecological conditions reports that low pregnancy weight gain was common. Determinants of infant size at birth and during the first 6 months of life were maternal weight and fat gain during pregnancy and lactation. In our study, the Pokot farming community may equally be vulnerable due to the effects of climatic changes that are leaving their fields dry and bear.

In Kenya, early retardation of growth during infancy and throughout the second year of life has been reported in infants from the semi-arid area of the Embu 
district [29]. In our study, in both pastoral and farming communities infant weight/age $z$ scores deviated below the NCHS/WHO reference population. Protein energy malnutrition (PEM) in infants manifests as growth retardation. Where PEM is prevalent, it is inevitable that other nutrient deficiencies will also be present. Up to $80 \%$ of the infant mortality associated with under-nutrition is attributable to mild and moderate malnutrition [35]. In rural communities of sub-saharan Africa, interventions aimed at improving maternal and child nutrim tion [36] should have an appropriate mix of acceptable and affordable strategies including the promotion of breast-feeding and the control of infections as well as dietary diversification [37]

\section{Implications for public health}

Food and nutrition along with different life-styles are recognized as the principal environmental components affecting a wide range of disease that have public health significance. Societal characteristics that determine human behavior and economic well being, as well as climate, tradition, and culture, all affect food patterns and dietary practices. We have shown that in West Pokot, the geographic distribution of under-nutrition or well-being is likely to vary considerably. Such knowledge is a first step towards understanding what determines this pattern, what drives these outcomes at community level, and ultimately for formulating and implementing pro-poor development strategies that are both effective and inclusive. Improving nutritional status of women, now more than before, needs greater focus. [38]. Ensuring proper nutrition throughout the life of women enables them to have a much healthier life to pursue their multiple responsibilities. This will safeguard the nutrition of infants, children and indeed future generations $[33,39]$.

Based on the fact that the way of life for the women living in Pokot, and their nutritional health are intricately entwined, a number of recommendations can be made. A greater understanding and awareness of specific roles that women play in both pastoral and farming communities will help in the design and implementation of household level intervention strategies aimed at bringing about changes in maternal and child nutrition. For any meaningful improvement in the Pokot infant's growth, one must first deal with those ways in which the health and nutrition of a woman are adversely affected by their existing lifestyle. Women need to be provided with the necessary resources that will enable them fulfill their roles of ensuring household food security for their families.

\section{Based on data obtained from our studies [Chapter 5, Chapter 6 and Chapter} 7] we suggest that Pokot pastoral and farming households should be empowered to reduce maternal workload during pregnancy and be helped to ensure that 
pregnant and lactating mothers eat well. The government should therefore find ways in which basic mother and child health-care can be provided. Strategies that ensure household food security should be put in place [40]. Use of our data from the West Pokot district to promote and advocate a plan of action will potentially be a powerful way of helping to enhance accessibility of resources that are critical in the fight against the high level of under-nutrition and micronutrient malnutrition observed in the pregnant and lactating women of this area. Their pastoral and farming communities are in dire need of help for developing their ability to make use of the present trend in the rapid decentralization of public resources. They should no longer be overlooked by central authorities, and therefore should not lose out, but be empowered to participate in activities critical for the development of their communities $[33,41]$.

\section{Future research}

It is recognized that newborns of reduced weight $(<2.5 \mathrm{~kg})$ have increased risk of infection and death during the neonatal period and infancy. In this study, due to field logistics, LBW combines those babies that may have been pre-maturely born (BWT $<2500 \mathrm{~g}$ and gestation age $<37$ weeks) and those that may have been small for their gestational age (BWT $<2500 \mathrm{~g}$ and gestation age $>37$ ) often termed intrauterine growth retarded (IUGR). Data on the prevalence of LBW in rural developing countries does not distinguish between pre-term babies and babies with IUGR [42]. From our experience, a contributing factor could be the limited access to health care and the belief in and the practice of using traditional birth attendants. This needs further research. In a study examining the range of traditional and spiritual concepts surrounding pregnancy and child birth, women in Guinea Bissau had beliefs and practices that prevented appropriate nutrition, antenatal and delivery care. The women's knowledge of danger signs and risk factors was virtually absent. The perceived curative orientation of antenatal services results in their under-utilization [43].

Studies are needed on how to improve the household food security of these women, in particularly in the Pokot farming community as it is more at risk in situations of extreme weather conditions. To contribute towards empowering these communities and stimulating more efficient allocation of limited resources, further exploration should be made into outcomes and factors underlying the differences in poverty incidence rates reported for West Pokot. Combined with the nutrition status data that we provide, analysts and policy makers can be assisted in the designing and monitoring of possible poverty alleviation measures. 


\section{A personal view on community level approaches of how to improve the matemal mutrient intake of pregnant and lactating women from Nandi and Pokot.}

In communities at risk of under-nutrition any meaningful improvement must first deal with those ways in which health and nutrition of the women are adversely affected by the existing social, cultural and economic systems. It must go beyond the provision of health and nutrition services and recognize that nutritional problems have their origin in social and economic systems [44]. The United Nations Millennium Declaration (General Assembly resolution 55/2) [45] adopted 8 September 2000 has the first goal as eradication of extreme poverty and hunger. In Kenya the Millennium Development Goals (MDGs) were officially launched in January 2005 , five years after adoption by the general assembly of UN. As long as these MDGs remain stated but unachieved, their greatest burden will be borne by the pregnant and lactating women living in the most remote rural areas of sub-saharan Africa. Given that all the issues around poverty are interconnected and demand cross-cutting solutions, interventions need to aim at having people centered initiatives that are supplemented with sound national policies. An education policy that provides the skills that can lift families out of extreme poverty and preserve community health would be a step in the right direction. In particular, when society facilitates girls' empowerment through education, the eventual impact on their and their families' daily lives is unequalled. To improve maternal and newborn health care requires a health policy that aims at increasing access to health services and promotion of appropriate community practices in support of safe motherhood and reduction of under-five mortality.

Based on the results of the research work described in this thesis we llave made a contribution towards beginning to reduce the existing information gap on the little addressed issue of how the socio-economic/environmental conditions are likely to impact on the body composition, iron stores, and vitamin A status of pregnant and lactating women in rural Kenya. Such data is critical in the design and implementation of more specific targeted policies and possibly generation of further insights into potential community level approaches for tackling the root causes of such rampant high levels of poverty that lead to poor maternal and infant nutritional status.

Pastoral and farming Pokot women are veteran goat herders. Unfortunately, decisions on how income from their sale is used, rests with their husbands. With a milk production of about 200 milliliters per day, the goats are hardly consid- 
ered a source of milk for the family. This is a situation that could be changed. Through the Ministry of livestock and fisheries development, very useful lessons have been learnt on keeping cross-breed goats. Such a project has been implemented in Meru District where 114 farmer separated into groups of 25 nembers each, have formed the Meru Goat Breeders Association (MGBA). On average each farmer keeps four milking Toggenburge - East African goats and one buck. Each goat produces about four liters of milk daily ${ }^{1}$. The animals achieve excellent growth and mature body sizes with one-year olds reaching 45 $\mathrm{kg}$. These cross breed goats have a fairly high disease and heat tolerance with a very high market value. Women all over Kenya, including those living in West Pokot, are forming groups with the aim of improving their health and economic situation. Through these groups, implementation of a project such as the MGBA will have many benefits. This may provide an opportunity to train the women in key aspects of goat husbandry, group dynamics and leadership skills. Ownership of goats will provide much needed additional milk for the family. Their sale will provide some degree of economic freedom for the women.

A lot of the sunflower plant is grown in the rift valley province. Available now is a village-based technology for production of sunflower oil. Put in the hands of women, especially in Nandi, such a project can have many benefits. The oil produced can be used to improve energy density of their food intake. Oil production can be made a communal activity and once a certain amount is made available to the families, the surplus can be sold. Activities related to the project could include health and nutrition counseling. Income generated by the sale of oil can be re-invested in the project to eventually create a viable and sustainable sunflower oil for the better health project.

\section{References}

1. Shetty PS, Henry C1, Black AE, Prentice AM. Energy requirements of adults; an update on basal metabolic rates (BMRs) and physical activity lewels (PALs) Eur J Clin Nutr. 1996:50 Suppl 1:511-23

2. Shetty $\mathrm{PS}$. Adaptation to low energy intakes: the response and limits to intakes in infants, chilclen and adults. Eur I Clin Nutr. 199953 Suppl 1:S14-33

3. Dallman PR. Iron deficiency and the immune response. Am J Clin Nutr 1987;46:329-34

4. Haas JD Brownlic T. Iron deficiency and reduced work capacity: a critical review of the research to determine a causal relationship. J Nutr 2001;131:6765-905 
5. Bender DA. The vitamins. In: Introduction to Human Nutrition. First Bd. Michael j Gibne Hester H Worster, Franks ] Kok eds. Blackwell Science GB 2002 pp 125-136

6. van Lieshout $M$, West $C E$,Muhilal, Permaesih D et al. Bioefficacy of B-catotene dissolved in oil studied in children in Indonesia. A J Clin Nurr 2001,73,949-958

7. Allen LH Aneamia and iron deficiency: eftects on pregnancy outcome. Am J Clin Nutr 2000:71:1280S-4S.

8. de Pee S, Bloem MW, Satoto, Yip R. Sukaton A et al Impact of sacial marketing campaign promoting dark-green leafy wegetables and eggs in central Jawa, Indonesia. Int J Vitamin Nutr Res, 1998;68(6):389-98.

9. Wieringa F T, Dijkhuizen M A, Clive E. West C E, Northrop-Clewes C A \& Muhilal Estimation of the Effect of the Acute Phase Response on Indicators of Micronutrient Status in Indonesian Infants J Nutr.2002; 132:3061-3066.

10. Muhilal, Permeisil D, Idjadinata YR, Muherdiyantiningsih et al. Vitamin A-fortified monosodium glutanate and healt], growth and surwiwal of children: a controlled field trial. Am J Clin Nutr. 1988;48(5):1271-6

11. Muslimatun S Schmidr MK West CE Schultink W Hautwast JGAI Karyadi D. Weekly vitamin $A$ and iron supplementation during pregrnancy increases vitamin A concentration of breast milk but not iron status in Indonesian lactating women.J Nutr 2001; 131:2664-2669.

12. Rice AL Stoltzfus RJ de Francisco A Chakraborty J, Kjolhede CL Wahed MA. Maternal vitamin $A$ or (1- carotene supplementation in lactaring Bangladeshi women benefits mothers and infants but does not prevent sub-clinical deficiency. I Nutr. 1999;129:356-65

13. Humprey JH Amy LR: Vitamin A stupplementation of young children. Lamcer: 2000; 356:422-424

14. Stoltzfus RJ Underwood BA. Breast-milk vitamin A as an indicator of the vitamin A status of women and infants. Bull WHO 1995:73:703-711.

15. WHO. Safe vitamin A dosage during pregnancy and lactation. The micro nutrient initiative. 1998 WHO/NUT. 98.4

16. Underwood BA. Maternal vitamin A status and its importance in infancy and early childhood. Am J Clin Nutr. 1994;59 (2): $517 \mathrm{~S}-522 \mathrm{~S}$.

17. Oslon JA, Gunning DB, Tilton RA. Liver concentrations of vitamin A and carotenoids, as a function of age and other parameters, of American children who died of various causes. Am II Clin Nutr. $1984 ; 39(6): 903-10$

18. Zachman RD . Retinol (vitamin A) and the neonatespecial problems of the human premature infant. Am J Clin Nutr. 1989:50(3):413-24

19. West KP Jr, Katz J, Shresha SR et al Mortality of infants < 6 months of age supplemetuted with vitamin A: a randomized double-masked trial in Nepal. Am I Clin Nutr $1995 ; 62: 143-48$.

20. Stoltzfus RJ, Underwood BA. Breast-milk witamin A as an indicator of the vitamin A status of women and infants. Bull World Health Organ. 1995;73(5):703- 11

21. WHO. Obesity: preventing and managing the global epidemic Genewa: W/HO 1998

22. Deurenberg P Roubenoff R. Bady composition In: Introduction to Human Nutrition . First Ed. Michael J Gibney, Hester H Vorster, Franks I Kok eds. Blackwell Science GB 2002 pP $12-30$

23. Wang ZM Heshka S Pierson Jr Heymsfield SB. Systematic organization of body composition methodology: an overview with emphersis on component- based methods An J Clin Nutr1995:61:457-4.65

24. Durnin JVG Womersley J: Body fat assessed from total body density and its estimation from skinfold thickness: neasurements in 481 men and women aged from 16 to 72 years. B. J Nutr 1974; 32:77-97 
25. Westerterp KR Wouters $L$ wan Marken Lichtenbelt WD: The Mastricht protocol for the measurement of body composition and energy expenditure with labeled water. Obes Res 1995 [suppl] 3:49-57.

26. Coward $W A_{\text {s }}$ Cole TJ, Sawyer $M B$, Prentice AM. Breast-milk intake measurement in mixed fed infants by administration of deuterium oxide to their mothers. Fum Nutr Clin Nutr. 1982;36(2):141-8.

27. Fjeld $\mathrm{CR}$, Brown KH, Schoeller DA. Validation of the deuterilum axide method for measuring average daily milk intake in infants Am J Clin Nutr 1988; 48:671-679.

28. Butte NF Villalpando S, Wong WW, Flores-Huerta s et al. Human milk intake and growth faltering of rural Mesoamerindian infants. Am J Clin Nutr 1992;55(6):1 109-16.

29. Caire $G$, Calderon de la Barca AM, Bolanos AV et al. Measurement of deuterium oxide by infrared spectroscopy and isotope ratio mass spectrometry for quantifying daily milk intake of breast fed infants and maternal body fat Food Nut Bull 2002;23(3) 38-41.

30. Butte NF Nutrient adequacy of exclusive breast feeding for the term infant during the first six months of life. World Health Organization 2002 WHO Geneva Switzerland.

31. Newmanin CG, Harrison $G C$ Onset and evolution of stunting in infants and children. Examples from the Human Nutrition Collaborative Research Support Programme. Kenya and Esgypt studies. Eur J Clin Nutr 1994:48 supp 1:590-102.

32. Incidence of poverty in Kenya www.Worldbank.org/research/poverty maps/Kenya.

33. ACC/SCN (2000). Fourth report on the world nutrition situation. Nutrition throughout the life cycle. Geneva: ACC/SCN in collaboration with IFPRI

34. Andersson R, Bergstrom S. Maternal nutrition and socio-economic status as determinats of birth weight in chronically malnourished African women. Trop Med Int Health 1997: 2(11):1080-7

35. Pelletier D Frongillo EA Habiche JP. Epidemiologic evidence for a potentiating effect of malnutrition on child mortality. Am J Pub health 831995 pp $1130-1133$

36. Underwood BA Arthur P.(1996) The contribution of vitamin A to public health. FASEB Journal 10(9): 1040-8

37. Kramer MS (1993). Effects of energy and protein intake on pregnancy outcome: An overview of the research evidence from controlled clinical trials. Am J Clin Nutr 58, 627-635.

38. ACC/SCN. Women and nutrition - Nutrition policy discussion paper No.6 (ACC/SCN) 1990.

39. Schuftan C Ramalingaswami V Levinson FI. Micronutrient deficiencies and protein energy malnutrition Lancet $1998 ; 351: 1812$

40. ACC/SCN. Adequate food: A human right . SCN News 1999; 11-90

41. World bank. Nutrition programming at the community level in Sri Lanka; changing. behavior and reducing serious malnutrition. 1999. Washington. DC: World Bank

42. ACC/SCN News (1994) Maternal and child nutrition (ACC/SCN) No 11

43. Oosterbaan MM da Costa MV.(1195) Guinea-Bissan: What women know about the risks an anthropological study. World - Health - Satat -Q 48 (1):39-43.

44. Ettyang GA. A community based health intervention programme in pastoral and agricultural Pokot communities in Westem Kenya. Acta Paediatr. 1999:429:42-2

45. UN: Millennium Declaration. General Assembly. Fifty fifth session. Agenda item 60 (b) $18^{\text {th }}$ September 2000. UN. A/RES/55/2 wwwallAfrica.com 


\section{Summary}

Malnutrition, has for a long time, been one of the worst public health problems that face countries in sub-saharan Africa. Inadequate access to food and health care remains prevalent in specific regions of most countries within sub-saharan Africa. Without a balanced intake of macro- and micronutrients, the human body cannot maintain the biochemical and metabolic processes associated with healthy growth and development of its' organs, or supply energy for physical activity. Accordingly, good nutrition is a critical requirement of life and the proper mix of nutrients under clean and safe conditions must be available to all. Within any society, the provision of a nutritious food supply depends on the complex interplay between factors including the environment, economic and social structures, food production knowledge and technology and human behavior. In the past, it has been tempting to single out one factor, or even a few factors contributing to the complex interplay between nutrition and health, and think that they can somehow be resolved in isolation. The continued existence of undernutrition and therefore micronutrient malnutrition in sub Saharan Africa makes it clear how unrealistic such an approach is.

For women living in countries within sub-sahara Africa and who are pregnant or lactating, the conditions of anaemia and iron deficiency remain high. In addition, there is an increased risk of infection, blindness and death for children of pre-school age because they too are vitamin A deficient. These findings reflect how poor nutritional status combined with a poor economic status and hence poor human rights, result in poor health. For nutrition to be promoted as the corner stone of social and economic development, we need to use valid indicators to increase our understanding of how inadequate access to food, combined with an inadequate health-care system, has continued to result in serious malnutrition of epidemic proportions.

Between October 1998 and September 2001, we conducted studies within the farming and pastoral communities of Kenya. The aim of these studies was to contribute to the development of programmes designed to prevent macro- and micronutrient deficiency in women who were living in rural communities in sub-saharan Africa, and who were pregnant and lactating.. The immediate objectives were: 1) to investigate factors underlying the prevalence of low body composition, iron stores, and vitamin A levels in serum and breast milk ;2) to 
examine the validity of methods used for assessing body composition and infant breast milk intake in rural Africa; 3) to investigate the role of lifestyle on matemal nutritional status during periods of pregnancy and lactation, as well as on the first four months of infant growth. Lactating women $(\mathrm{n}=88)$ were recruited from 7 farming villages within the rural community of the Nandi. In addition, women who were $28-36$ weeks pregnant $(n=250)$, were recruited from 8 pastoral and 6 farming villages located in the community of the Pokot; for a longitudinal study, 223 of these women were retained until their infants were approximately 4 months of age.

In the Nandi study, lactating women were found to have a high prevalence of anaemia and sub-clinical levels of vitamin $A$. The women with a low concentration of vitamin $\mathrm{A}$ in their breast milk had a lower serum retinol concentration $(\mathrm{P}<0.05) .11 .4 \%$ of the infants born to these women and who were breast-fed, were found to have a weight-for-age Z score of $<-2.00 \mathrm{~A}$ total of $78 \%$ women had breast milk retinol $<1.05 \mu \mathrm{mol}$. The prevalence of severely deficient serum retinol $<0.35 \mu \mathrm{mol} / 1$ was $10 \%$. For the $37 \%$ women with serum ferritin $<12$ $\mu \mathrm{g} / 1$ was found a significantly lower average hemoglobin ( $\mathrm{p}<0.01)$, heamatocrit $(p<0.01)$ and serum retinol $(p<0.05)$. The women who had lactated for $<4$ months were $38 \%$. In this group of women serum retinol was significantly but negatively correlated with total body fat $(\mathrm{r}=-0.40 ; \mathrm{p}<0.05)$. A close relationship was also found between serum retinol and hemoglobin $(r=0.26 \mathrm{p}<0.01)$, serum retinol and serum ferritin $(r=0.20 ; p<0.05)$. Their fat free mass was significantly but negatively correlated with breast milk fat $(r=-0.27 ; p<0.05)$. In the Nandi study population important predictors of maternal $\mathrm{Hb}$ were the serum retinol concentration and \% body fat. An important interaction between vitamin A status, iron stores and body composition was established [Chapter 2].

The accuracy of the skinfold method (SF) for measuring body composition was validated against the deuterium method $\left(\mathrm{D}_{2} \mathrm{O}\right)$. Ten women who were breast-feeding infants aged 2-3 months were measured using both body composition methods. The variability $(5.8-17.5 \%)$ observed in the SF technique may result in lower prediction of $\%$ BF. This may be an important factor for community-based nutritional interventions that aim at improving the body composition of vulnerable groups such as pregnant and lactating women, or subjects with severe under nutrition [Chapter 3].

Decades of exclusive support for children's programmes have meant neglect of the welfare of the lactating woman. The ability to produce nutritionally adequate breast milk that is required for the normal growth and development of 
infants may be compromised when lactating women consume nutritionally deficient diets. A dietary survey revealed a very low intake of vitamin $A$ from both plant and animal sources. Both mother and infant were at high risk from a low intake of foods that are rich in vitamin A. Infants who are breast-fed may not receive the appropriate foods that are rich in vitamin A. In addition, although exclusive breastfeeding is advocated, most breast milk is defictent in retinol, further heightening the risk of vitamin $A$ deficiency [Chapter 4].

Infant milk intake and maternal body composition $(\mathbf{n}=10)$ by 'the-dose-to-the-mother' method was used to evaluate the breast milk intake of exclusively breast-fed pastoral infants. During the period of evaluation, the infant mean (SD) weight gain was 20(4) g/day. Milk intake was estimated to be $555(22) \mathrm{ml} /$ day. The estimated gross energy content was significantly lower $(\mathrm{p}<0.05)$ compared to recommended intake. Data from this study on the volume of breast milk produced, suggested for this group of infants that adequate growth may not be achieved. There is a possibility that lactating mothers practicing exclusive breast feeding and living under harsh conditions may experience periods of low breast milk volume. Body composition and biochemical findings among this group of Pokot pastoral mothers indicate dietary inadequacies that require nutritional intervention [Chapter 5].

We went further to investigated the effect of differences in diet and life under harsh conditions on body composition, iron stores, and vitamin A status, in women living in pastoral and farming Pokot communities who were pregnant or lactating. The estimated relative risk of having a new-born infant with a birth weight $<2.5 \mathrm{~kg}$ was 2.3 times greater for women living in the farming community than for those in the pastoral community. The serum retinol concentration measured during lactation as well as \% body fat during pregnancy were predictors of lactation \% body fat in both pastoral and farming women. An additional predictor for the pastoral women was $\mathrm{Hb}$ concentrations measured during lactation. Predictors of pregnancy outcome were parity and bicep and tricep skinfold measurements for the pastoral women whereas for the farming women, the predictors were parity, height and $\%$ body fat. In both pastoral and farming women, predictors of serum ferritin were parity and $\mathrm{Hb}$. A third predictor of for the farming women was the years of formal education. Compared to pastoralists, the lifestyle of the Pokot farmers, with its' inherently higher level of risk for food shortages, was associated with negative changes in maternal body composition and micronutrient status during pregnancy. Accordingly, it can be speculated that the farming lifestyle may partially determine pregnancy outcome [Chapter 6 ]. 
There was also a need to further investigate the prevalence and risk factors associated with Pokot infants being underweight from birth until 4 months of age. Pastoral infants had significantly higher neonatal weight $(\mathbb{P}<0.05)$, and at 4 months of age they also had a higher weight/age $z$ score $(P<0.05)$. At 4 months of age, $16 \%$ of infants in farming and $21 \%$ of infants in the pastoral communities, had a Wt/Age $z$ score $<-2.00$. The estimated relative risk of Wt/Age $z$ score $<$ -2.00 was 1.5 times greater for infants aged 4 months and who were born to women living in the farming community as compared to those born to women living in the pastoral community. Predictors of the weight of pastoral infants at the age of 4 months were birth-weight, maternal weight during the third trimester of pregnancy, and midupper arm circumference of the mother when the infant was 4 months old. For the infants born in the farming community, the predictors were birth-weight, maternal $\%$ body fat during the third trimester,and maternal serum retinol $<0.70 \mu \mathrm{mol} / 1$. Half of the lactating women had a breast milk vitamin $A$ concentration $<1.05 \mu \mathrm{mol} / 1$ and $29.8 \%$ had a serum retinol concentration $<0.70 \mu \mathrm{mol} / \mathrm{l}$. In the pastoral community, the predictors of breast milk retinol concentration were serum retinol concentration during pregnancy of $<0.70 \mu \mathrm{mol} / 1$ and $\%$ body fat of the mother 4 months after delivery of their infant. For the farming women, the predictors were age, serum ferritin concentration during pregnancy and body mass index of the mother four months after delivery. During the first four months of life, the infants in the farming community were more likely to be underweight than the infants in the pastoral community. Women living in pastoral and farming communities had vitamin A concentrations in their breast milk that were inadequate to meet the nutritional requirements of their infant and to build up infant liver stores [Chapter 7].

In mothers who may appear otherwise healthy, marginal vitamin A deficiency is likely to compromise iron stores. This makes it imperative to prevent maternal iron and vitamin A deficiency so that the true long-term benefits of these two nutrients are realized for both the mother and the infant. To achieve a measurable effect, future nutritional interventions for communities at risk of low food intake must ensure that women enter pregnancy with a good nutritional status. In addition, this nutritional status must be maintained throughout lactation. The basic information regarding under-nutrition and micronutrient deficiencies in a rural society that we have described within this thesis has until now been largely unavailable. Our findings provide essential background information for planning nutrition interventions in a manner that will enhance the human rights of the women and children and be most conducive to improvement of the lifestyles of those living in the Pokot community. 


\section{Acknowledgment}

This Thesis is the result of five years of research work. This was made possible by the collaboration between Moi University and Maastricht University in the Netherlands MHO/NUFFIC Project. This enabled me to work closely with Dr. W.D. van Marken Lichtenbelt from the department of Human Biology at Maastricht University. Through visits to the Netherlands I was also able to meet Prof. W.H.M. Saris the director of NUTRIM Mastricht University. All the field work was done in Kenya. I am grateful for the role-played by my dean Prof. B.O. Kwa-Otsyula and the former dean of the Faculty of Health sciences Prof. H.N.K. Mengech. Their keen interest and concern ensured continuation of the collaborative project thus enabling me finish the research work. Prof. M. de Vries who inspired me to do research work in West Pokot.

Dr. W. D. van Marken Lichtenbelt you were instrumental in keeping me going especially during a very difficult personal period for this I am grateful. Your visits to the field were a source of encouragement. Prof. Saris I am grateful to you for allowing me to learn from my mistakes and for giving me time to adjust not only to the Dutch weather but also to the PhD programme as well. Through your untiring support, preparation of articles for publication has been possible and this thesis written.

During my fieldwork in Nandi and West Pokot districts, I received tremendous support from both individuals and organizations. Special mention and thanks go to Prof. D. Ngare for his useful suggestion during the early stages of the research work. Prof Oloo for support and supervision of the research during his stay at the Faculty of Health Science. Dr. J. Wakhisi for his tremendous help and support in setting up the HPLC machine and providing very useful suggestions on sample analysis. Prof F. Esamai for his invaluable suggestions and review of the articles in this thesis. Dr D. Ayuku my colleague in the programme for moral support and encouragement. Very special thanks go to my colleagues in the Department of Human Nutrition and Dietetic especially Ms S. Korir for very ably shouldering a heavy teaching load while managing the department.

The Nandi study would not have been possible without the comoperation of the Mosoriot Health centre staff and the assistant chief Ms Monica whose keen interest in the welfare of women facilitated use of the village elders in the 
recruitment of women into the study Nandi study. The former Medical Officer of Kapenguria District Hospital Dr. Mutanya for help with accommodation and use of the hospital laboratory facilities. The Anglican Church programmes co-ordinator Mr. D. Ngimor for availing his field staff and allowing me to use his project area to recruit the mothers for the Pokot study. The members of the village health committees for Ortum, Morbus, Kerelwa, Kosolol, Sobokwo and Shepkobegh for their untiring effort in keeping track of the mothers in the study areas.

I also want to thank Mr. Kimeli for help with sample collection for the Nandi study and analysis at the Moi Teaching and Referral Hospital. Ms H. Chesop for help with sample collection for the Pokot study. To both Mr. Njoroge and $\mathrm{Mr}$ Musonik for setting up the HPLC machine and sparing time to ensure that urgent lab work was done in good time. Mr. W. Emonyi for his expertise in the use of the ELIZA machine.

Finally, I wish to express my deep appreciation to my family for all their inspiration and moral support. 
Your children are not your children

They are the sons and daughters of life's longing for itself

They come through you but not from you

And though they are with you,

Yet they belong not to you.

You may give them your love

But not your thoughts

For they have their own thoughts.

You may house their bodies

But not their souls

For their souls dwell in the house of tomorrow

Which you cannot visit not even in your dreams.

You may strive to be like them but

Seek not to make them like you.

For life goes not backward nor tarries with yesterday

KAHLIL GIBRAN 


\section{About the author}

Grace Adisa Ettyang was born in Kenya on $18^{\text {th }}$ December 1952. She graduated with honors in 1976 from the University of Nairobi and qualified as a recognized teacher with the Ministry of Education to teach Foods and Nutrition at secondary schools. She opted to work for the Ministry of Health as a Nutritionist in 1977 and in 1978 received a British Government scholarship to study Human Nutrition further at the London School of Hygiene and Tropical Medicine (University of London) and obtained a post graduate diploma in Human Nutrition in 1979. After some work experience as a nutritionist and the deputy principle of the Ministry of Health Karen College of Nutrition, she undertook post-graduate studies at the University of Nairobi and obtained her M.Sc. in Human nutrition in 1989. She went to Zambia in 1990 and worked as a FAO Nutrition consultant on a vitamin A project for Luapula Province. At the end of the one-year contract she came back to Kenya in 1991 and joined Moi University, Faculty of Health Sciences as a lecturer in Human Nutrition. During her work at the Faculty of Health Sciences, she streamlined the incorporation of Human Nutrition in the medical, nursing, and envirommental health programmes. With the establishment of the Institute of Public Health she developed courses for the MPH Nutrition Tract. Between 1993 and 1996 she served as the chairperson for the Faculty of Health Sciences Community Based Education programme (COBES). She was appointed to act as the head of department of health management and health economics in 1996. She helped establish the department of human nutrition and dietetics and was appointed its acting head in 1998. Between 1998 - 2000 she combined teaching and administrative responsibilities with her $\mathrm{PhD}$ research work in Nandi and West Pokot districts. She was granted a two-year study leave to carry out the field work in West Pokot District. The lab analysis done for the research work has helped establish at the Faculty of Health Sciences a state of art HPLC machine. She carried out the work described in this thesis within the framework of the collaboration between Moi University and Maastricht University MHO/NUFFIC Project. Upon completion of her PhD work she will resume her teaching responsibilities at Moi University. As a result of the research reported in this thesis, she has been requested to offer nutrition consultancy services to the Millennium Village projects being implemented in Bar Sauri Kenya and several other sites in Africa. In collaboration with Columbia University Institute of Human Nutrition she is involved in establishing a nutrition reference and research laboratory at Moi University. 
Research papers

G.A. Ettyang, W.D. van Marken Lichtenbelt, A. Oloo and W.H.M. Saris. Serum retinol, iron status and body composition of lactating women in Nandi Kenya. Annals of Nutrition and Metabolism 2003;47:276-283.

G.A. Ettyang, WD van Marken Lichtenbelt, A. Oloo, W.H.M. Saris. Consumption of Vitamin $A$ by breastfeeding children in rural Kenya. Food and Nutrition Bulletin 2004; 25(3):256-263.

G.A. Ettyang, W.D. wan Marken Lichtenbelt, W.H.M. Saris, K.R. Westerterp. Assessment of body composition in lactating mothers in a rural African community using deuterium oxide dilution. South African Joumal of Clinical Nutrition 2004;17(1):10-15.

G.A. Ettyang, W.D. van Marken Lichtenbelt, W.H.M. Saris. K.R. Westerterp Assessment of body composition and breast milk volume in lactating mothers in pastoral communities in Pokot, Kenya, using deuterium oxide. Annals of Nutrition and Metabolism 2005:49;110-117.

G.A. Ettyang, W.D. van Marken Lichtenbelt, F. Esamai W.H.M. Saris. Differences in body composition, iron stores and vitamin A status between pastoral and farming women in West Pokot, Kenya, during late pregnancy and early lactation. (Conditionally accepted and under correction; Food and Nutrition Bulletin)

G.A. Ettyang, W.D. van Marken Lichtenbelt, F. Esamai W.H.M. Saris. A study of factors underlying the prevalence of low infant weight at birth and up to 4 months in pastoral and farming communities of West Pokot, Kenya. (Conditionally accepted and under correction; Journal of Public Health Nutrition)

D. Ayuku, G.A. Ettyang, W. Odero, M. deVries. Psycho-social and nutritional status of street children in comparison to school children: A case of Eldoret town. African Joumal of Food, Agriculture, Nutrition and Development $2004 ; 4(1): 1-11$.

P.O. Ayuo, G.A. Ettyang. Glycaemic response after ingestion of some local foods by non-insulin dependent diabetic subjects. The East African Medical Journal 1996; 73:782-785. 
Short communication

Ettyang G.A. (1999). A community - based health intervention programme in pastoral and agricultural Pokot communities in Western Kenya Acta Paediatr Supp 429:41-2.

Presentations

Ettyang G.A. (1998) Improving maternal-child nutrition in Western Kenyan communities. A paper presented at the tenth Anniversary. Prof. Letten F Saugstad's Fund. (LFSF). Academy of Science, Drammensun 78,0271, OSLO. 